WSRC-STI-2006-00069

Revision 0

\title{
STATISTICAL REVIEW OF CESIUM CARBONATE FUSION MEASUREMENTS OF ARCHIVED GLASS SAMPLES FROM THE DWPF PROCESS
}

Thomas B. Edwards

July 2006

Statistical Consulting Section

Savannah River National Laboratory

Aiken, SC 29808

Prepared for the U.S. Department of Energy Under Contract Number DEAC09-96SR18500

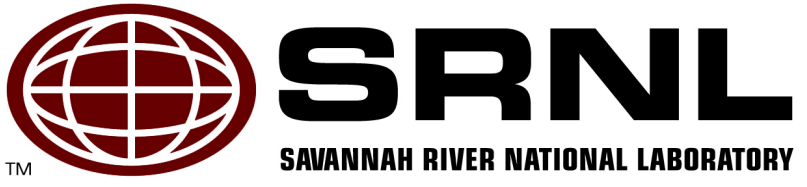




\section{DISCLAIMER}

This report was prepared by Washington Savannah River Company (WSRC) for the United States Department of Energy under Contract No. DE-AC09-96SR18500 and is an account of work performed under that contract. Neither the United States Department of Energy, nor WSRC, nor any of their employees makes any warranty, expressed or implied, or assumes any legal liability or responsibility for the accuracy, completeness, or usefulness, of any information, apparatus, or product or process disclosed herein or represents that its use will not infringe privately owned rights. Reference herein to any specific commercial product, process, or service by trademark, name, manufacturer or otherwise does not necessarily constitute or imply endorsement, recommendation, or favoring of same by WSRC or by the United States Government or any agency thereof. The views and opinions of the authors expressed herein do not necessarily state or reflect those of the United States Government or any agency thereof.

\section{Printed in the United States of America \\ Prepared For \\ U.S. Department of Energy}

The Savannah River National Laboratory is operated for the U.S. Department of Energy by Washington Savannah River Company. 
Key Words: statistics, uncertainty, SME, waste loading

Retention: Permanent

\section{STATISTICAL REVIEW OF CESIUM CARBONATE FUSION MEASUREMENTS OF ARCHIVED GLASS SAMPLES FROM THE DWPF PROCESS}

Thomas B. Edwards

July 2006 


\section{REVIEWS AND APPROVALS}

\section{AUTHOR:}

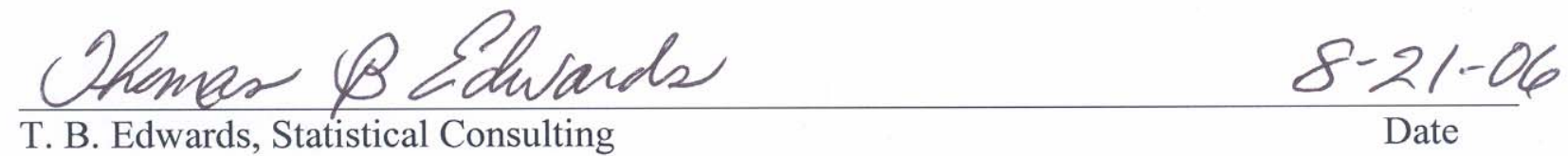

TECHNICAL REVIEWER:

n $\mathrm{n}$

$8 / 2,106$

S. P. Harris, Statistical Consulting

\section{APPROVERS:}

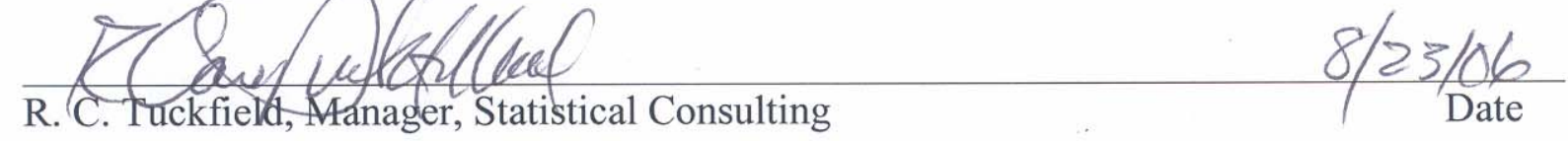

C. C. Herman, Manager, Process Engineering Technology $8 / 22 / 06$

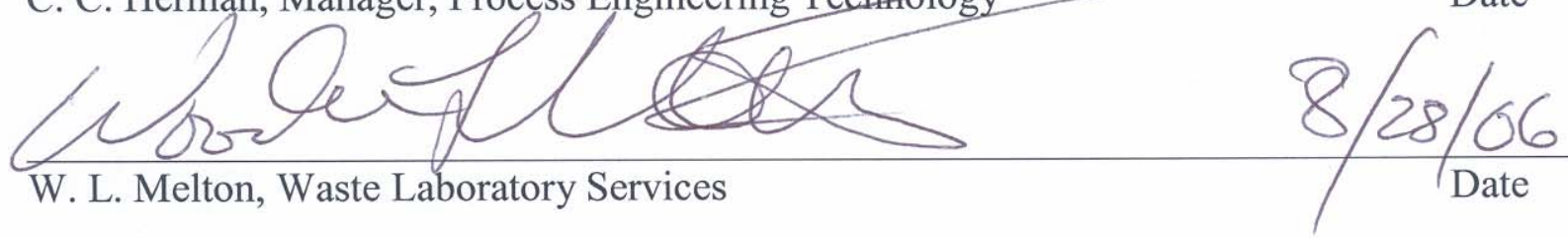

J. E. Occhipinti, Waste Solidification Engineering $\frac{8-24-06}{\text { Date }}$




\section{EXECUTIVE SUMMARY}

This technical report provides a statistical review of measurements that the Defense Waste Processing Facility (DWPF) Laboratory (Lab) generated by Inductively-Coupled Plasma - Atomic Emission Spectroscopy (ICP-AES) for samples of archived Slurry Mix Evaporator (SME) glass that were prepared using a cesium carbonate $\left(\mathrm{Cs}_{2} \mathrm{CO}_{3}\right)$ fusion dissolution method. Measurements were generated by both of the Lab's ICPs, which are designated as M-13 and M-14. Comparisons between the two ICPs suggest that for the ARG-1 measurements the M-14 provided lower (on average) concentration measurements for about 13 of the 16 elements reported by DWPF with $\mathrm{Cr}, \mathrm{Mn}, \mathrm{Ni}$, and $\mathrm{Zr}$ being statistically lower (at a 5\% significance level) for the ARG-1 samples. One of the three exceptions is $\mathrm{Li}$, for which the M-14 yielded (on average) higher concentration measurements than the M-13. For the SME samples, the M-14 and M-13 measurements had statistically different (at the $5 \%$ significance level) means for $\mathrm{B}, \mathrm{Ca}, \mathrm{Cr}, \mathrm{Cu}, \mathrm{Fe}, \mathrm{Li}, \mathrm{Mg}, \mathrm{Mn}, \mathrm{Na}, \mathrm{Ni}, \mathrm{Si}, \mathrm{Ti}, \mathrm{U}$, and $\mathrm{Zr}$ with the M14 being lower than the M-13 for all of these elements except for $\mathrm{Li}$.

For the screened SME samples, statistically significant (at the 5\% level) differences between the means of the $\mathrm{Cs}_{2} \mathrm{CO}_{3}$ and prototypic preparations are seen for $\mathrm{Ca}\left(\mathrm{Cs}_{2} \mathrm{CO}_{3}\right.$ higher for both ICPs), $\mathrm{Cr}$ ( $\mathrm{Cs}_{2} \mathrm{CO}_{3}$ higher for both ICPs), $\mathrm{Cu}\left(\mathrm{Cs}_{2} \mathrm{CO}_{3}\right.$ higher for $\left.\mathrm{M}-13\right), \mathrm{K}\left(\mathrm{Cs}_{2} \mathrm{CO}_{3}\right.$ higher for M-13), $\mathrm{Mn}$ $\left(\mathrm{Cs}_{2} \mathrm{CO}_{3}\right.$ lower for M-14), $\mathrm{Ni}\left(\mathrm{Cs}_{2} \mathrm{CO}_{3}\right.$ lower for $\left.\mathrm{M}-14\right)$, $\mathrm{Si}\left(\mathrm{Cs}_{2} \mathrm{CO}_{3}\right.$ lower for $\left.\mathrm{M}-14\right)$, $\mathrm{Ti}\left(\mathrm{Cs}_{2} \mathrm{CO}_{3}\right.$ higher for M-13), $\mathrm{U}\left(\mathrm{Cs}_{2} \mathrm{CO}_{3}\right.$ higher for both ICPs), and $\mathrm{Zr}\left(\mathrm{Cs}_{2} \mathrm{CO}_{3}\right.$ lower for M-14).

The $\mathrm{Cs}_{2} \mathrm{CO}_{3}$ fusion method provided elemental of glass samples made from SME batches that were statistically comparable to the DWPF prototypic dissolution methods when the $\mathrm{Cs}_{2} \mathrm{CO}_{3}$ solutions were analyzed by the $\mathrm{M}-13$. However, when the same solutions were analyzed with the $\mathrm{M}-15$, the elemental analyses from the $\mathrm{Cs}_{2} \mathrm{CO}_{3}$ method were slightly lower and more prone to fail the $95 \%$ sum of oxides criterion imposed by DWPF's Product Composition Control System (PCCS). The $\mathrm{Cs}_{2} \mathrm{CO}_{3}$ fusion method dissolutions also provided slightly lower waste loading values than the prototypic dissolutions because of slightly higher lithium values when the M-14 was used. In essence, subtle differences in the analyses form the M-13 and M-14 ICPs make it difficult to assess the viability of the $\mathrm{Cs}_{2} \mathrm{CO}_{3}$ fusion method to replace the prototypic dissolution methods. The DWFP Laboratory should investigate the causes of these subtle differences between the M-13 and M-14 ICPs as the effort to employ the $\mathrm{Cs}_{2} \mathrm{CO}_{3}$ fusion method for SME elemental analyses continues. 
WSRC-STI-2006-00069

Revision 0

This page intentionally left blank. 


\section{TABLE OF CONTENTS}

EXECUTIVE SUMMARY iii

List of Tables $\quad$ vi

List of Figures $\quad$ vi

List of Acronyms vi

1.0 INTRODUCTION AND BACKGROUND 1

2.0 RESULTS 1

2.1 Overview of Measurements and Initial Plots 1

2.2 Initial Comparisons among the M-13, M-14, and Screened Prototypic Measurements 2

2.3 Uncertainties of M-13 and M-14 Measurements Based Upon the ARG-1 Results 3

2.4 PCCS MAR Results for the M-13, M-14, and Prototypic Measurements 5

2.5 Comparisons of WLs $\quad 7$

3.0 CONCLUSIONS 10

4.0 REFERENCES 11 


\section{LIST OF TABLES}

Table 2-1. Details of ARG-1 Analyses by ICP and the Resulting ICP Uncertainties .............. 4

Table 2-2. PCCS Results by Measurement Category by SME Batch ...................................... 6

Table 2-3. PCCS MAR Results by Measurement Category by SME Batch ............................ 7

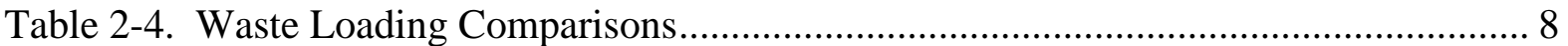

\section{LIST OF FIGURES}

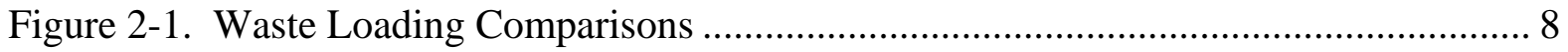

Figure 2-2. Pair-Wise Statistical Comparisons of WLs................................................ 10

\section{LIST OF ACRONYMS}

$\begin{array}{ll}\mathrm{AD} & \text { Analytical Development } \\ \mathrm{Cs}_{2} \mathrm{CO}_{3} & \begin{array}{l}\text { Cesium Carbonate } \\ \text { DWPF }\end{array} \\ \text { Defense Waste Processing Facility } \\ \text { JMP } & \begin{array}{l}\text { Inductively-Coupled Plasma - Atomic Emission Spectroscopy } \\ \text { Pronounced “jump.” It’s a statistical software package, a registered trademark } \\ \text { of SAS Institute, Inc. }\end{array} \\ \text { MAR } & \text { Measurement Acceptability Region } \\ \text { MFT } & \text { Melter Feed Tank } \\ \text { PCCS } & \text { Product Composition Control System } \\ \text { PET } & \text { Process Engineering Technology } \\ \text { SCS } & \text { Statistical Consulting Section } \\ \text { SME } & \text { Slurry Mix Evaporator } \\ \text { SRAT } & \text { Sludge Receipt and Adjustment Tank } \\ \text { SRNL } & \text { Savannah River National Laboratory } \\ \text { SRS } & \text { Savannah River Site } \\ \text { TT\&QA } & \text { Task Technical and Quality Assurance (plan) } \\ \text { TTR } & \text { Technical Task Request } \\ \text { WL } & \text { Waste Loading }\end{array}$




\subsection{INTRODUCTION AND BACKGROUND}

The Statistical Consulting Section (SCS) of the Savannah River National Laboratory (SRNL) is working with Analytical Development (AD) and Process Engineering Technology (PET) at SRNL to pursue opportunities for improvements in analytical turnaround times at the Defense Waste Processing Facility (DWPF) Laboratory (Lab) that were identified as part of a Six Sigma study of that facility's operation. The Six Sigma study identified several steps that needed to be taken to assess the viability of sampling and analytical methods that were proposed for use in characterizing the contents of DWPF's Slurry Mix Evaporator (SME) tank [1]. Two phases of work have already been completed as reported in [2], [3], and [4]. The success of these phases has led to the recommendation for a Phase III effort as defined in technical task requests (TTRs) [5] and [6]. SRNL issued a task technical and quality assurance (TT\&QA) plan [7] to address the scope of work defined in the first of the two TTRs [5].

The TT\&QA plan [7] covers the statistical review of two sets of data. The first is a set of elemental analyses of archived SME (i.e., powdered glass) samples that DWPF Lab prepared using the proposed cesium carbonate $\left(\mathrm{Cs}_{2} \mathrm{CO}_{3}\right)$ fusion method and subsequently measured by inductively-coupled plasma - atomic emission spectroscopy (ICP-AES). The statistical review of these measurements and of their comparison to the original (prototypic) measurements of these production samples is the focus of this report. The second set of measurements is to be from a true side-by-side testing of the two analytical protocols: the DWPF Lab's current protocol that uses peanut vials and the dual dissolution methods of peroxide fusion and mixed acid versus the new protocol that relies on a large bottle sampling approach and the $\mathrm{Cs}_{2} \mathrm{CO}_{3}$ fusion dissolution method. The statistical review of this second set of measurements is to be provided in a separate report.

\subsection{RESULTS}

This section provides the statistical review of the measurements. In addition to the general review of the measurements, there are some specific issues that are considered. These include

(1) Is there any indication of a significant bias between the $\mathrm{Cs}_{2} \mathrm{CO}_{3}$ fusion method and the DWPF Lab's current method for any element?

(2) Are there any issues related to the particular ICP used?

(3) What would the best 4 of 6 samples mean for the elemental analyses generated by the $\mathrm{Cs}_{2} \mathrm{CO}_{3}$ fusion method? (Should all 6 samples be used?)

(4) What is the impact of the $\mathrm{Cs}_{2} \mathrm{CO}_{3}$ results on the process and product quality predictions (i.e., on the SME acceptability decisions) for the batches under study?

(5) What is the impact of the $\mathrm{Cs}_{2} \mathrm{CO}_{3}$ results on the estimated waste loadings (WLs) for the SME batches under study?

The statistical analyses presented in this paper were conducted using JMP Version 5.1.2 from SAS Institute, Inc. [8].

\subsection{Overview of Measurements and Initial Plots}

Table A1 in Appendix A lists the measurement data that are the subject of the statistical review provided in this report. Measurements of glass samples from 7 different SME batches are shown in this table. The batch numbers are indicated and the 6 process samples for each batch are 
labeled as rep1 through rep 6. The "rep" samples and the ARG-1 (standard glass) samples, which appear at the beginning and end of each block of measurements, were prepared using the $\mathrm{Cs}_{2} \mathrm{CO}_{3}$ fusion dissolution method, and the elemental composition of the prepared samples were determined by ICP-AES by both Leeman ICPs (the instruments are designated as the M-13 and M-14 ICPs and these labels are indicated in the headings for the measurements in Table A1).

Other information is also provided as part of the block of results. For the ARG-1 samples, the known or reference values for the elemental composition of the ARG-1 standard are provided. For the "rep" samples, the prototypic measurements (derived from samples prepared by peroxide fusion and mixed acid dissolution methods) are provided. The latter data were the "production" measurements generated by the DWPF Lab as the SME batches were originally processed. Situations where the prototypic measurements were rejected by the DWPF Lab are also indicated as part of Table A1. The rejected measurements were excluded from the analyses that follow, and this is indicated by the use of the descriptor "screened prototypic" to represent these measurements.

Exhibit A1 in Appendix A provides initial plots of these measurements. For the ARG-1 measurements, even though a "place-holder" is provided for the screened prototypic grouping, no data were generated for ARG-1 by the prototypic preparation methods for this study. The following observations are noted from this exhibit: the measurements for both ARG-1 samples for batch 362 are low for several elements (e.g., Al, B, Fe, Mg, Mn, and Si), the measurements for rep 5 of batch 357 are high for several elements, one of the K measurements by the M-13 is higher for batch 359. The sums of oxides for the ARG-1 and SME rep samples are plotted in this exhibit by grouping by batch. The ARG-1 results for batch 362 and the $\mathrm{Cs}_{2} \mathrm{CO}_{3}$ results for the SME rep samples for batch 357 (both ICPs) and for batch 359 (the M-14 ICP) fall below the 95\% working limit for these sums.

\subsection{Initial Comparisons among the M-13, M-14, and Screened Prototypic Measurements}

Exhibit A2 in Appendix A provides initial comparisons using all of the $\mathrm{Cs}_{2} \mathrm{CO}_{3}$ measurement data along with the screened prototypic measurements. This exhibit provides the results of pair-wise tests for differing means for M-13 versus M-14 for the ARG-1 data and pair-wise tests for

differing means for $M-13$ versus $M-14$, for $M-13$ versus screened prototypic, and for $M-14$ versus screened prototypic for the SME rep samples. For each of these tests, a value for Prob $>|t|$ of 0.05 or less indicates that the two means being compared are statistically different at a significance level of $5 \%$.

For the ARG-1 comparisons, the means being compared are those for the ICPs (i.e., the M-13 and $\mathrm{M}-14)$. In this case, the samples were prepared using the $\mathrm{Cs}_{2} \mathrm{CO}_{3}$ method. Statistically significant (at the $5 \%$ level) differences between the means of the ICPs are seen for $\mathrm{Cr}, \mathrm{Mn}, \mathrm{Ni}$, $\mathrm{U}$, and Zr. Note that there is no $\mathrm{U}$ in the ARG-1 glass, so the $\mathrm{U}$ difference is probably due to a difference in the calibrations of the two instruments. Another observation of note for the ARG-1 results is that the M-14 ICP yields average measurements that are often (13 of the 16 elements) less than those provided by the M-13 ICP with the exceptions being the measurements for $\mathrm{Li}, \mathrm{Ti}$, and Zr.

For the SME rep samples, comparisons are made between the two ICPs for the $\mathrm{Cs}_{2} \mathrm{CO}_{3}$ prepared process samples and between the $\mathrm{Cs}_{2} \mathrm{CO}_{3}$ and prototypic preparations. In the latter case, the $\mathrm{Cs}_{2} \mathrm{CO}_{3}$ results are represented in turn by the M-13 measurements and by the M-14 measurements. From the exhibit, statistically significant (at the 5\% level) differences between 
the means of the two ICPs are seen for $\mathrm{B}, \mathrm{Ca}, \mathrm{Cr}, \mathrm{Cu}, \mathrm{Li}, \mathrm{Mg}, \mathrm{Mn}, \mathrm{Na}, \mathrm{Ni}, \mathrm{Si}, \mathrm{Ti}, \mathrm{U}$, and $\mathrm{Zr}$. From the exhibit, statistically significant (at the 5\% level) differences between the means of the $\mathrm{Cs}_{2} \mathrm{CO}_{3}$ and prototypic preparations are seen for $\mathrm{Ca}$ (the $\mathrm{Cs}_{2} \mathrm{CO}_{3} \mathrm{M}-13$ is higher), $\mathrm{Cr}$ (the $\mathrm{Cs}_{2} \mathrm{CO}_{3}$ results for both ICPs are higher), $\mathrm{Cu}$ (the $\mathrm{Cs}_{2} \mathrm{CO}_{3} \mathrm{M}-13$ is higher), $\mathrm{K}$ (the $\mathrm{Cs}_{2} \mathrm{CO}_{3} \mathrm{M}-13$ is higher), $\mathrm{Mg}$ (the $\mathrm{Cs}_{2} \mathrm{CO}_{3} \mathrm{M}-13$ is higher), and $\mathrm{U}$ (the $\mathrm{Cs}_{2} \mathrm{CO}_{3}$ results for both ICPs are higher).

To make sure that the potential outliers noted in the previous section for the $\mathrm{Cs}_{2} \mathrm{CO}_{3}$ measurements are not adversely affecting the results of these pair-wise comparisons, Exhibit A3 in Appendix A was prepared. In this exhibit, the pair-wise comparisons of Exhibit A2 were repeated with the ARG-1 data for batch 362 and with the rep 5 measurements for batch 357 excluded from the analysis. For the ARG-1 comparisons, recall that the means being compared are those for the ICPs (i.e., the M-13 and M-14). For the screened $\mathrm{Cs}_{2} \mathrm{CO}_{3}$ data, statistically significant (at the $5 \%$ level) differences between the means of the ICPs are seen for $\mathrm{Cr}, \mathrm{Mn}, \mathrm{Ni}$, $\mathrm{U}$, and Zr. As before, note that there is no $\mathrm{U}$ in the ARG-1 glass, so the $\mathrm{U}$ difference is probably due to a difference in the calibrations of the two instruments. For the screened SME rep samples, comparisons are made between the two ICPs for the $\mathrm{Cs}_{2} \mathrm{CO}_{3}$ prepared process samples and between the $\mathrm{Cs}_{2} \mathrm{CO}_{3}$ and prototypic preparations. In the latter case, the $\mathrm{Cs}_{2} \mathrm{CO}_{3}$ results are represented in turn by the M-13 measurements and by the M-14 measurements. From Exhibit A3, statistically significant (at the 5\% level) differences between the means of the two ICPs are seen for B, Ca, Cr, Cu, Fe, Li, Mg, Mn, Na, Ni, Si, Ti, U, and Zr. From the exhibit, statistically significant (at the 5\% level) differences between the means of the $\mathrm{Cs}_{2} \mathrm{CO}_{3}$ and prototypic preparations are seen for Ca (both ICPs), Cr (both ICPs), Cu (M-13), K (M-13), Mn (M-14), Ni (M-14), Si (M-14), Ti (M-13), U (both ICPs), and Zr (M-14).

\subsection{Uncertainties of M-13 and M-14 Measurements Based Upon the ARG-1 Results}

The ARG-1 measurements of Table A1 provide an opportunity for an investigation into the uncertainties, both bias and precision errors, in the $\mathrm{Cs}_{2} \mathrm{CO}_{3}$ measurements for the two ICPs. Using the screened ARG-1 values (i.e., excluding the ARG1 results for batch 362), a components-of-variance analysis was conducted using JMP, and the results are summarized in Table 2-1.

The upper portion of the table covers the M-13 results while the lower covers the M-14. The first column indicates the element, the second column provides the ARG-1 reference concentration in $\mathrm{wt} \%$ for the element, the next column provides the average measurement in wt $\%$, the next column provides the percent bias (\% bias), and the next column provides the number of observations (n). An estimate of the between batch variance (Estimate of Between Var), an estimate of the within batch variance (Estimate of Within Var), and an estimate of the total variance (Estimate of Total Var) are the next columns. The three columns that follow provide the percent relative standard deviation (\%RSD) for each of the sources of variation (Between, Within, and Total). The Mean Squares Between Batch and its degrees of freedom (DoF) follow next. From all of this information, a 95\% confidence interval for the mean is computed and shown next. Finally, the 95\% uncertainty interval for a single measurement when made using the indicated ICP for the element is shown. The interpretation of these intervals may be illustrated using the $\mathrm{M}-13 \mathrm{Al}$ results. The uncertainty interval is (7.16\%, 8.81\%), which implies that, for a single $\mathrm{Al}$ measurement using the M-13 ICP, the true value may be $7.16 \%$ lower or $8.81 \%$ higher than the measurement itself. 
WSRC-STI-2006-00069

Revision 0

Table 2-1. Details of ARG-1 Analyses by ICP and the Resulting ICP Uncertainties

\begin{tabular}{|c|c|c|c|c|c|c|c|c|c|c|c|c|c|c|c|c|}
\hline & wt\% & $\mathrm{M}-13$ & & & Estimate of & Estimate of & Estimate of & Estimate of & Estimate of & Estimate of & Mean Squares & & \multicolumn{2}{|c|}{ 95\% Confidence Interval for Mean } & \multicolumn{2}{|c|}{ 95\% Measurement Uncertainty } \\
\hline Analyte & Ref. Value & Avg. wt\%e & $\%$ Bias & $\mathrm{n}$ & (B)etween Var & (W)ithin Var & (T)otal Var. & \%RSD (B) & $\% \mathrm{RSD}(\mathrm{W})$ & \%RSD(T) & Between Batch & DoF & Lower & Upper & \% Lower & \% Upper \\
\hline $\mathrm{Al}$ & 2.5 & 2.418 & $-3.27 \%$ & 12 & 0 & 0.004533 & 0.004533 & $0.00 \%$ & $2.78 \%$ & $2.78 \%$ & 0.00327 & 5 & 2.376 & 2.461 & $7.16 \%$ & $8.81 \%$ \\
\hline $\mathrm{B}$ & 2.69 & 2.606 & $-3.13 \%$ & 12 & 0 & 0.007842 & 0.007842 & $0.00 \%$ & $3.40 \%$ & $3.40 \%$ & 0.00681 & 5 & 2.545 & 2.667 & $8.74 \%$ & $10.37 \%$ \\
\hline $\mathrm{Ca}$ & 1.02 & 1.056 & $3.51 \%$ & 12 & 0.000413 & 0.007342 & 0.007755 & $1.92 \%$ & $8.12 \%$ & $8.34 \%$ & 0.00817 & 5 & 0.989 & 1.123 & $23.55 \%$ & $21.44 \%$ \\
\hline $\mathrm{Cr}$ & 0.06 & 0.160 & $166.67 \%$ & 12 & 0.00069 & 0.0005 & 0.00119 & $16.42 \%$ & $13.98 \%$ & $21.56 \%$ & 0.00188 & 5 & 0.128 & 0.192 & $99.48 \%$ & $55.42 \%$ \\
\hline $\mathrm{Cu}$ & 0.0001 & 0.009 & $9067.00 \%$ & 12 & 0.000028 & 0.000092 & 0.00012 & $57.72 \%$ & $104.63 \%$ & $119.50 \%$ & 0.00015 & 5 & 0.000 & 0.018 & $365.49 \%$ & $307.18 \%$ \\
\hline $\mathrm{Fe}$ & 9.79 & 9.866 & $0.77 \%$ & 12 & 0.002335 & 0.070158 & 0.072493 & $0.49 \%$ & $2.68 \%$ & $2.73 \%$ & 0.07483 & 5 & 9.663 & 10.069 & $7.56 \%$ & $7.02 \%$ \\
\hline $\mathrm{K}$ & 2.25 & 2.414 & $7.30 \%$ & 12 & 0 & 0.474458 & 0.474458 & $0.00 \%$ & $28.53 \%$ & $28.53 \%$ & 0.29103 & 5 & 2.014 & 2.814 & $76.98 \%$ & $73.34 \%$ \\
\hline $\mathrm{Li}$ & 1.49 & 1.468 & $-1.51 \%$ & 12 & 0.003572 & 0.000592 & 0.004164 & $4.07 \%$ & $1.66 \%$ & $4.40 \%$ & 0.00774 & 5 & 1.402 & 1.533 & $11.67 \%$ & $11.30 \%$ \\
\hline $\mathrm{Mg}$ & 0.52 & 0.522 & $0.32 \%$ & 12 & 0 & 0.000317 & 0.000317 & $0.00 \%$ & $3.41 \%$ & $3.41 \%$ & 0.00029 & 5 & 0.509 & 0.534 & $9.19 \%$ & $8.77 \%$ \\
\hline $\mathrm{Mn}$ & 1.46 & 1.430 & $-2.05 \%$ & 12 & 0.000318 & 0.002383 & 0.002701 & $1.25 \%$ & $3.41 \%$ & $3.63 \%$ & 0.00302 & 5 & 1.389 & 1.471 & $9.37 \%$ & $9.34 \%$ \\
\hline $\mathrm{Na}$ & 8.53 & 8.608 & $0.92 \%$ & 12 & 0 & 0.1004 & 0.1004 & $0.00 \%$ & $3.68 \%$ & $3.68 \%$ & 0.05679 & 5 & 8.431 & 8.785 & $9.92 \%$ & $9.46 \%$ \\
\hline $\mathrm{Ni}$ & 0.83 & 0.832 & $0.20 \%$ & 12 & 0.000208 & 0.000717 & 0.000925 & $1.73 \%$ & $3.22 \%$ & $3.66 \%$ & 0.00113 & 5 & 0.807 & 0.857 & $9.93 \%$ & $9.40 \%$ \\
\hline $\mathrm{Si}$ & 22.39 & 22.998 & $2.71 \%$ & 12 & 0 & 0.534125 & 0.534125 & $0.00 \%$ & $3.18 \%$ & $3.18 \%$ & 0.24085 & 5 & 22.633 & 23.362 & $9.20 \%$ & $8.17 \%$ \\
\hline $\mathrm{Ti}$ & 0.69 & 0.683 & $-1.09 \%$ & 12 & 0 & 0.000225 & 0.000225 & $0.00 \%$ & $2.20 \%$ & $2.20 \%$ & 0.00013 & 5 & 0.674 & 0.691 & $5.65 \%$ & $5.65 \%$ \\
\hline $\mathrm{U}$ & 0 & 0.126 & & 12 & 0.037603 & 0.033242 & 0.070845 & $154.10 \%$ & $144.89 \%$ & $211.52 \%$ & 0.10845 & 5 & -0.119 & 0.370 & - & - \\
\hline $\mathrm{Zr}$ & 0.1 & 0.110 & $10.00 \%$ & 12 & 0.000002 & 0.000017 & 0.000019 & $1.29 \%$ & $3.75 \%$ & $3.96 \%$ & 0.00002 & 5 & 0.107 & 0.113 & $15.82 \%$ & $10.19 \%$ \\
\hline \multirow[t]{2}{*}{ Sum Ox } & 99.3 & 100.863 & $1.57 \%$ & 12 & 0 & 9.239066 & 9.239066 & $0.00 \%$ & $3.01 \%$ & $3.01 \%$ & 2.51214 & 5 & 99.687 & 102.039 & $8.21 \%$ & $7.75 \%$ \\
\hline & $\mathrm{wt} \%$ & M-14 & & & Estimate of & Estimate of & Estimate of & Estimate of & Estimate of & Estimate of & Mean Squares & & \multicolumn{2}{|c|}{ 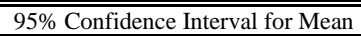 } & \multirow{2}{*}{\multicolumn{2}{|c|}{ 95\% Measurement Uncertainty }} \\
\hline Analyte & Ref. Value & Avg. wt\%e & $\%$ Bias & $\mathrm{n}$ & Between Var & Within Var & Total Variance & $\%$ RSD (B) & $\% \operatorname{RSD}(\mathrm{W})$ & \%RSD(T) & Between Batch & DoF & Lower & Upper & $\%$ Lower & \\
\hline $\mathrm{Al}$ & 2.5 & 2.408 & $-3.67 \%$ & 12 & 0.000147 & 0.0053 & 0.005447 & $0.50 \%$ & $3.02 \%$ & $3.06 \%$ & 0.00559 & 5 & 2.353 & 2.464 & $7.88 \%$ & $9.97 \%$ \\
\hline $\mathrm{B}$ & 2.69 & 2.575 & $-4.28 \%$ & 12 & 0.001358 & 0.002683 & 0.004041 & $1.43 \%$ & $2.01 \%$ & $2.47 \%$ & 0.0054 & 5 & 2.520 & 2.630 & $6.35 \%$ & $9.14 \%$ \\
\hline $\mathrm{Ca}$ & 1.02 & 1.039 & $1.88 \%$ & 12 & 0 & 0.006708 & 0.006708 & $0.00 \%$ & $7.88 \%$ & $7.88 \%$ & 0.00557 & 5 & 0.984 & 1.095 & $21.49 \%$ & $20.26 \%$ \\
\hline $\mathrm{Cr}$ & 0.06 & 0.139 & $131.95 \%$ & 12 & 0.000375 & 0.000358 & 0.000733 & $13.91 \%$ & $13.60 \%$ & $19.45 \%$ & 0.00111 & 5 & 0.114 & 0.164 & $89.85 \%$ & $50.01 \%$ \\
\hline $\mathrm{Cu}$ & 0.0001 & -0.002 & $-1770.00 \%$ & 12 & 0.000098 & 0.000017 & 0.000115 & $592.78 \%$ & $246.89 \%$ & $642.14 \%$ & 0.00021 & 5 & -0.012 & 0.009 & $1736.12 \%$ & $1650.68 \%$ \\
\hline $\mathrm{Fe}$ & 9.79 & 9.750 & $-0.41 \%$ & 12 & 0 & 0.0466 & 0.0466 & $0.00 \%$ & $2.21 \%$ & $2.21 \%$ & 0.03232 & 5 & 9.617 & 9.883 & $5.77 \%$ & $5.69 \%$ \\
\hline $\mathrm{K}$ & 2.25 & 2.190 & $-2.67 \%$ & 12 & 0.004423 & 0.059033 & 0.063456 & $3.04 \%$ & $11.09 \%$ & $11.50 \%$ & 0.06788 & 5 & 1.997 & 2.383 & $30.19 \%$ & $29.57 \%$ \\
\hline $\mathrm{Li}$ & 1.49 & 1.508 & $1.23 \%$ & 12 & 0 & 0.001217 & 0.001217 & $0.00 \%$ & $2.31 \%$ & $2.31 \%$ & 0.00113 & 5 & 1.483 & 1.533 & $6.60 \%$ & $5.95 \%$ \\
\hline $\mathrm{Mg}$ & 0.52 & 0.515 & $-0.96 \%$ & 12 & 0 & 0.000283 & 0.000283 & $0.00 \%$ & $3.27 \%$ & $3.27 \%$ & 0.0002 & 5 & 0.505 & 0.525 & $8.46 \%$ & $8.40 \%$ \\
\hline $\mathrm{Mn}$ & 1.46 & 1.409 & $-3.48 \%$ & 12 & 0.000655 & 0.002958 & 0.003613 & $1.82 \%$ & $3.86 \%$ & $4.27 \%$ & 0.00427 & 5 & 1.361 & 1.458 & $10.96 \%$ & $13.03 \%$ \\
\hline $\mathrm{Na}$ & 8.53 & 8.419 & $-1.30 \%$ & 12 & 0.075873 & 0.147542 & 0.223415 & $3.27 \%$ & $4.56 \%$ & $5.61 \%$ & 0.29929 & 5 & 8.013 & 8.825 & $14.85 \%$ & $14.43 \%$ \\
\hline $\mathrm{Ni}$ & 0.83 & 0.802 & $-3.41 \%$ & 12 & 0 & 0.00085 & 0.00085 & $0.00 \%$ & $3.64 \%$ & $3.64 \%$ & 0.00041 & 5 & 0.787 & 0.817 & $9.35 \%$ & $10.80 \%$ \\
\hline $\mathrm{Si}$ & 22.39 & 22.607 & $0.97 \%$ & 12 & 0 & 0.447317 & 0.447317 & $0.00 \%$ & $2.96 \%$ & $2.96 \%$ & 0.25783 & 5 & 22.230 & 22.983 & $8.05 \%$ & $7.61 \%$ \\
\hline $\mathrm{Ti}$ & 0.69 & 0.690 & $0.00 \%$ & 12 & 0.000075 & 0.00035 & 0.000425 & $1.26 \%$ & $2.71 \%$ & $2.99 \%$ & 0.0005 & 5 & 0.673 & 0.707 & $8.05 \%$ & $7.68 \%$ \\
\hline $\mathrm{U}$ & 0 & -0.154 & & 12 & 0.04815 & 0.014108 & 0.062258 & $-142.33 \%$ & $-77.04 \%$ & $-161.84 \%$ & 0.11041 & 5 & -0.401 & 0.092 & - & - \\
\hline $\mathrm{Zr}$ & 0.1 & 0.101 & $0.83 \%$ & 12 & 0.000023 & 0.000042 & 0.000065 & $4.76 \%$ & $6.43 \%$ & $8.00 \%$ & 0.00009 & 5 & 0.094 & 0.108 & $21.99 \%$ & $20.55 \%$ \\
\hline Sum Ox & 99.3 & 98.833 & $-0.47 \%$ & 12 & 0 & 6.843413 & 6.843413 & $0.00 \%$ & $2.65 \%$ & $2.65 \%$ & 3.15096 & 5 & 97.515 & 100.150 & $6.86 \%$ & $6.80 \%$ \\
\hline
\end{tabular}




\subsection{PCCS MAR Results for the M-13, M-14, and Prototypic Measurements}

During DWPF operation, the measured chemical compositions of the SME samples (i.e., the rep measurements in this study) are entered into DWPF's Product Composition Control System (PCCS) to facilitate the SME acceptability decision. PCCS is used to make the acceptability decision for each process batch of HLW prior to its being transferred to the melter. The chemical composition measurements of the SME samples are judged against various acceptance criteria, and the glass compositions that satisfy the most stringent of these criteria are designated as being in the Measurement Acceptance (or Acceptability) Region (MAR) of PCCS. The criteria rely directly on chemical composition measurements of the glass or on predictions from models that relate important process (e.g., viscosity or liquidus temperature) or product quality (specifically, the durability of the final waste form) properties of the glass to the chemical composition measurements. SME batches that satisfy the MAR criteria are deemed acceptable and are transferred to the melter for processing via the Melter Feed Tank (MFT). The technical basis for SME acceptability is provided by reference [9], and this document has been in place to support the DWPF since it began radioactive operation in 1996.

For this study, there is an opportunity to compare PCCS outcomes from the $\mathrm{Cs}_{2} \mathrm{CO}_{3}$ results for both the $\mathrm{M}-13$ and the M-14 with the outcomes from the screened prototypic results. Before providing the comparisons, it should be noted that the PCCS results being discussed do not necessarily reflect the production results for the batches presented here. As part of its production process, DWPF utilizes the best 4 of 6 SME sample results. No attempt was made to duplicate this process as part of this study. For the comparisons presented here, all of the available prototypic measurements were used except for the values excluded as a result of the screening process discussed above.

Table 2-2 provides a subset of the PCCS predictions and measurement assessments for each of the three categories of measurements. The SME batch is indicated in this table along with the category of measurements being evaluated. Columns are provided for predictions of the normalized leachate for boron in grams/liter $(\mathrm{g} / \mathrm{L})$, of liquidus temperature $\left(\mathrm{T}_{\mathrm{L}}\right)$ in ${ }^{\circ} \mathrm{C}$, viscosity in Poise $(\mathrm{P})$, sum of oxides in weight percent ( $w t \%), \mathrm{Al}_{2} \mathrm{O}_{3}$ concentration in $\mathrm{wt} \%, \mathrm{Cr}_{2} \mathrm{O}_{3}$ concentration in wt $\%$, and the sum of alkali content (denoted by $\mathrm{R}_{2} \mathrm{O}$ ) in wt\%. 
WSRC-STI-2006-00069

Revision 0

Table 2-2. PCCS Results by Measurement Category by SME Batch

\begin{tabular}{|c|c|c|c|c|c|c|c|c|}
\hline Batch & $\begin{array}{l}\text { Category of } \\
\text { Measurements }\end{array}$ & $\mathrm{NL}[\mathrm{B}(\mathrm{g} / \mathrm{L})]$ & $\begin{array}{c}\mathrm{T}_{\mathrm{L}} \text { Prediction } \\
\left({ }^{\circ} \mathrm{C}\right)\end{array}$ & $\begin{array}{c}\text { Viscosity } \\
\text { Prediction } \\
\text { (P) }\end{array}$ & $\begin{array}{l}\text { Sum of Oxide } \\
\text { (wt\%)s }\end{array}$ & $\begin{array}{c}\mathrm{Al} 2 \mathrm{O} 3 \\
\mathrm{wt} \%\end{array}$ & $\begin{array}{c}\text { Cr2O3 } \\
\text { wt } \%\end{array}$ & $\begin{array}{l}\mathrm{R} 2 \mathrm{O} \\
\mathrm{wt} \%\end{array}$ \\
\hline 354 & $\mathrm{M}-13$ & 0.69 & 978.4 & 61.00 & 100.38 & 6.15 & 0.17 & 17.15 \\
\hline 354 & $\mathrm{M}-14$ & 1.00 & 951.7 & 47.17 & 99.34 & 6.32 & 0.14 & 18.14 \\
\hline 354 & $\begin{array}{c}\text { Screened } \\
\text { Prototypic }\end{array}$ & 0.53 & 959.1 & 68.42 & 97.60 & 6.24 & 0.09 & 16.41 \\
\hline 357 & M-13 & 0.43 & 963.3 & 75.72 & 93.41 & 5.51 & 0.20 & 15.51 \\
\hline 357 & $\mathrm{M}-14$ & 0.46 & 954.5 & 73.17 & 93.86 & 5.44 & 0.18 & 15.71 \\
\hline 357 & $\begin{array}{c}\text { Screened } \\
\text { Prototypic }\end{array}$ & 0.48 & 928.2 & 73.65 & 96.22 & 5.70 & 0.09 & 16.03 \\
\hline 359 & $\mathrm{M}-13$ & 0.56 & 979.6 & 73.89 & 96.25 & 5.62 & 0.26 & 16.37 \\
\hline 359 & M-14 & 0.39 & 970.3 & 79.21 & 94.25 & 5.56 & 0.20 & 15.36 \\
\hline 359 & $\begin{array}{l}\text { Screened } \\
\text { Prototypic }\end{array}$ & 0.55 & 930.0 & 78.85 & 99.46 & 5.69 & 0.09 & 16.48 \\
\hline 361 & M-13 & 0.75 & 901.6 & 65.02 & 96.89 & 5.48 & 0.11 & 17.09 \\
\hline 361 & $\mathrm{M}-14$ & 0.65 & 906.3 & 65.73 & 96.26 & 5.59 & 0.11 & 16.74 \\
\hline 361 & $\begin{array}{c}\text { Screened } \\
\text { Prototypic }\end{array}$ & 0.57 & 896.1 & 77.29 & 96.97 & 5.27 & 0.08 & 16.44 \\
\hline 362 & M-13 & 0.52 & 954.5 & 85.68 & 100.35 & 5.55 & 0.22 & 16.35 \\
\hline 362 & M-14 & 0.48 & 942.9 & 82.19 & 97.48 & 5.56 & 0.20 & 16.05 \\
\hline 362 & $\begin{array}{c}\text { Screened } \\
\text { Prototypic }\end{array}$ & 0.44 & 903.2 & 90.40 & 96.60 & 5.36 & 0.08 & 15.76 \\
\hline 364 & M-13 & 0.55 & 993.4 & 77.66 & 99.48 & 6.03 & 0.23 & 16.53 \\
\hline 364 & M-14 & 0.50 & 969.4 & 72.49 & 97.13 & 5.69 & 0.19 & 16.14 \\
\hline 364 & $\begin{array}{c}\text { Screened } \\
\text { Prototypic }\end{array}$ & 0.63 & 919.7 & 63.04 & 95.67 & 5.66 & 0.09 & 16.68 \\
\hline 365 & $\mathrm{M}-13$ & 0.54 & 1000.4 & 67.55 & 97.74 & 5.97 & 0.18 & 16.40 \\
\hline 365 & M-14 & 0.55 & 972.8 & 57.96 & 94.05 & 5.95 & 0.15 & 16.30 \\
\hline 365 & $\begin{array}{c}\text { Screened } \\
\text { Prototypic }\end{array}$ & 0.53 & 959.4 & 66.10 & 97.91 & 6.15 & 0.08 & 16.32 \\
\hline
\end{tabular}

The acceptability of these predictions and the other MAR criteria for each of the measurement categories is summarized in Table 2-3. This table indicates using a short-hand notation those criteria that are not met. The lsum designation indicates that the low of sum of oxides constraint is not met; the $\mathrm{Cr}_{2} \mathrm{O}_{3}$ designation indicates that the chromium oxide solubility limit criterion is exceeded. As seen in Table 2-3, low sum of oxides is a problem for the $\mathrm{Cs}_{2} \mathrm{CO}_{3}$ measurements from both ICPs for batch 357 and for the M-14 ICP for batch 359 and for batch 365 . The M-14 $\mathrm{Cs}_{2} \mathrm{CO}_{3}$ measurements leading to more low of sum of oxides problems may be a reflection of the tendency of the M-14 to provide lower concentration measurements for most of the oxides as compared to the M-13 as was noted above. The $\mathrm{Cr}_{2} \mathrm{O}_{3}$ solubility constraint is not met by the M-13 measurements for batch 359 and for batch 364; these may have been calibration issues for the M-13. Thus, in general, the $\mathrm{Cs}_{2} \mathrm{CO}_{3}$ measurements met the PCCS MAR criteria. 
WSRC-STI-2006-00069

Revision 0

Table 2-3. PCCS MAR Results by Measurement Category by SME Batch

\begin{tabular}{|c|c|c|c|}
\hline $\begin{array}{l}\text { Type of } \\
\text { Sample }\end{array}$ & Batch & Method & MAR Status \\
\hline SME & 354 & M-13 & \\
\hline SME & 354 & M-14 & \\
\hline SME & 354 & Screened Prototypic & \\
\hline SME & 357 & M-13 & lsum \\
\hline SME & 357 & M-14 & lsum \\
\hline SME & 357 & Screened Prototypic & \\
\hline SME & 359 & M-13 & $\mathrm{Cr}_{2} \mathrm{O}_{3}$ \\
\hline SME & 359 & M-14 & lsum \\
\hline SME & 359 & Screened Prototypic & \\
\hline SME & 361 & M-13 & \\
\hline SME & 361 & M-14 & \\
\hline SME & 361 & Screened Prototypic & \\
\hline SME & 362 & M-13 & \\
\hline SME & 362 & M-14 & \\
\hline SME & 362 & Screened Prototypic & \\
\hline SME & 364 & M-13 & $\mathrm{Cr}_{2} \mathrm{O}_{3}$ \\
\hline SME & 364 & M-14 & \\
\hline SME & 364 & Screened Prototypic & \\
\hline SME & 365 & M-13 & \\
\hline SME & 365 & $\mathrm{M}-14$ & lsum \\
\hline SME & 365 & Screened Prototypic & \\
\hline
\end{tabular}

\subsection{Comparisons of WLs}

Another important use of the SME measurements at DWPF is in the determination of the waste loading (WL) attained for the SME batch. The targeting of the WL takes place during the blending of the SME; this involves the heel of the previous SME batch, a transfer from the current batch in the Sludge Adjustment and Receipt Tank (SRAT), and the addition of frit. But it is in the SME that the attained WL is determined.

The measurements of the rep samples in this study provide an opportunity for additional estimations of attained WL and for comparisons among these values and the values recorded at blending and for the original SME batches. Figure 2-1 provides a plot of these various WLs by batch, and Table 2-4 provides a listing of these values. 
WSRC-STI-2006-00069

Revision 0

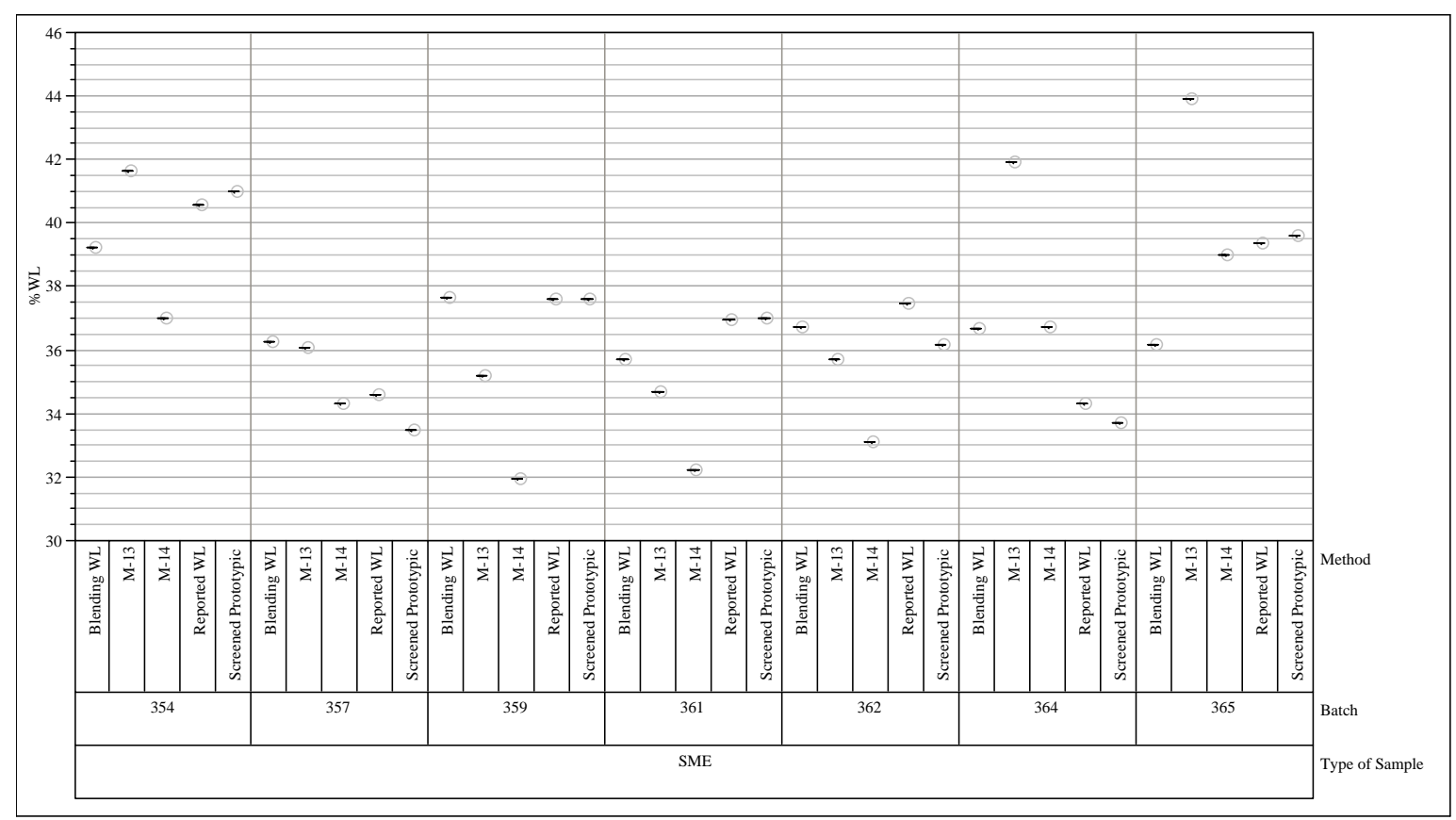

Figure 2-1. Waste Loading Comparisons

Table 2-4. Waste Loading Comparisons

\begin{tabular}{|c|c|c|c|c|c|c||}
\hline Type of Sample & Batch & Blending WL & M-13 & M-14 & Reported WL & Screened Prototypic \\
\hline SME & 354 & 39.25 & 41.67 & 37.05 & 40.62 & 41.03 \\
\hline SME & 357 & 36.29 & 36.10 & 34.33 & 34.63 & 33.49 \\
\hline SME & 359 & 37.66 & 35.23 & 31.96 & 37.63 & 37.62 \\
\hline SME & 361 & 35.71 & 34.71 & 32.26 & 36.96 & 37.01 \\
\hline SME & 362 & 36.76 & 35.74 & 33.13 & 37.51 & 36.19 \\
\hline SME & 364 & 36.70 & 41.93 & 36.74 & 34.32 & 33.74 \\
\hline SME & 365 & 36.18 & 43.96 & 39.04 & 39.41 & 39.63 \\
\hline
\end{tabular}

From Table 2-4, it appears that for the $\mathrm{Cs}_{2} \mathrm{CO}_{3}$ data the WLs determined using the $\mathrm{M}-14$ measurements are consistently lower than those determined using the M-13 measurements. This is probably a consequence of the M-14 providing a larger Li concentration (on average) as compared to the M-13 for these measurements. This is also reflected in the Li measurements for ARG-1 (see Table 2-1). A higher Li concentration leads to a lower estimation of WL (all other things being equal).

Figure 2-2 provides pair-wise statistical comparisons among these WLs values. As suggested by the discussion in the preceding paragraph, the M-14 yielded a statistically lower ( 3.5 points lower) estimated WL value for the batches covered in this study as compared to the M-13. While the WLs values are somewhat noisy and other differences in the averages range a high of 2.37 points to a low of 0.02 points, there are no other statistically significant differences at the $5 \%$ significance level. 
WSRC-STI-2006-00069

Revision 0

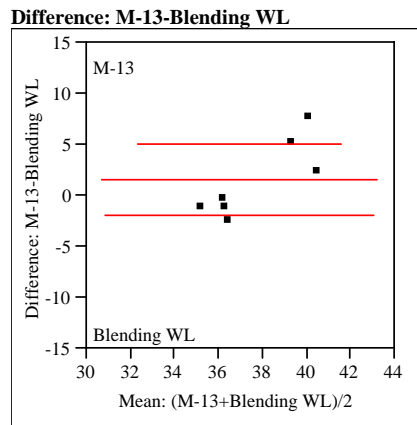

M-13 $38.4771 \quad$ t-Ratio 1.082969

$\begin{array}{llll}\text { Blending WL } & 36.9357 & \mathrm{DF} & \end{array}$

Mean Difference $1.54143 \quad$ Prob $>|t| \quad 0.3204$

$\begin{array}{lrll}\text { Std Error } & 1.42334 & \text { Prob }>\mathrm{t} & 0.1602 \\ \text { Upper95\% } & 5.0242 & \text { Prob }<\mathrm{t} & 0.8398\end{array}$

Lower95\% $\quad-1.9413$

$\begin{array}{lr}N & 7 \\ \text { Correlation } & 0.24326\end{array}$

Difference: M-14-Blending WL

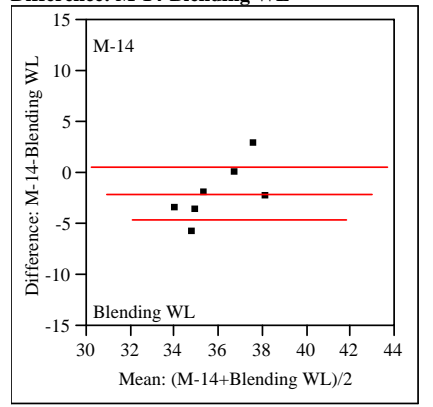

$\begin{array}{lrll}\text { M-14 } & 34.93 & \text { t-Ratio } & -1.91089\end{array}$

Blending WL $\quad 36.9357$ DF $\quad 6$

Mean Difference $-2.0057 \quad$ Prob $>|t| \quad 0.1046$

$\begin{array}{llll}\text { Std Error } & 1.04963 & \text { Prob }>t & 0.9477\end{array}$

Upper95\% $\quad 0.56263 \quad$ Prob $<\mathrm{t} \quad 0.0523$

Lower95\% $\quad-4.5741$

Correlation $\quad 0.16543$

Difference: M-14-M-13

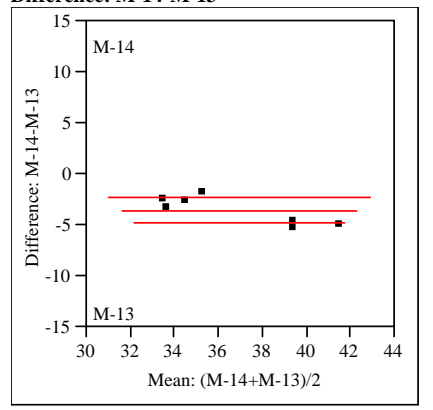

M-14 $\quad 34.93 \quad$ t-Ratio $\quad-6.91493$

$\begin{array}{lrlr}\text { M-13 } & 38.4771 & \text { DF } & 6 \\ \text { Mean Difference } & -3.5471 & \text { Prob }>|t| & 0.0005\end{array}$

$\begin{array}{llll}\text { Std Error } & 0.51297 & \text { Prob }>t & 0.9998\end{array}$

Upper95\% $-2.292 \quad$ Prob $<\mathrm{t} \quad 0.0002$

Lower95\% $\quad-4.8023$

Correlation $\quad 0.97636$

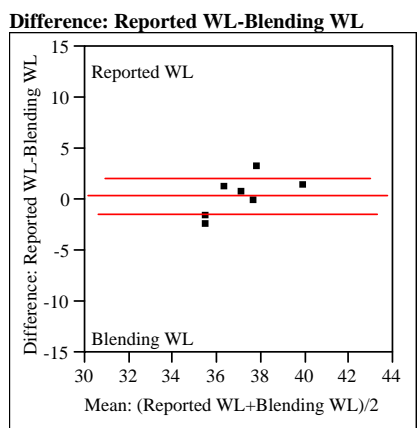

Reported WL $\quad 37.2971 \quad$ t-Ratio 0.500053 Blending WL 36.9357 DF 6

Mean Difference $0.36143 \quad$ Prob $>|t| \quad 0.6348$

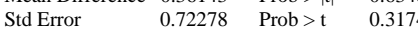

Upper95\% $2.13001 \quad$ Prob $<\mathrm{t} \quad 0.6826$

Lower95\% $\quad-1.4072$

Correlation $\quad 0.5574$

Difference: Reported WL-M-13

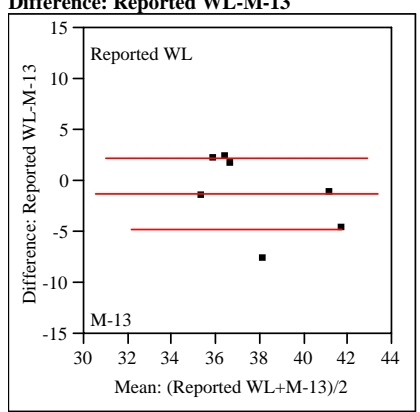

Reported WL $\quad 37.2971 \quad$ t-Ratio $\quad-0.82421$ $\begin{array}{llll}\text { M-13 } & 38.4771 & \text { DF } & 6\end{array}$

$\begin{array}{lrlr}\text { Mean Difference } & -1.18 & \text { Prob }>|t| & 0.4413\end{array}$

$\begin{array}{lrll}\text { Mean Difference } & -1.18 & \text { Prob }>|t| & 0.4413 \\ \text { Std Error } & 1.43167 & \text { Prob }>t & 0.7793\end{array}$

$\begin{array}{llll}\text { Std Error } & 1.43167 & \text { Prob }>\text { t } & 0.7793 \\ \text { Upper95\% } & 2.32317 & \text { Prob }<\mathrm{t} & 0.2207\end{array}$

Lower95\% $\quad-4.6832$

$\begin{array}{lr}\mathrm{N} & 7 \\ \text { Correlation } & 0.33401\end{array}$

Difference: Reported WL-M-14

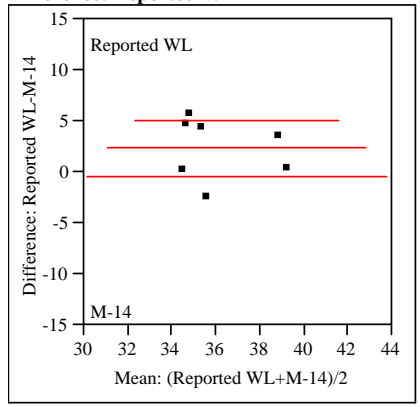

Reported WL $\quad 37.2971 \quad$ t-Ratio 2.106671

$\begin{array}{lllr}\text { M-14 } & 34.93 & \text { DF } & 6\end{array}$

Mean Difference 2.36714 Prob $>|t|$

$\begin{array}{llll}\text { Std Error } & 1.12364 & \text { Prob }>t & 0.0399\end{array}$

Upper95\% $\quad 5.11659 \quad$ Prob $<\mathrm{t} \quad 0.9601$

Lower95\% $\quad-0.3823$

Correlation $\quad 0.30609$
Difference: Screened Prototypic-Blending WL

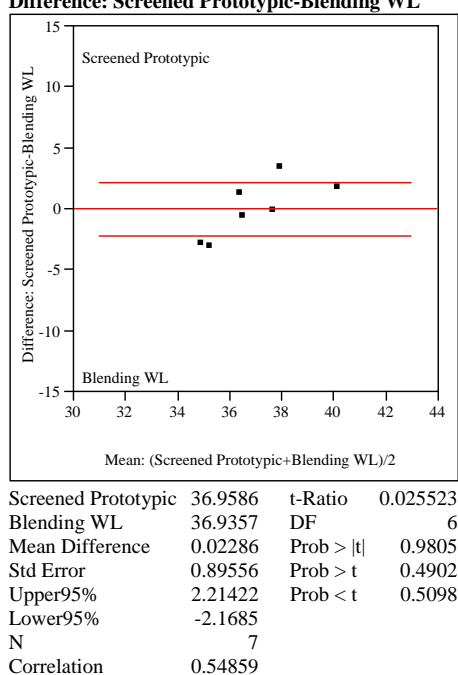

Difference: Screened Prototypic-M-13

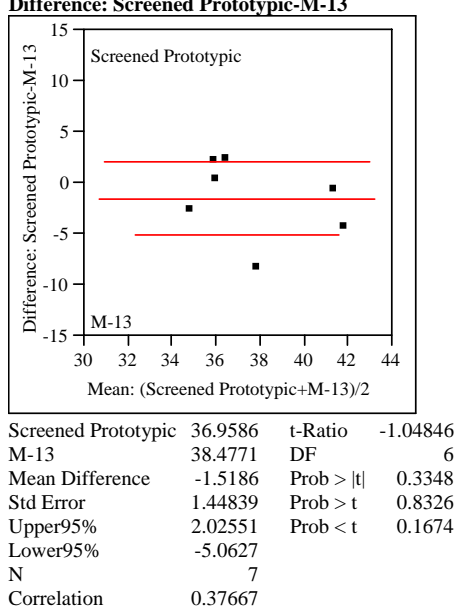

Difference: Screened Prototypic-M-14

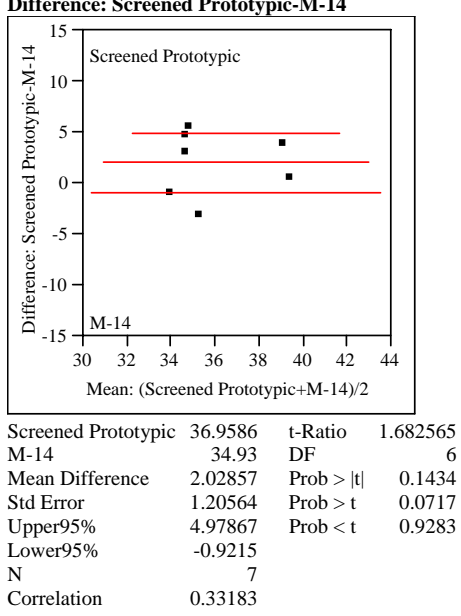

Figure 2-2. Pair-Wise Statistical Comparisons of WLs 


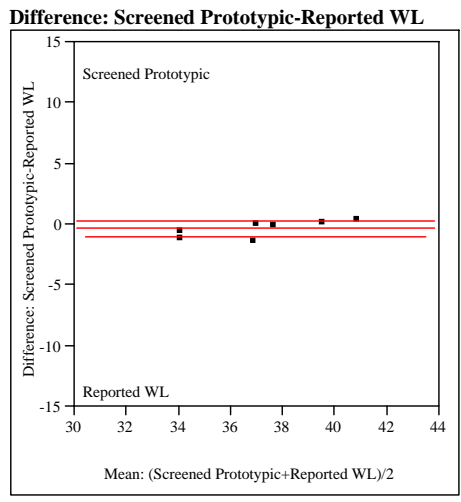

$\begin{array}{lrlr}\text { Screened Prototypic } & 36.9586 & \text { t-Ratio } & -1.31243 \\ \text { Reported WL } & 37.2971 & \text { DF } & 6 \\ \text { Mean Difference } & -0.3386 & \text { Prob }>|t| & 0.2373 \\ \text { Std Error } & 0.25797 & \text { Prob }>\text { t } & 0.8813 \\ \text { Upper95\% } & 0.29266 & \text { Prob }<\mathrm{t} & 0.1187 \\ \text { Lower95\% } & -0.9698 & & \\ \text { N } & 7 & & \\ \text { Correlation } & 0.98344 & & \end{array}$

Figure 2-2. Pair-Wise Statistical Comparisons of WLs

(continued)

\subsection{CONCLUSIONS}

This report provides a statistical review of measurements that the DWPF Lab generated by ICP-AES for samples of archived SME glass that were prepared using a $\mathrm{Cs}_{2} \mathrm{CO}_{3}$ fusion dissolution method. Measurements were generated by both of the Lab's ICPs. Comparisons between the two ICPs for the $\mathrm{Cs}_{2} \mathrm{CO}_{3}$-prepared samples suggest that, for the ARG-1 measurements, the $\mathrm{M}-14$ provided lower concentration measurements for about 13 of the 16 elements reported by DWPF with $\mathrm{Cr}, \mathrm{Mn}, \mathrm{Ni}$, and $\mathrm{Zr}$ being statistically lower (at a 5\% significance level) for the ARG-1 samples. One of the three exceptions is $\mathrm{Li}$, for which the M-14 yielded (on average) higher concentration measurements than the M-13. For the $\mathrm{Cs}_{2} \mathrm{CO}_{3}$-prepared SME samples, the M-14 and M-13 measurements had statistically different (at the $5 \%$ significance level) means for B, Ca, Cr, Cu, Fe, Li, Mg, Mn, Na, Ni, Si, Ti, U, and Zr with the M-14 being lower than the M-13 for all of these elements except for Li.

For the screened SME samples, statistically significant (at the $5 \%$ level) differences between the means of the $\mathrm{Cs}_{2} \mathrm{CO}_{3}$ and prototypic preparations are seen for $\mathrm{Ca}\left(\mathrm{Cs}_{2} \mathrm{CO}_{3}\right.$ higher for both ICPs), $\mathrm{Cr}\left(\mathrm{Cs}_{2} \mathrm{CO}_{3}\right.$ higher for both ICPs), $\mathrm{Cu}\left(\mathrm{Cs}_{2} \mathrm{CO}_{3}\right.$ higher for $\left.\mathrm{M}-13\right), \mathrm{K}$ ( $\mathrm{Cs}_{2} \mathrm{CO}_{3}$ higher for $\left.\mathrm{M}-13\right)$, $\mathrm{Mn}\left(\mathrm{Cs}_{2} \mathrm{CO}_{3}\right.$ lower for $\left.\mathrm{M}-14\right)$, $\mathrm{Ni}\left(\mathrm{Cs}_{2} \mathrm{CO}_{3}\right.$ lower for $\left.\mathrm{M}-14\right)$, $\mathrm{Si}\left(\mathrm{Cs}_{2} \mathrm{CO}_{3}\right.$ lower for $\left.\mathrm{M}-14\right)$, Ti $\left(\mathrm{Cs}_{2} \mathrm{CO}_{3}\right.$ higher for $\left.\mathrm{M}-13\right), \mathrm{U}\left(\mathrm{Cs}_{2} \mathrm{CO}_{3}\right.$ higher for both ICPs), and $\mathrm{Zr}\left(\mathrm{Cs}_{2} \mathrm{CO}_{3}\right.$ lower for M-14).

The $\mathrm{Cs}_{2} \mathrm{CO}_{3}$ fusion method provided elemental of glass samples made from SME batches that were statistically comparable to the DWPF prototypic dissolution methods when the $\mathrm{Cs}_{2} \mathrm{CO}_{3}$ solutions were analyzed by the $\mathrm{M}-13$. However, when the same solutions were analyzed with the M-15, the elemental analyses from the $\mathrm{Cs}_{2} \mathrm{CO}_{3}$ method were slightly lower and more prone to fail the 95\% sum of oxides criterion imposed by DWPF's Product Composition Control System (PCCS). The $\mathrm{Cs}_{2} \mathrm{CO}_{3}$ fusion method dissolutions also provided slightly lower waste loading values than the prototypic dissolutions because of slightly higher lithium values when the M-14 was used. In essence, subtle differences in the analyses form the M-13 and M-14 ICPs make it difficult to assess the viability of the $\mathrm{Cs}_{2} \mathrm{CO}_{3}$ fusion method to 
replace the prototypic dissolution methods. The DWFP Laboratory should investigate the causes of these subtle differences between the M-13 and M-14 ICPs as the effort to employ the $\mathrm{Cs}_{2} \mathrm{CO}_{3}$ fusion method for SME elemental analyses continues.

In these analyses all of the $\mathrm{Cs}_{2} \mathrm{CO}_{3}$ measurements available for each of the SME batches were used in the comparisons, and there is no reason that use of all 6 samples might not be adopted as the standard operating procedures for the measurements from a $\mathrm{Cs}_{2} \mathrm{CO}_{3}$-prepared SME samples. A step can be incorporated into such procedures to screen for potential outliers in the measurements.

\subsection{REFERENCES}

[1] Mahannah, RN, “Technical Task Request: DWPF Process Improvement Test Plan,” HLW/DWPF/TTR-2004-0011, Revision 1, April 5, 2004.

[2] Coleman, CJ, TB Edwards, and DR Click, "SRNL Evaluation of Sub-Sampling Precision and Accuracy of DWPF Slurry Mix Evaporator Simulant,” WSRC-TR-2004-00339, Revision 0, August 19, 2004.

[3] Coleman, CJ and TB Edwards, "Phase II of a Six Sigma Initiative to Study DWPF SME Analytical Turnaround Times: SRNL's Evaluation of Carbonate-Based Dissolution Methods,” WSRC-TR2005-00396, Revision 0, October 5, 2005.

[4] Edwards, TB and RN Mahannah, "Phase II of a Six Sigma Initiative to Study DWPF Slurry Mix Evaporator Analytical Turnaround Times: Comparisons of Weight Percent Total Solids Measurements at DWPF of Large Bottle Samples versus Peanut Vial Samples,” WSRC-TR-200500492, Revision 0, October 2005.

[5] Mahannah, RN, “Technical Task Request: Statistical Analysis for DWPF Shielded Cell Tests on $\mathrm{Cs}_{2} \mathrm{CO}_{3}$ Fusions and Large Volume Sampling/Sub-Sampling,” HLW-DWPF-TTR-2006-0003, Revision 0, March 9, 2006.

[6] Mahannah, RN, “Technical Task Request: Six Sigma Phase III Support for Large Volume Sampling/Sub-Sampling, SRNL Mock-Up and SRNL Shielded Cell Work,” HLW-DWPF-TTR2006-0006, Revision 0, March 9, 2006.

[7] Edwards, TB, “Task Technical \& QA Plan: Statistical Analysis for DWPF Shielded Cell Tests of Cs2CO3 Fusions and Large Volume Sampling/Sub-Sampling,” WSRC-RP-2006-00567, Revision 0, April 17, 2006.

[8] SAS Institute, Inc., JMP Statistics and Graphics Guide, SAS Institute, Inc., Cary, NC, 2002.

[9] Brown, KG, RL Postles, and TB Edwards, "SME Acceptability Determination for DWPF Process Control,” WSRC-TR-95-0364, Revision 4, August 2002. 
WSRC-STI-2006-00069

Revision 0

This page intentionally left blank. 
WSRC-STI-2006-00069

Revision 0

Appendix A. Supplemental Data Tables and Exhibits 
Table A1. ICP-AES Elemental Measurements for Samples Prepared by $\mathrm{Cs}_{2} \mathrm{CO}_{3}$ Fusion, Peroxide Fusion, and Mixed Acid

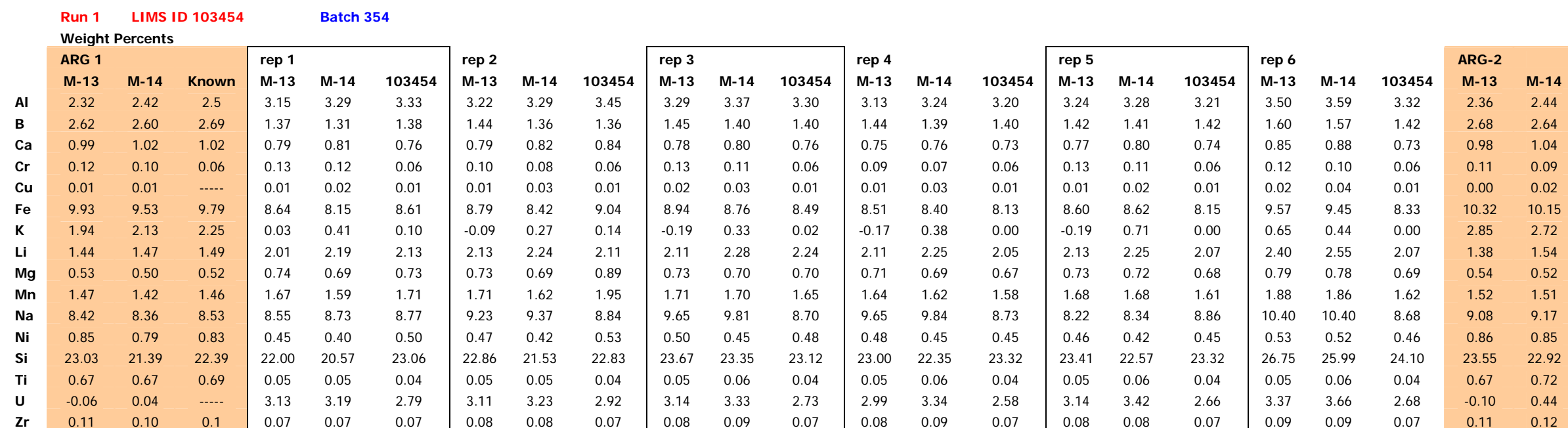

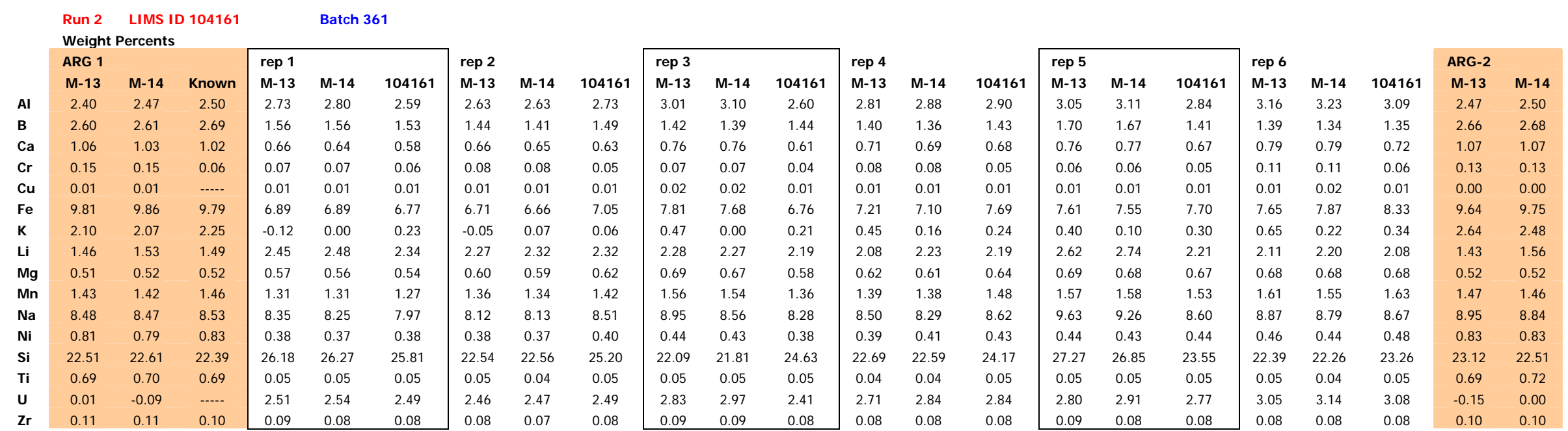


WSRC-STI-2006-00069

Revision 0

Table A1. ICP-AES Elemental Measurements for Samples Prepared by $\mathrm{Cs}_{2} \mathrm{CO}_{3}$ Fusion, Peroxide Fusion, and Mixed Acid

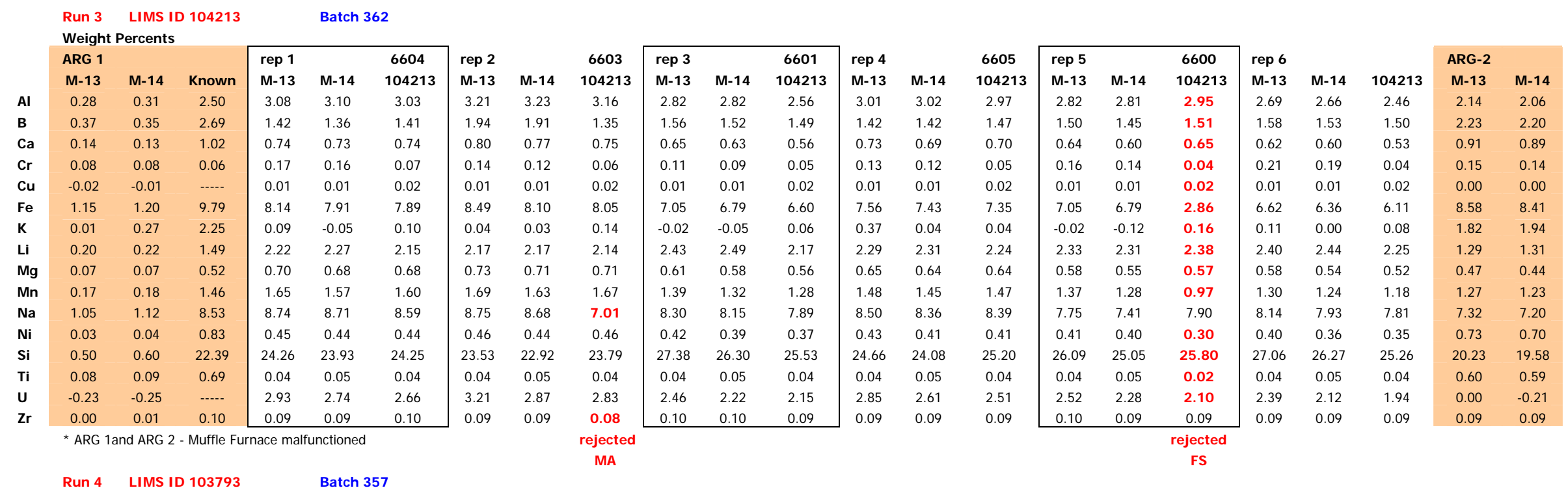

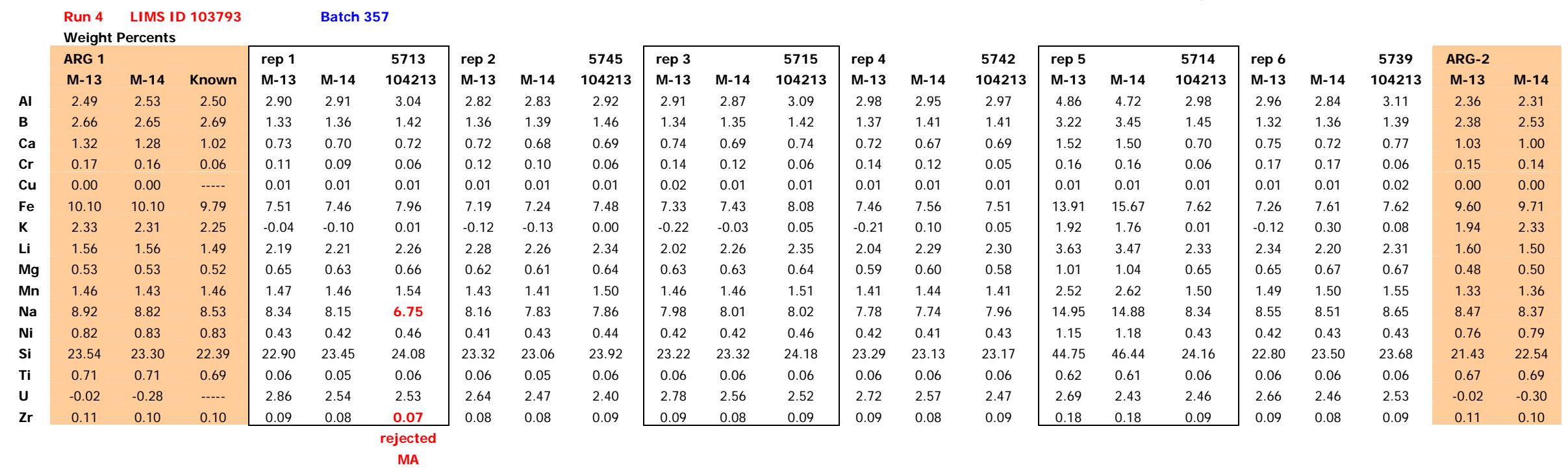


WSRC-STI-2006-00069

Revision 0

Table A1. ICP-AES Elemental Measurements for Samples Prepared by $\mathrm{Cs}_{2} \mathrm{CO}_{3}$ Fusion, Peroxide Fusion, and Mixed Acid

\begin{tabular}{|c|c|c|c|c|c|c|c|c|}
\hline & Run 5 & LIMS I & & & Batch & & & \\
\hline & Weight & Percent: & & & & & & \\
\hline & ARG 1 & & & rep 1 & & 6057 & rep 2 & \\
\hline & M-13 & M-14 & Known & M-13 & M-14 & 103992 & M-13 & M-14 \\
\hline Al & 2.41 & 2.43 & 2.50 & 2.92 & 2.94 & 3.02 & 3.03 & 2.95 \\
\hline B & 2.61 & 2.59 & 2.69 & 1.35 & 1.38 & 1.44 & 1.41 & 1.38 \\
\hline $\mathrm{Ca}$ & 1.01 & 1.00 & 1.02 & 0.74 & 0.75 & 0.72 & 0.77 & 0.73 \\
\hline $\mathrm{Cr}$ & 0.18 & 0.15 & 0.06 & 0.12 & 0.09 & 0.06 & 0.13 & 0.09 \\
\hline Cu & 0.01 & -0.01 & ----- & 0.03 & 0.01 & 0.02 & 0.02 & 0.00 \\
\hline $\mathrm{Fe}$ & 9.86 & 9.62 & 9.79 & 7.73 & 7.71 & 7.93 & 7.61 & 7.43 \\
\hline K & 2.14 & 1.84 & 2.25 & 0.19 & -0.39 & -0.04 & 0.13 & 0.48 \\
\hline $\mathbf{L i}$ & 1.48 & 1.49 & 1.49 & 2.13 & 2.23 & 2.24 & 2.20 & 2.30 \\
\hline Mg & 0.53 & 0.51 & 0.52 & 0.71 & 0.69 & 0.72 & 0.71 & 0.67 \\
\hline Mn & 1.46 & 1.43 & 1.46 & 1.57 & 1.60 & 1.64 & 1.55 & 1.54 \\
\hline $\mathrm{Na}$ & 8.44 & 8.05 & 8.53 & 8.23 & 8.15 & 8.79 & 8.28 & 7.96 \\
\hline $\mathbf{N i}$ & 0.82 & 0.82 & 0.83 & 0.45 & 0.42 & 0.46 & 0.46 & 0.40 \\
\hline Si & 23.37 & 22.93 & 22.39 & 24.14 & 23.57 & 24.84 & 23.96 & 22.89 \\
\hline Ti & 0.69 & 0.70 & 0.69 & 0.06 & 0.05 & 0.06 & 0.07 & 0.05 \\
\hline u & 0.17 & -0.42 & ----- & 2.82 & 2.50 & 2.49 & 2.80 & 2.58 \\
\hline Zr & 0.11 & 0.10 & 0.10 & 0.10 & 0.09 & 0.10 & 0.09 & 0.08 \\
\hline
\end{tabular}

\begin{tabular}{c|ccc|cc}
$\mathbf{6 0 1 5}$ & $\mathbf{r e p ~ 3}$ & & $\mathbf{6 0 5 9}$ & rep 4 & \\
$\mathbf{1 0 3 9 9 2}$ & $\mathbf{M}-13$ & $\mathbf{M - 1 4}$ & $\mathbf{1 0 3 9 9 2}$ & $\mathbf{M - 1 3}$ & $\mathbf{M}-\mathbf{1 4}$ \\
2.92 & 3.00 & 3.01 & 3.10 & 3.12 & 3.12 \\
1.48 & 1.34 & 1.30 & 1.43 & 1.39 & 1.39 \\
0.71 & 0.76 & 0.74 & 0.76 & 0.79 & 0.74 \\
0.06 & 0.10 & 0.08 & 0.06 & 0.33 & 0.26 \\
0.02 & 0.02 & 0.01 & 0.02 & 0.04 & 0.00 \\
7.86 & 7.72 & 7.55 & 8.32 & 7.97 & 8.16 \\
-0.05 & 0.37 & -0.09 & -0.03 & 0.14 & -0.2 \\
2.19 & 2.13 & 2.16 & 2.16 & 2.17 & 2.26 \\
0.70 & 0.71 & 0.69 & 0.74 & 0.70 & 0.69 \\
1.59 & 1.58 & 1.58 & 1.67 & 1.59 & 1.57 \\
8.66 & 8.35 & 8.08 & 8.94 & 8.54 & 8.16 \\
0.45 & 0.45 & 0.42 & 0.47 & 0.45 & 0.42 \\
25.01 & 21.97 & 21.68 & 24.33 & 23.20 & 22.96 \\
0.06 & 0.06 & 0.05 & 0.06 & 0.07 & 0.05 \\
2.38 & 3.07 & 2.79 & 2.59 & 3.13 & 2.55 \\
0.10 & 0.09 & 0.08 & 0.10 & 0.10 & 0.09 \\
\cline { 2 - 3 } & &
\end{tabular}

\begin{tabular}{c|ccc|ccccc}
$\mathbf{6 0 6 6}$ & rep 5 & & $\mathbf{6 0 5 8}$ & rep 6 & & $\mathbf{6 0 5 6}$ & ARG-2 & \\
$\mathbf{1 0 3 9 9 2}$ & $\mathbf{M - 1 3}$ & $\mathbf{M - 1 4}$ & $\mathbf{1 0 3 9 9 2}$ & $\mathbf{M - 1 3}$ & $\mathbf{M - 1 4}$ & $\mathbf{1 0 3 9 9 2}$ & $\mathbf{M - 1 3}$ & $\mathbf{M - 1 4}$ \\
$\mathbf{2 . 7 4}$ & 2.73 & 2.61 & $\mathbf{2 . 8 6}$ & 3.06 & 3.03 & 3.00 & 2.48 & 2.34 \\
$\mathbf{1 . 3 5}$ & 1.45 & 1.52 & $\mathbf{1 . 7 1}$ & 1.34 & 1.37 & 1.44 & 2.54 & 2.49 \\
$\mathbf{0 . 6 6}$ & 0.64 & 0.60 & $\mathbf{0 . 6 4}$ & 0.80 & 0.74 & 0.74 & 1.06 & 1.00 \\
$\mathbf{0 . 0 6}$ & 0.16 & 0.13 & $\mathbf{0 . 0 6}$ & 0.22 & 0.18 & 0.07 & 0.23 & 0.18 \\
$\mathbf{0 . 0 2}$ & 0.03 & 0.00 & $\mathbf{0 . 0 1}$ & 0.04 & 0.00 & 0.01 & 0.03 & -0.01 \\
$\mathbf{7 . 5 5}$ & 6.02 & 6.41 & $\mathbf{6 . 8 5}$ & 7.49 & 7.54 & 7.93 & 9.56 & 9.65 \\
$\mathbf{- 0 . 0 6}$ & 0.69 & -0.39 & $\mathbf{- 0 . 0 3}$ & 0.39 & -0.11 & -0.01 & 4.19 & 2.17 \\
$\mathbf{1 . 9 4}$ & 2.39 & 2.42 & $\mathbf{2 . 6 1}$ & 2.20 & 2.23 & 2.19 & 1.51 & 1.49 \\
$\mathbf{0 . 6 8}$ & 0.55 & 0.55 & $\mathbf{0 . 6 0}$ & 0.72 & 0.70 & 0.73 & 0.52 & 0.49 \\
$\mathbf{1 . 5 2}$ & 1.19 & 1.23 & $\mathbf{1 . 3 6}$ & 1.19 & 1.11 & 1.61 & 1.40 & 1.41 \\
$\mathbf{8 . 4 9}$ & 7.87 & 6.94 & $\mathbf{7 . 8 7}$ & 8.76 & 7.98 & 8.86 & 8.95 & 7.32 \\
$\mathbf{0 . 4 3}$ & 0.36 & 0.32 & $\mathbf{0 . 3 9}$ & 0.42 & 0.39 & 0.45 & 0.85 & 0.77 \\
$\mathbf{2 2 . 9 6}$ & 25.22 & 25.88 & $\mathbf{2 9 . 0 2}$ & 23.56 & 24.51 & 24.95 & 22.71 & 23.13 \\
$\mathbf{0 . 0 6}$ & 0.07 & 0.05 & $\mathbf{0 . 0 7}$ & 0.07 & 0.05 & 0.06 & 0.68 & 0.68 \\
$\mathbf{2 . 2 8}$ & $\mathbf{2 . 4 5}$ & 1.74 & $\mathbf{2 . 0 6}$ & 3.14 & 2.44 & 2.40 & 0.53 & -0.42 \\
$\mathbf{0 . 1 0}$ & 0.10 & 0.09 & $\mathbf{0 . 1 0}$ & 0.08 & 0.06 & 0.10 & 0.12 & 0.10 \\
\cline { 2 - 8 }
\end{tabular}

Run 6 LIMS ID $104369 \quad$ Batch 364

\begin{tabular}{|c|c|c|c|c|c|c|c|c|c|c|c|c|c|c|}
\hline & & & & & & & & & & & & & & \\
\hline & ARG 1 & & & rep 1 & & 6914 & rep 2 & & 6920 & rep 3 & & 6926 & rep 4 & \\
\hline & M-13 & M-14 & Known & M-13 & M-14 & 104369 & M-13 & M-14 & 104369 & M-13 & M-14 & 104369 & M-13 & M-1 \\
\hline Al & 2.42 & 2.36 & 2.50 & 3.05 & 2.94 & 2.99 & 3.21 & 3.01 & 3.01 & 3.21 & 3.12 & 3.00 & 3.25 & 3.03 \\
\hline B & 2.58 & 2.52 & 2.69 & 1.38 & 1.38 & 1.34 & 1.41 & 1.36 & 1.36 & 1.41 & 1.37 & 1.39 & 1.38 & 1.32 \\
\hline Ca & 1.05 & 1.00 & 1.02 & 0.75 & 0.72 & 0.70 & 0.76 & 0.72 & 0.69 & 0.80 & 0.76 & 0.76 & 0.82 & 0.76 \\
\hline $\mathrm{Cr}$ & 0.15 & 0.12 & 0.06 & 0.15 & 0.12 & 0.05 & 0.15 & 0.13 & 0.06 & 0.18 & 0.15 & 0.06 & 0.17 & 0.14 \\
\hline Cu & 0.01 & -0.01 & ----- & 0.03 & 0.01 & 0.02 & 0.03 & 0.01 & 0.02 & 0.03 & 0.01 & 0.02 & 0.05 & 0.02 \\
\hline $\mathbf{F e}$ & 9.80 & 9.55 & 9.79 & 7.78 & 7.90 & 7.69 & 8.21 & 8.24 & 7.87 & 8.16 & 7.91 & 7.83 & 8.21 & 8.43 \\
\hline K & 2.00 & 2.09 & 2.25 & 0.05 & -0.11 & 0.09 & 0.15 & -0.18 & 0.09 & 0.41 & -0.12 & 0.09 & 0.36 & -0.27 \\
\hline Li & 1.43 & 1.52 & 1.49 & 2.07 & 2.19 & 2.27 & 2.08 & 2.23 & 2.29 & 2.14 & 2.18 & 2.29 & 2.05 & 2.16 \\
\hline Mg & 0.52 & 0.51 & 0.52 & 0.66 & 0.68 & 0.65 & 0.68 & 0.67 & 0.64 & 0.72 & 0.72 & 0.69 & 0.70 & 0.71 \\
\hline Mn & 1.43 & 1.42 & 1.46 & 1.55 & 1.51 & 1.48 & 1.53 & 1.45 & 1.51 & 1.65 & 1.59 & 1.59 & 1.54 & 1.54 \\
\hline $\mathrm{Na}$ & 8.36 & 8.64 & 8.53 & 8.29 & 8.35 & 8.34 & 8.49 & 8.48 & 8.52 & 8.93 & 8.94 & 8.84 & 8.79 & 8.68 \\
\hline Ni & 0.84 & 0.78 & 0.83 & 0.45 & 0.42 & 0.41 & 0.49 & 0.46 & 0.44 & 0.47 & 0.43 & 0.44 & 0.51 & 0.46 \\
\hline Si & 22.84 & 21.67 & 22.39 & 23.27 & 23.28 & 23.08 & 24.38 & 23.91 & 23.78 & 24.01 & 23.86 & 23.07 & 23.82 & 23.98 \\
\hline " & 0.69 & 0.67 & 0.69 & 0.05 & 0.04 & 0.05 & 0.05 & 0.04 & 0.05 & 0.05 & 0.04 & 0.05 & 0.05 & 0.0 \\
\hline 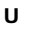 & 0.32 & -0.13 & ---- & 3.24 & 2.80 & 2.54 & 3.43 & 2.87 & 2.61 & 3.34 & 2.87 & 2.64 & 3.65 & 2.8 \\
\hline & 0.11 & 0.10 & 0.10 & 0.09 & 0.08 & 0.09 & 0.10 & 0.08 & 0.09 & 0.09 & 0.08 & 0.09 & 0.10 & \\
\hline
\end{tabular}

rejected

FS \& MA

\begin{tabular}{c|ccc|cccccc}
$\mathbf{6 9 1 7}$ & rep 5 & & $\mathbf{6 9 1 1}$ & rep 6 & & $\mathbf{6 9 2 3}$ & ARG-2 & \\
$\mathbf{1 0 4 3 6 9}$ & $\mathbf{M - 1 3}$ & $\mathbf{M - 1 4}$ & $\mathbf{1 0 4 3 6 9}$ & $\mathbf{M - 1 3}$ & $\mathbf{M - 1 4}$ & $\mathbf{1 0 4 3 6 9}$ & $\mathbf{M - 1 3}$ & $\mathbf{M - 1 4}$ \\
3.01 & 3.20 & 2.99 & 3.00 & 3.24 & 2.98 & 2.96 & 2.48 & 2.29 \\
1.33 & 1.43 & 1.40 & 1.39 & 1.37 & 1.35 & 1.33 & 2.58 & 2.50 \\
0.73 & 0.77 & 0.73 & 0.73 & 0.80 & 0.76 & 0.73 & 1.03 & 1.01 \\
0.06 & 0.16 & 0.12 & 0.06 & 0.15 & 0.11 & 0.06 & 0.20 & 0.17 \\
0.02 & 0.03 & 0.01 & 0.02 & 0.04 & 0.01 & 0.02 & 0.03 & -0.01 \\
8.00 & 7.97 & 7.91 & 7.88 & 8.04 & 7.95 & 7.62 & 9.60 & 9.59 \\
0.09 & 0.20 & -0.29 & 0.09 & 0.31 & -0.28 & 0.13 & 2.44 & 1.82 \\
2.20 & 2.12 & 2.30 & 2.29 & 1.95 & 2.14 & 2.28 & 1.42 & 1.46 \\
0.67 & 0.71 & 0.70 & 0.67 & 0.73 & 0.73 & 0.67 & 0.51 & 0.55 \\
1.55 & 1.59 & 1.57 & 1.57 & 1.60 & 1.59 & 1.55 & 1.41 & 1.39 \\
8.86 & 8.81 & 8.57 & 8.59 & 9.11 & 8.84 & 8.83 & 8.32 & 8.25 \\
0.44 & 0.47 & 0.43 & 0.44 & 0.49 & 0.46 & 0.43 & 0.84 & 0.78 \\
22.96 & 24.83 & 23.83 & 23.98 & 23.99 & 23.92 & 22.63 & 22.96 & 22.79 \\
0.05 & 0.05 & 0.05 & 0.05 & 0.05 & 0.05 & 0.05 & 0.66 & 0.66 \\
2.65 & 3.46 & 2.83 & 2.63 & 3.51 & 2.75 & 2.58 & 0.62 & -0.11 \\
0.10 & 0.10 & 0.08 & 0.09 & 0.10 & 0.08 & 0.09 & 0.11 & 0.10
\end{tabular}


Table A1. ICP-AES Elemental Measurements for Samples Prepared by $\mathrm{Cs}_{2} \mathrm{CO}_{3}$ Fusion, Peroxide Fusion, and Mixed Acid Run 7 LI MS ID $104455 \quad$ Batch 36

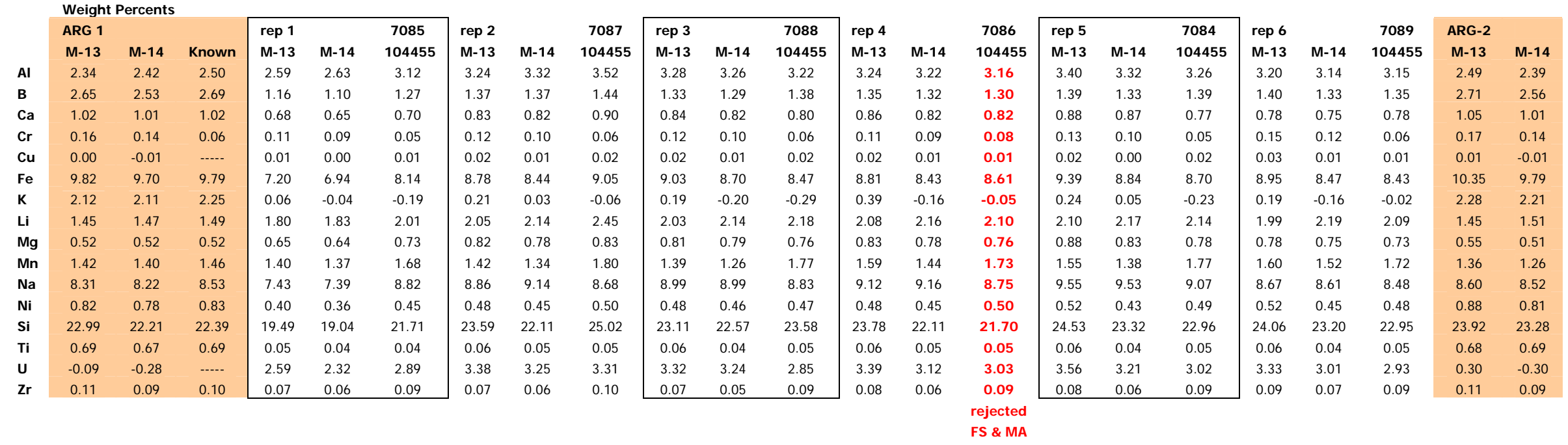


Exhibit A1. Initial Plots of Measurements by Type of Sample and by Element

Type of Sample=ARG-1, Analyte=Al

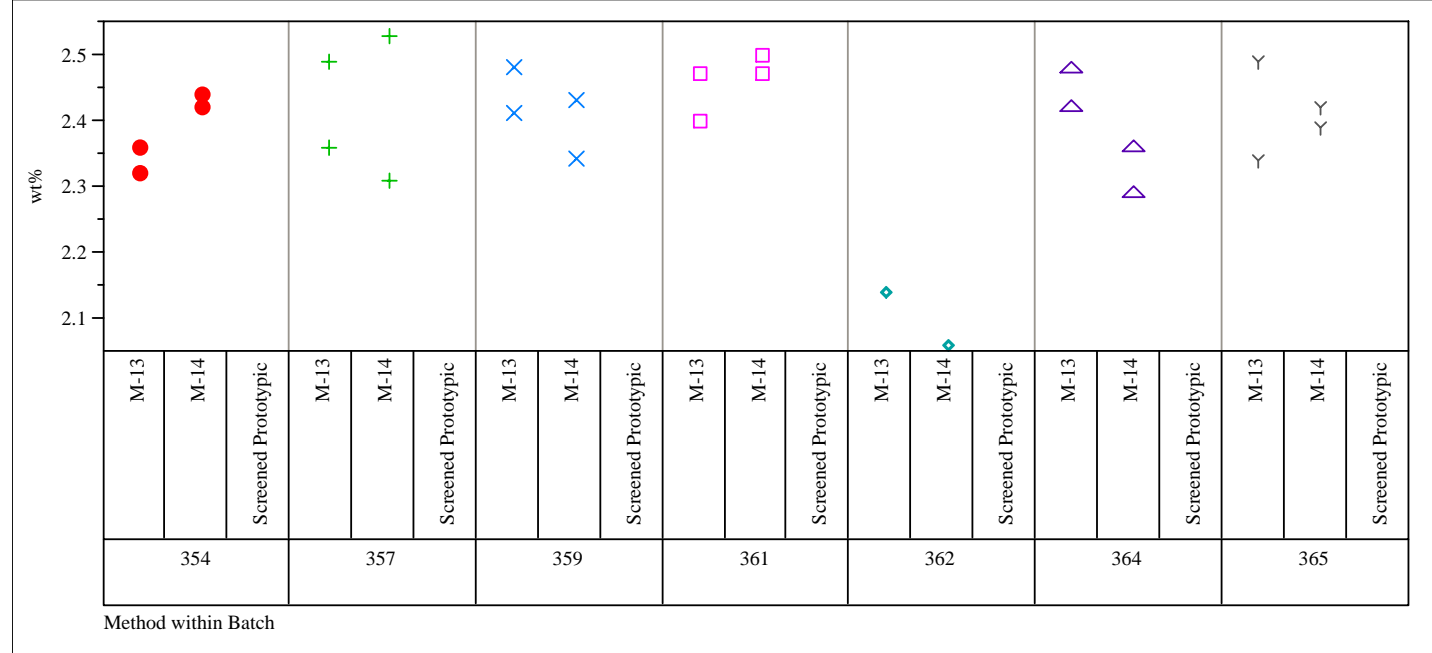

Type of Sample=ARG-1, Analyte=B

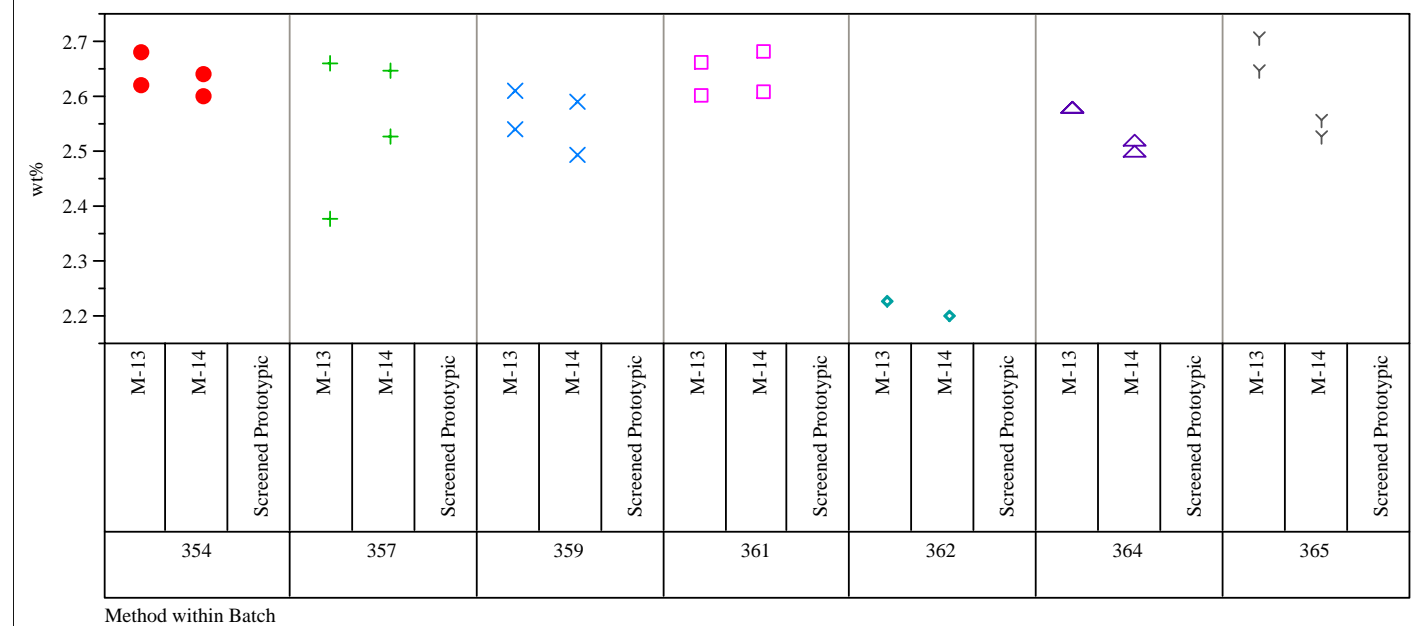

Type of Sample=ARG-1, Analyte $=$ Ca

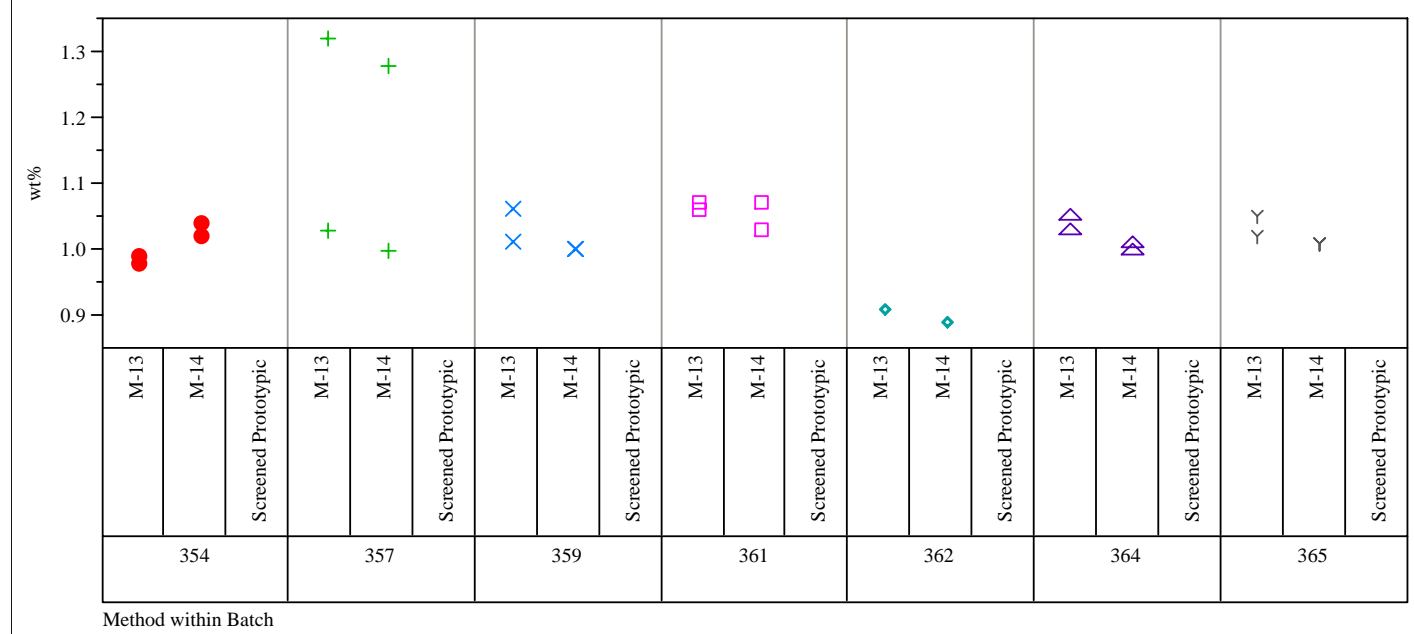


Exhibit A1. Initial Plots of Measurements by Type of Sample and by Element

Type of Sample $=$ ARG-1, Analyte $=\mathrm{Cr}$

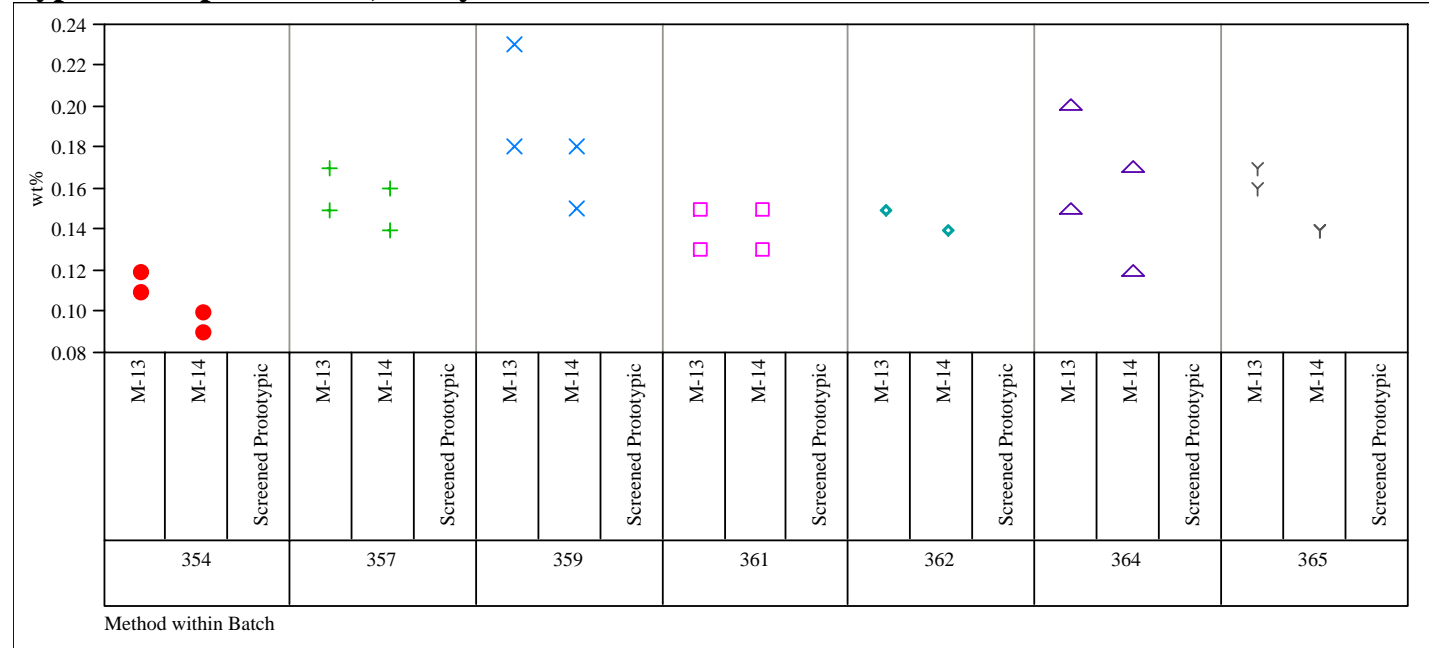

Type of Sample=ARG-1, Analyte $=\mathrm{Cu}$

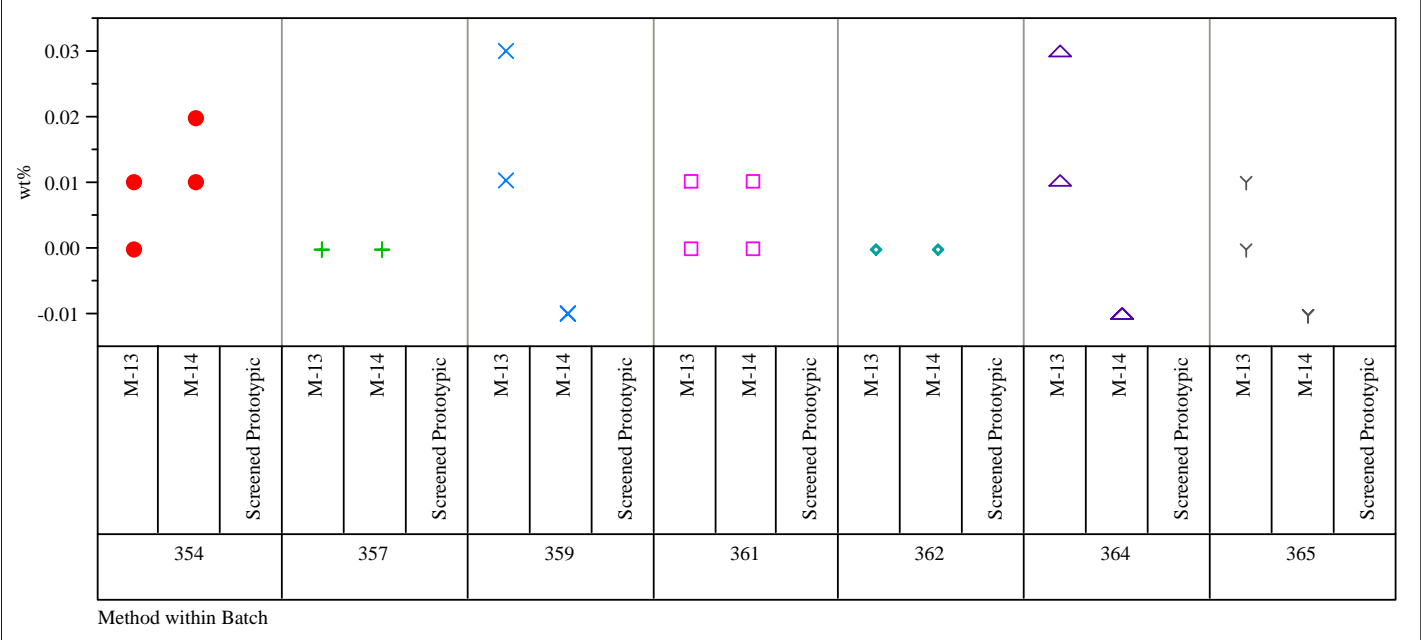

\section{Type of Sample=ARG-1, Analyte $=$ Fe}

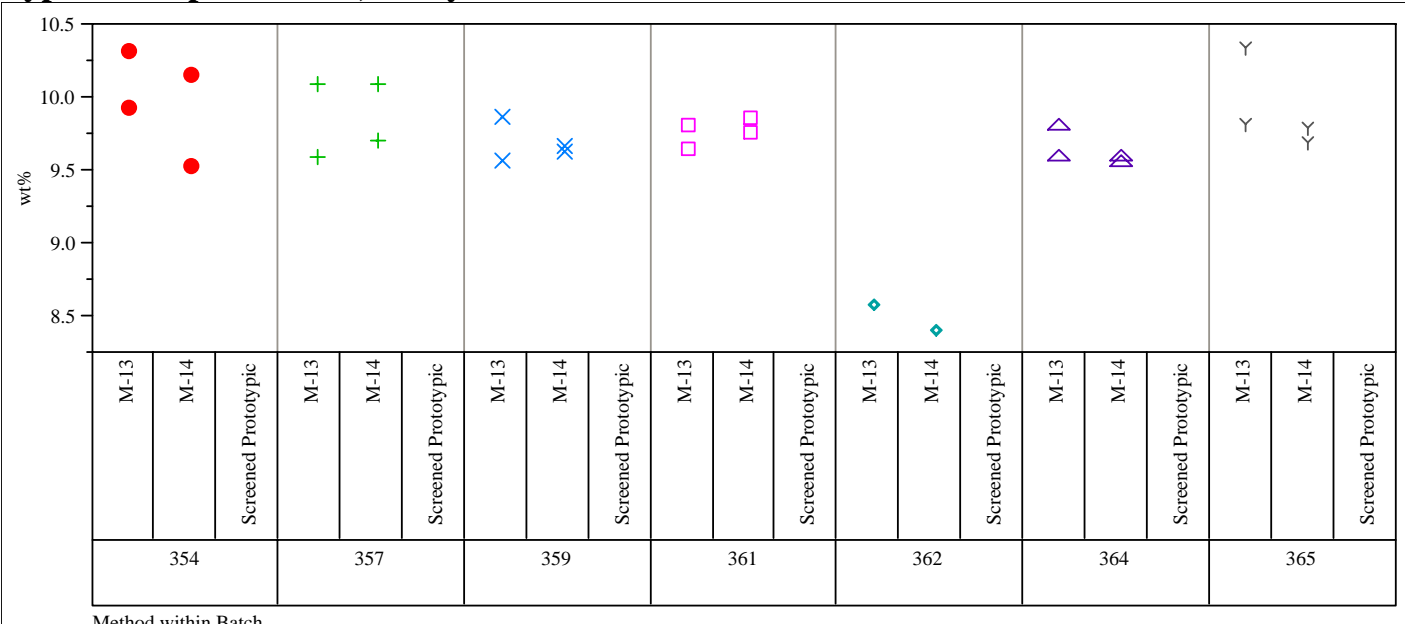

Method within Batch 
Exhibit A1. Initial Plots of Measurements by Type of Sample and by Element

Type of Sample=ARG-1, Analyte $=K$

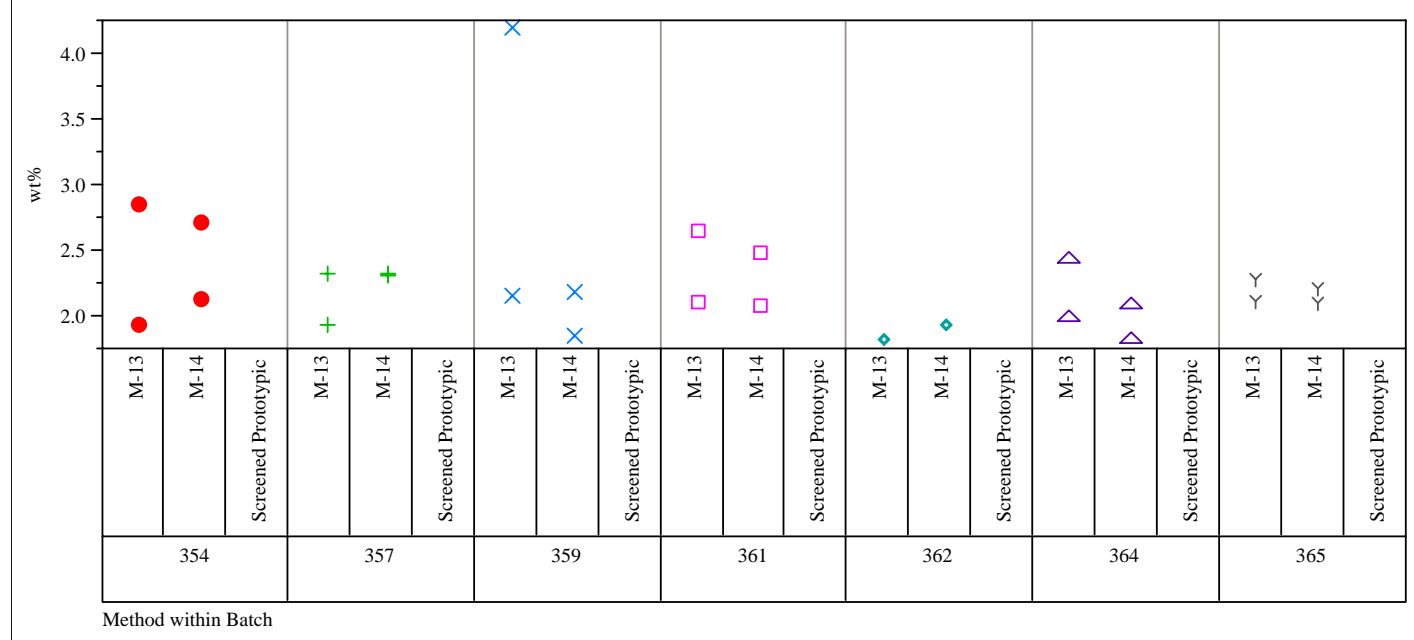

Type of Sample=ARG-1, Analyte=Li

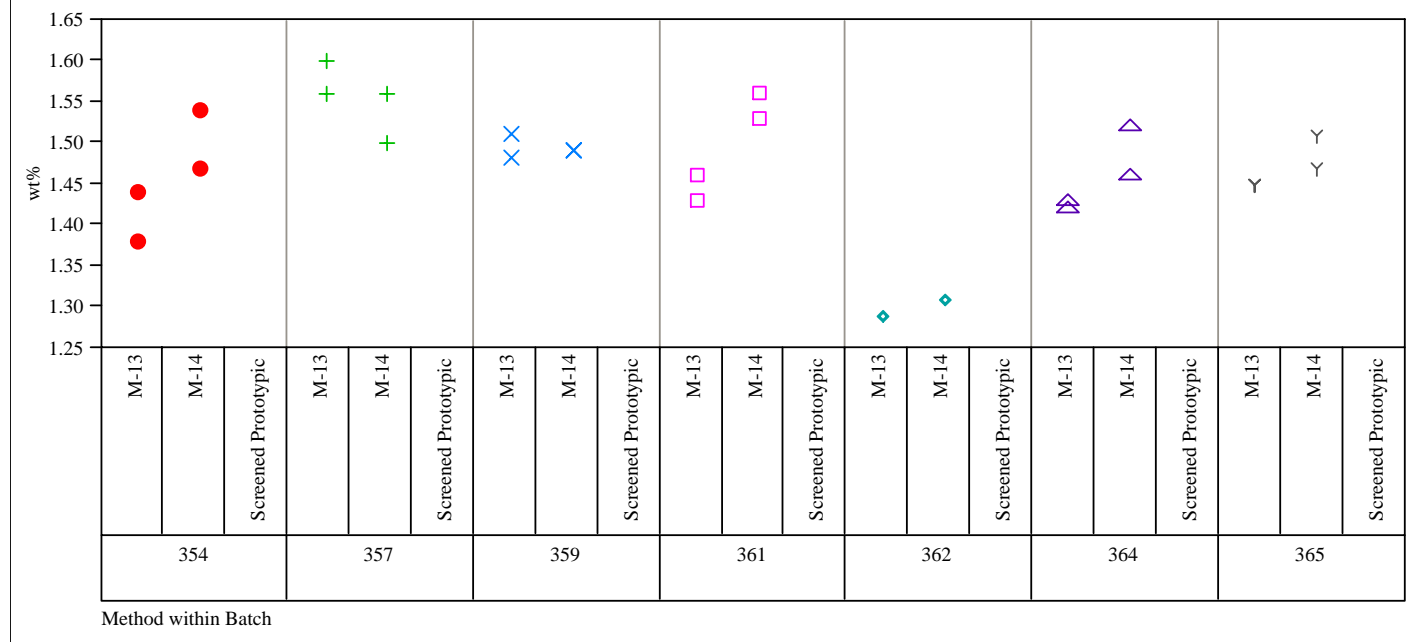

Type of Sample=ARG-1, Analyte=Mg

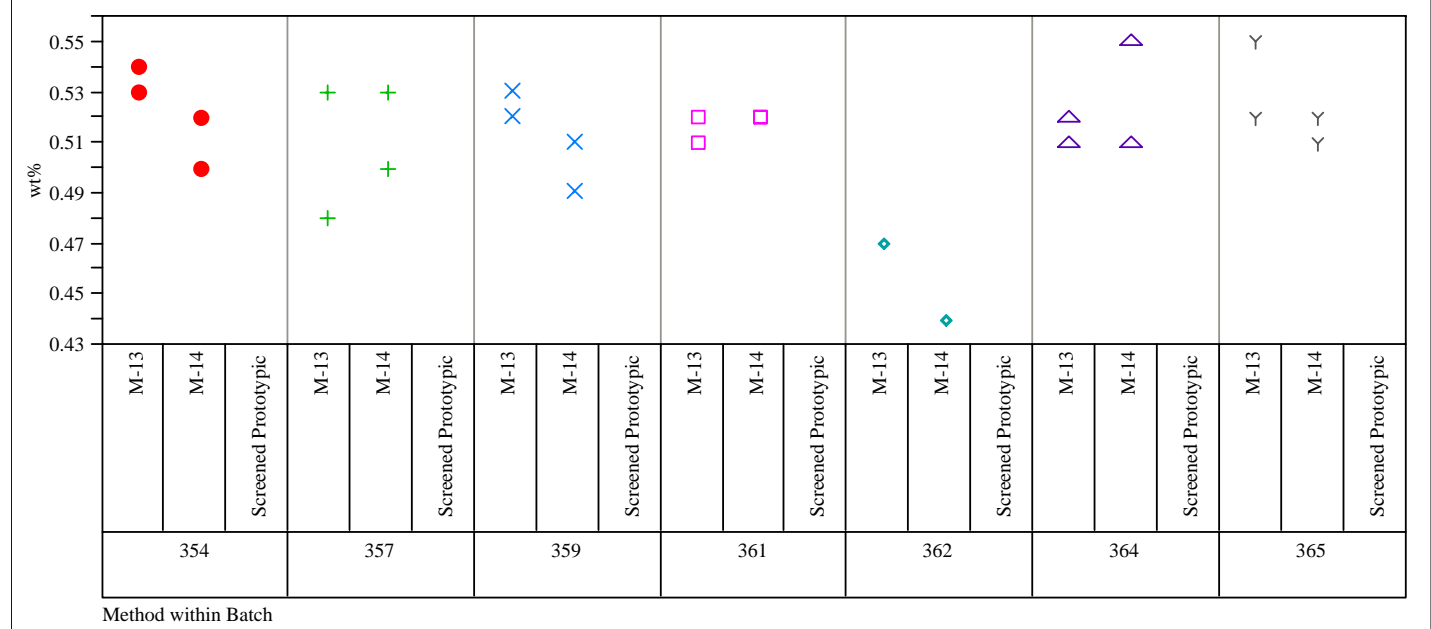


Exhibit A1. Initial Plots of Measurements by Type of Sample and by Element

Type of Sample=ARG-1, Analyte=Mn

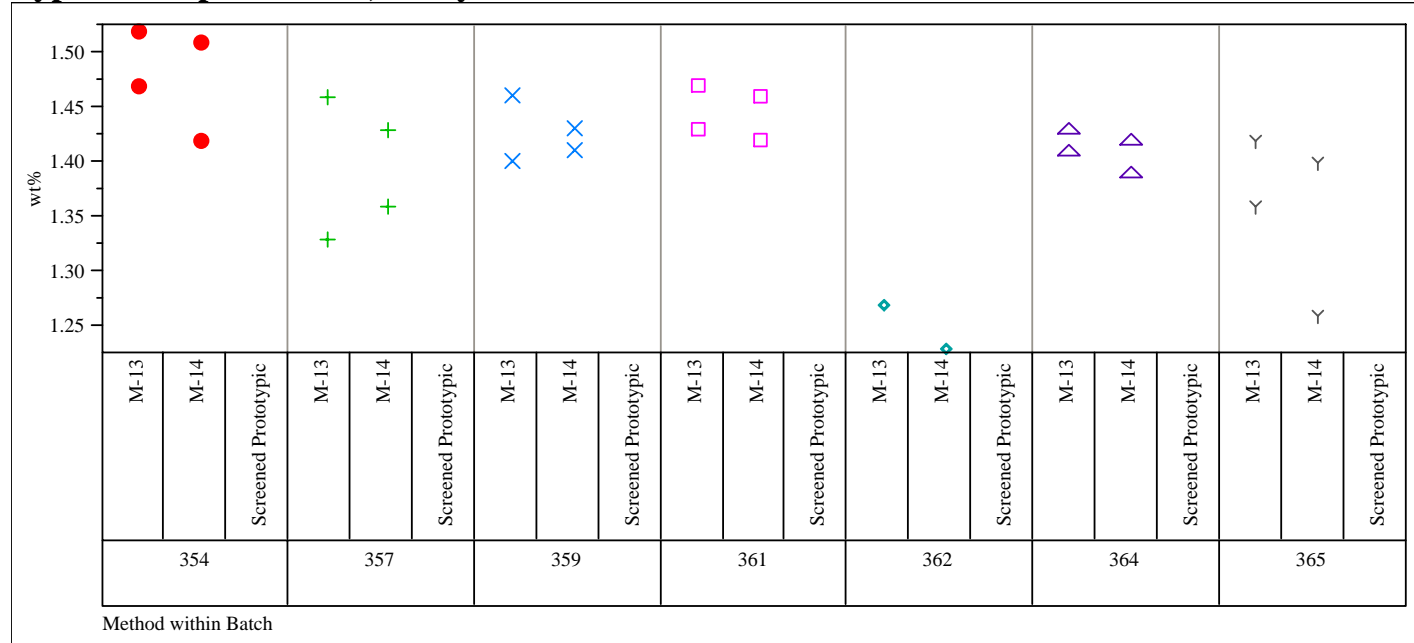

Type of Sample=ARG-1, Analyte=Na

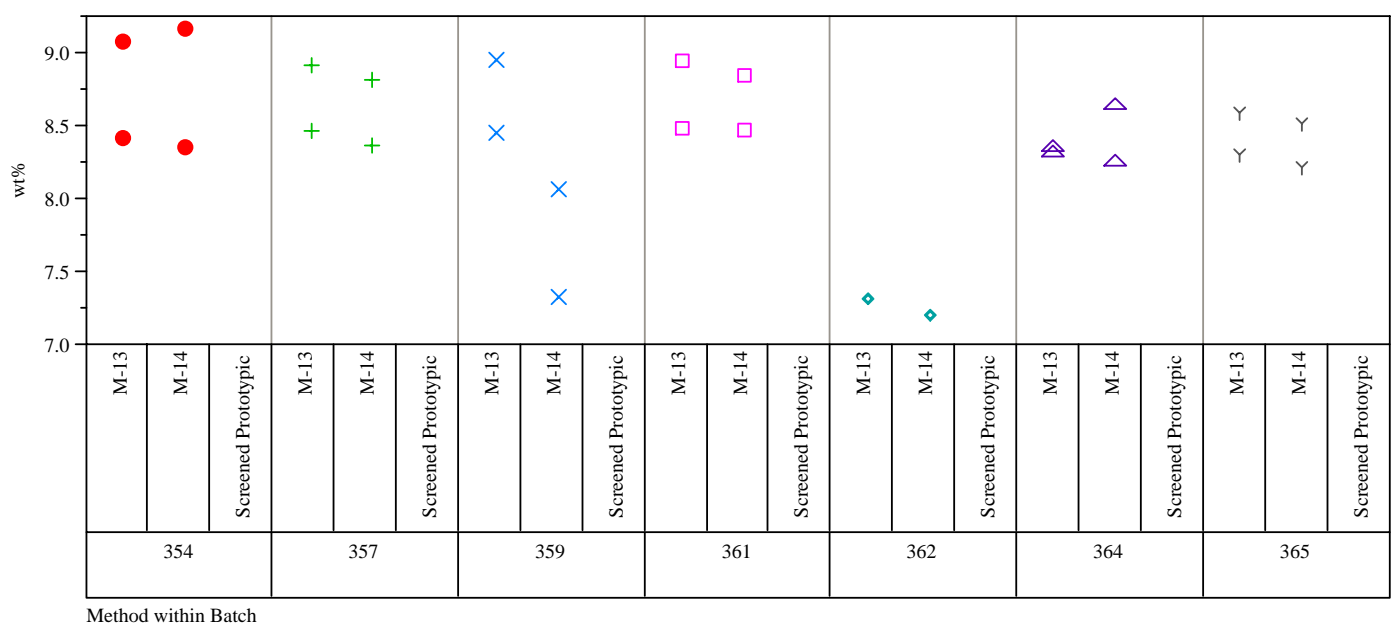

\section{Type of Sample=ARG-1, Analyte=Ni}

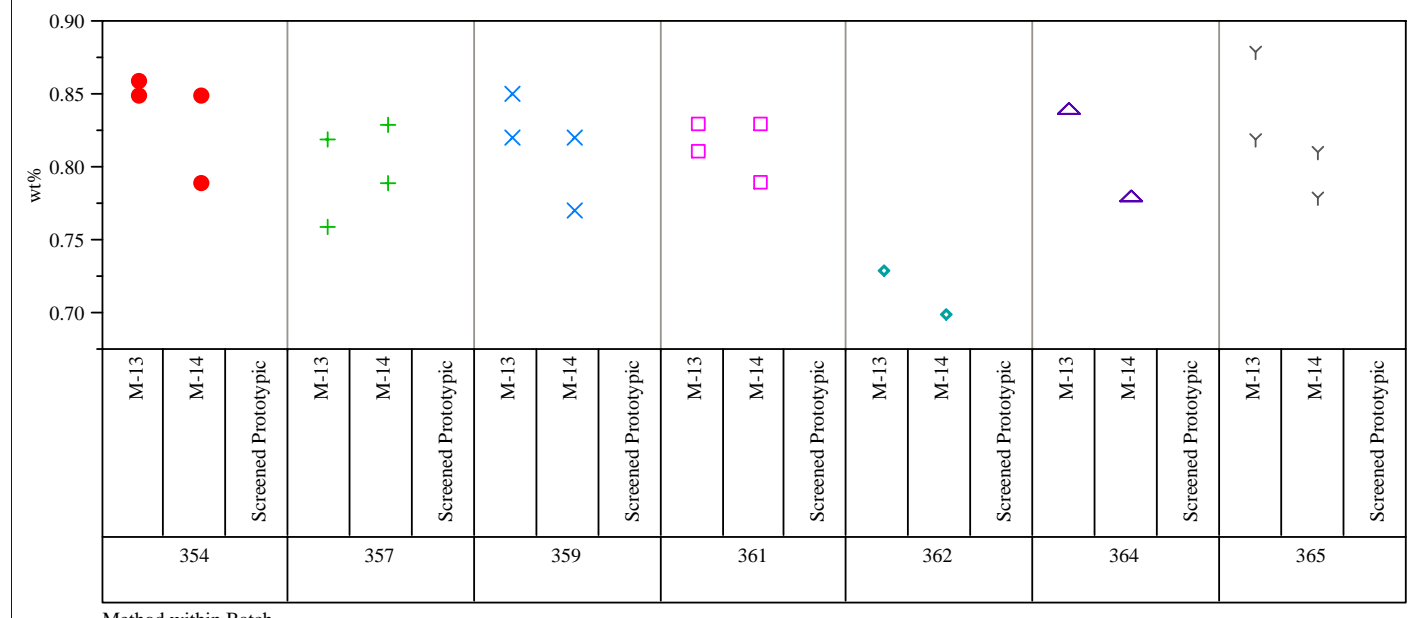

Method within Batch 
Exhibit A1. Initial Plots of Measurements by Type of Sample and by Element

Type of Sample $=$ ARG-1, Analyte $=$ Si

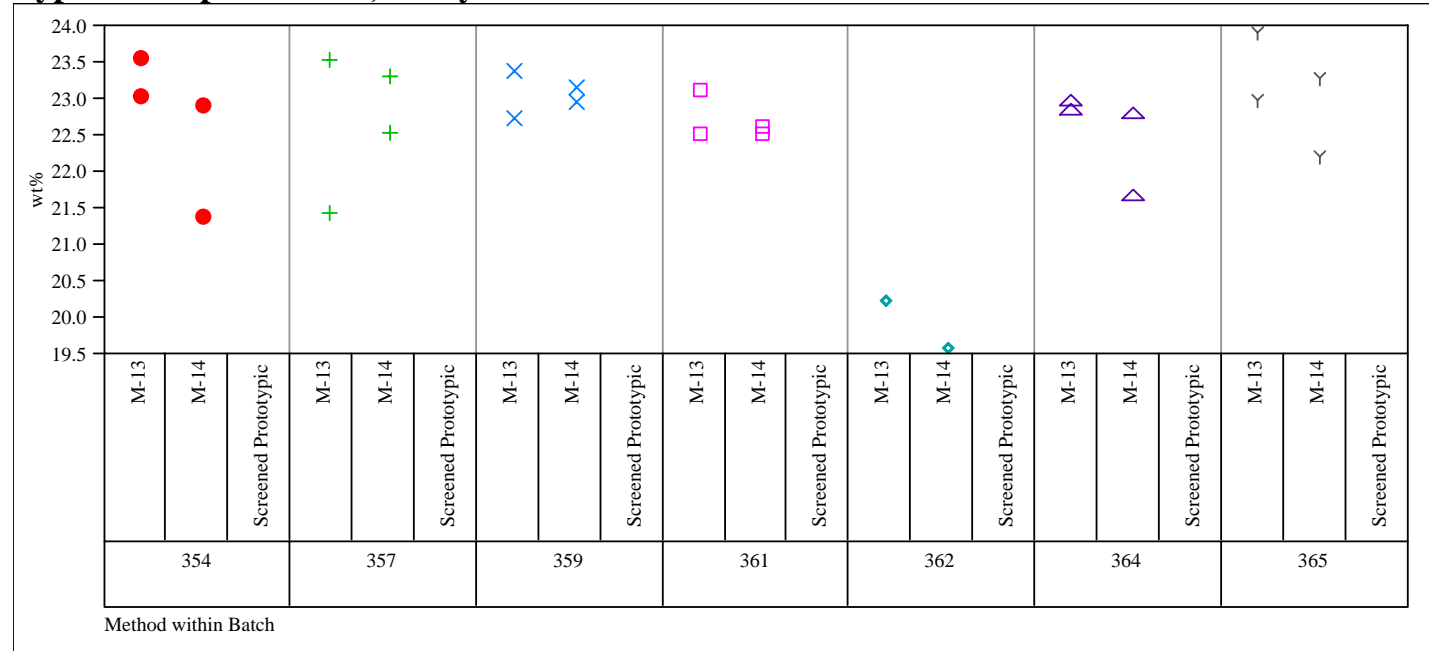

Type of Sample=ARG-1, Analyte=Ti

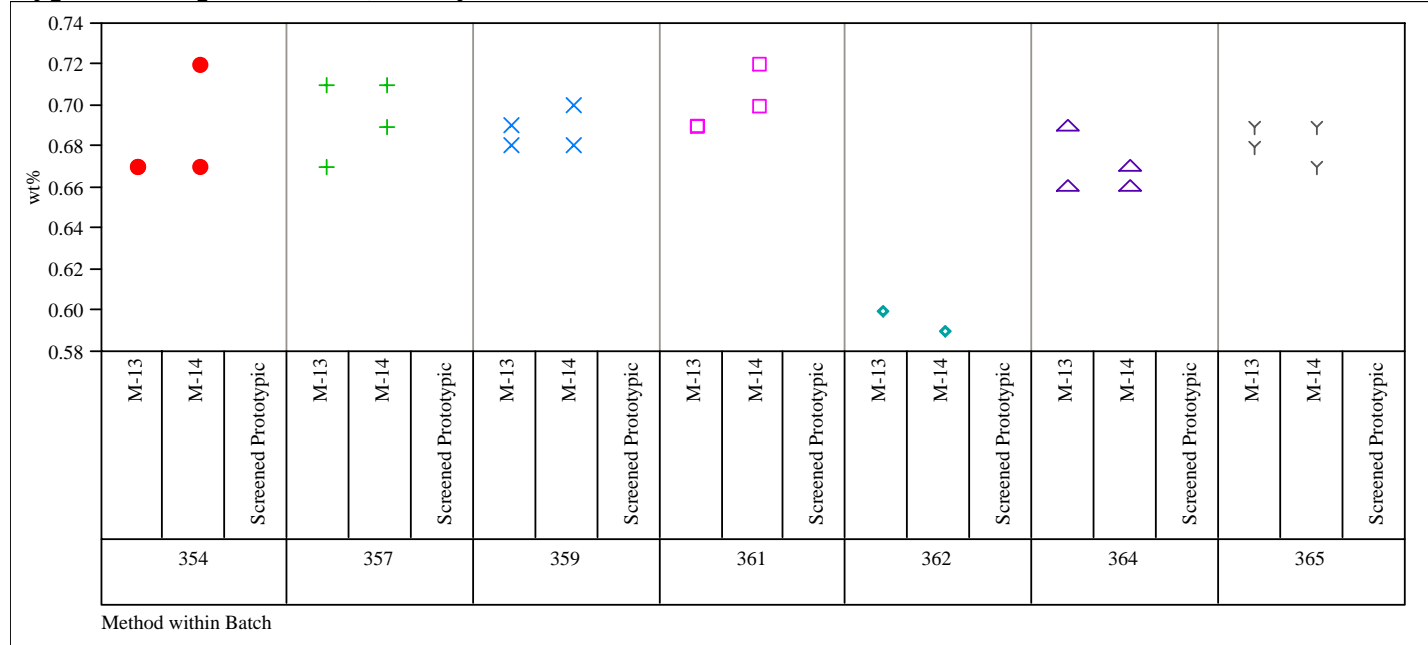

\section{Type of Sample=ARG-1, Analyte $=U$}

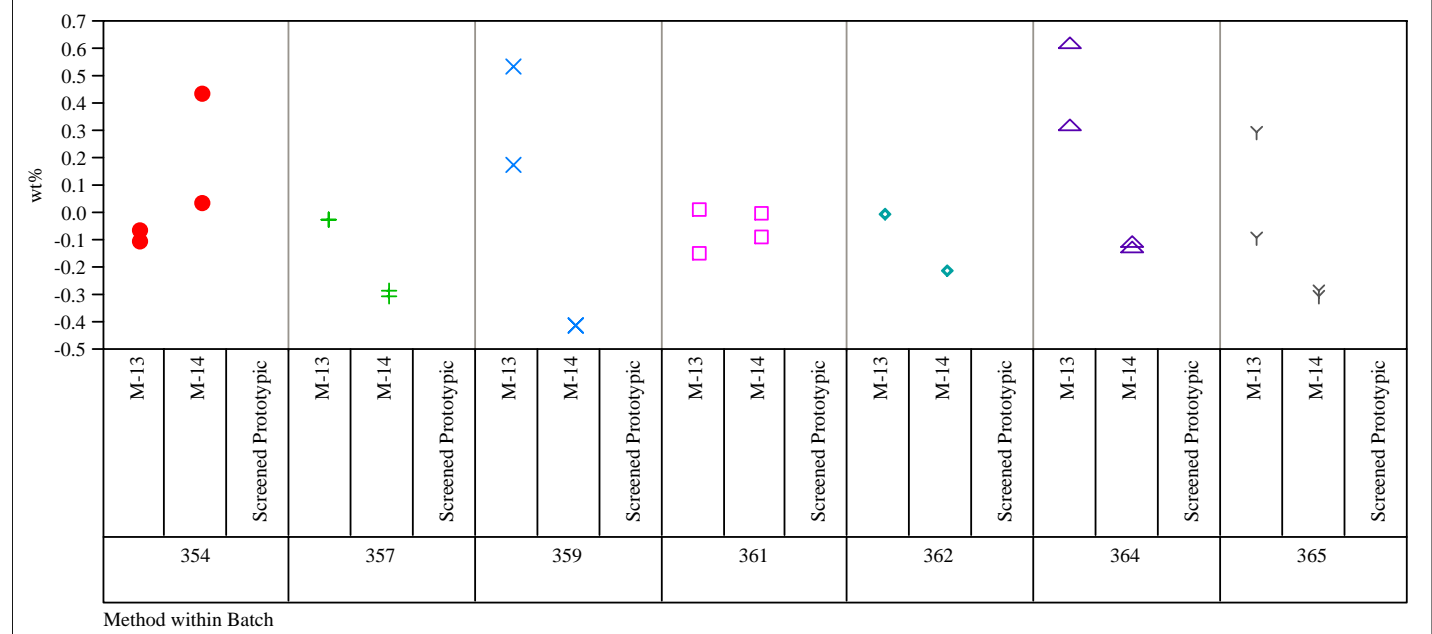


Exhibit A1. Initial Plots of Measurements by Type of Sample and by Element

Type of Sample=ARG-1, Analyte=Zr

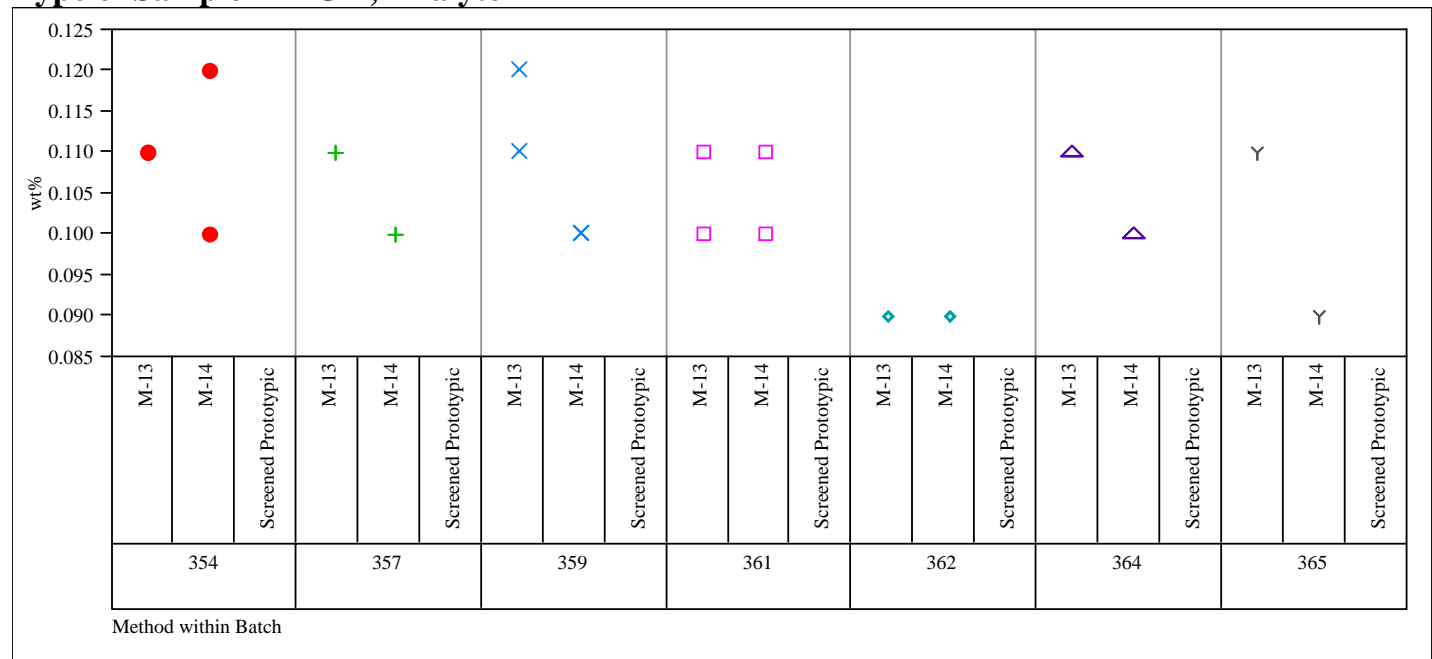

Type of Sample $=$ SME, Analyte $=$ Al

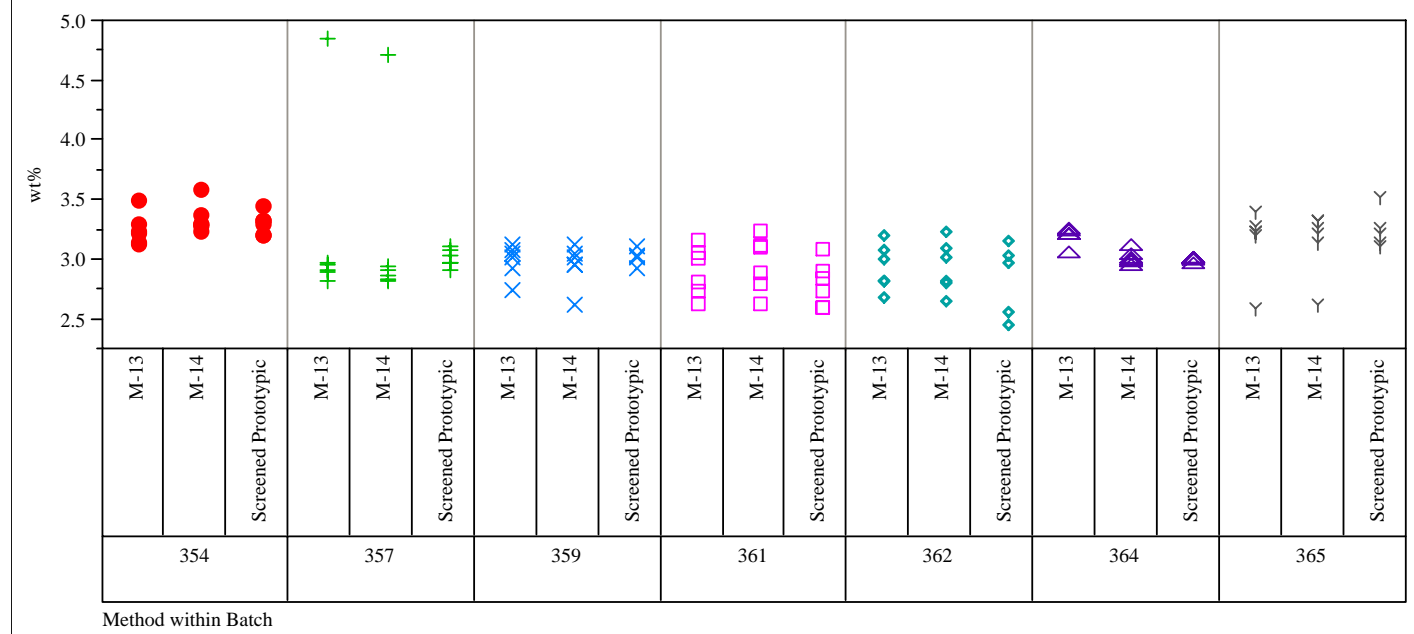

Type of Sample=SME, Analyte $=B$

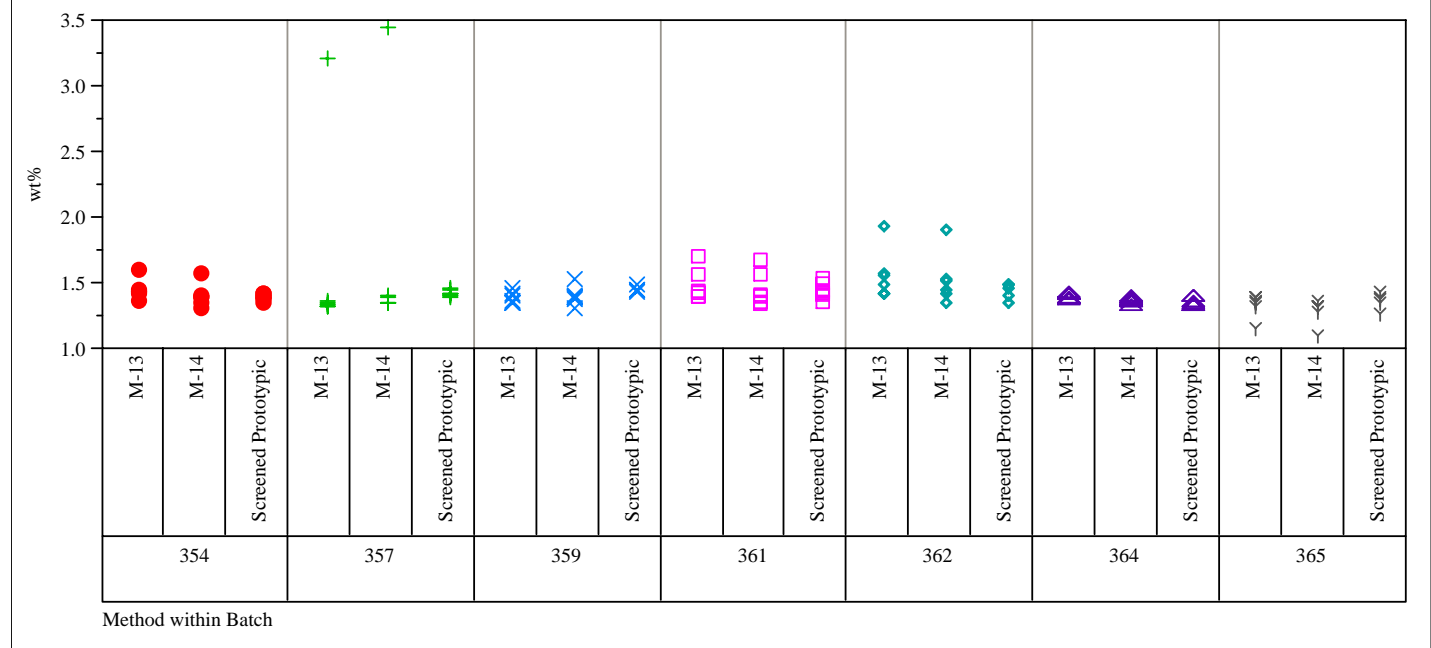


Exhibit A1. Initial Plots of Measurements by Type of Sample and by Element

Type of Sample=SME, Analyte $=$ Ca

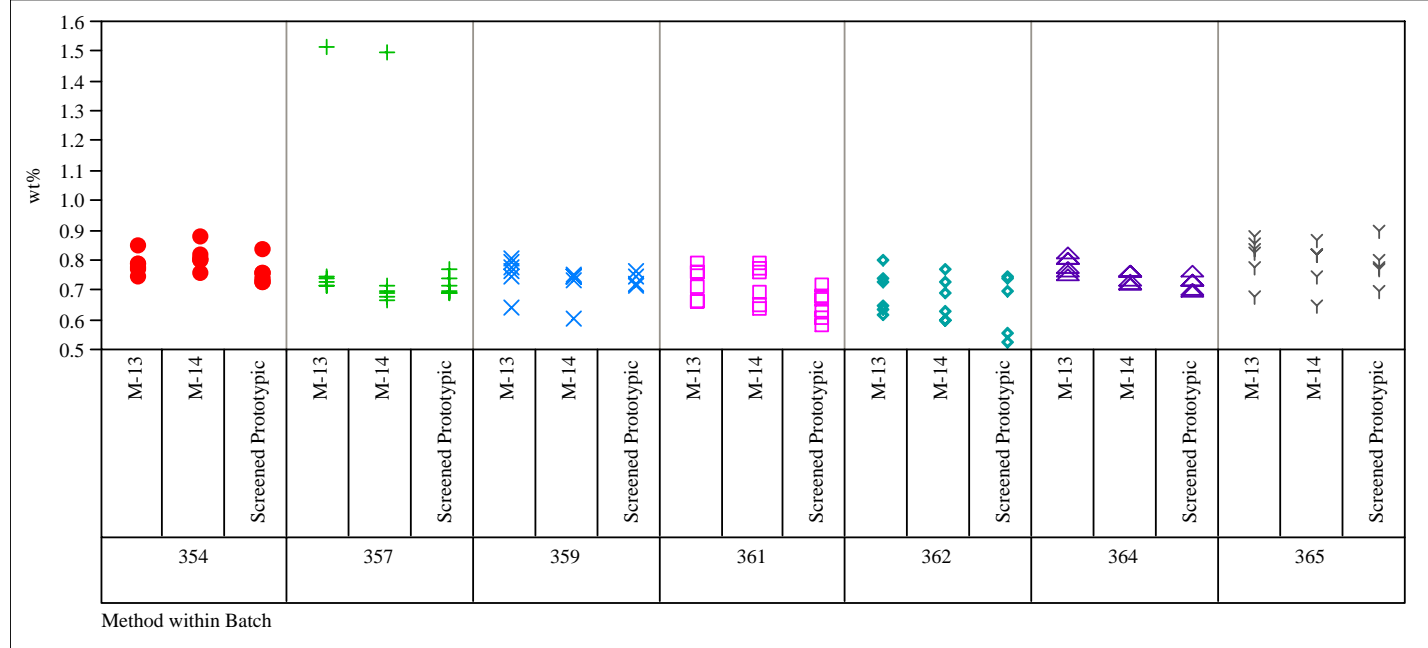

Type of Sample=SME, Analyte $=\mathrm{Cr}$

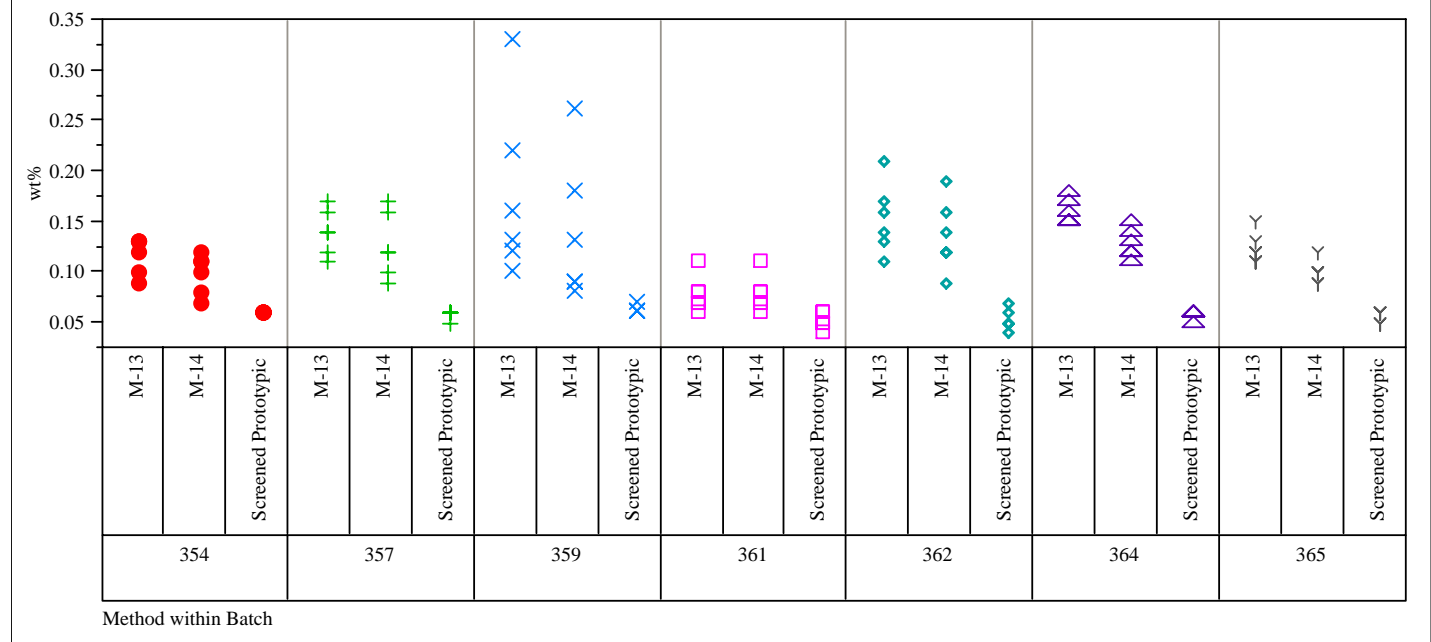

Type of Sample=SME, Analyte $=\mathrm{Cu}$

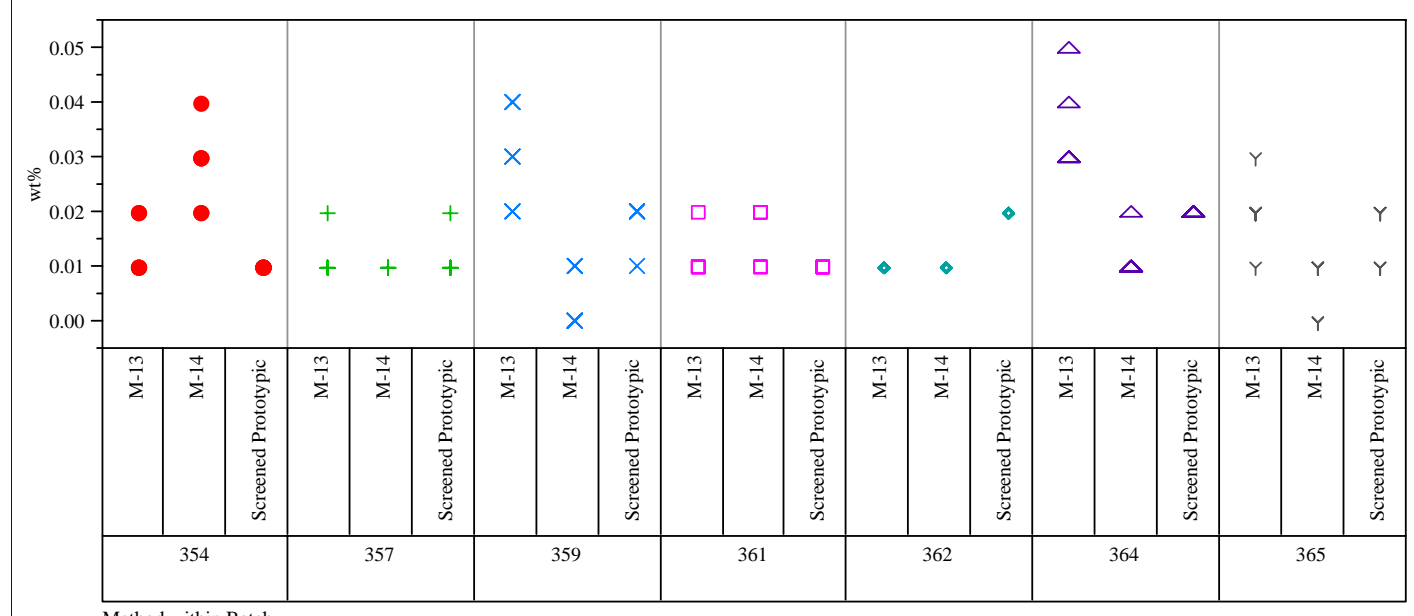

Method within Batch 
Exhibit A1. Initial Plots of Measurements by Type of Sample and by Element

Type of Sample=SME, Analyte $=$ Fe

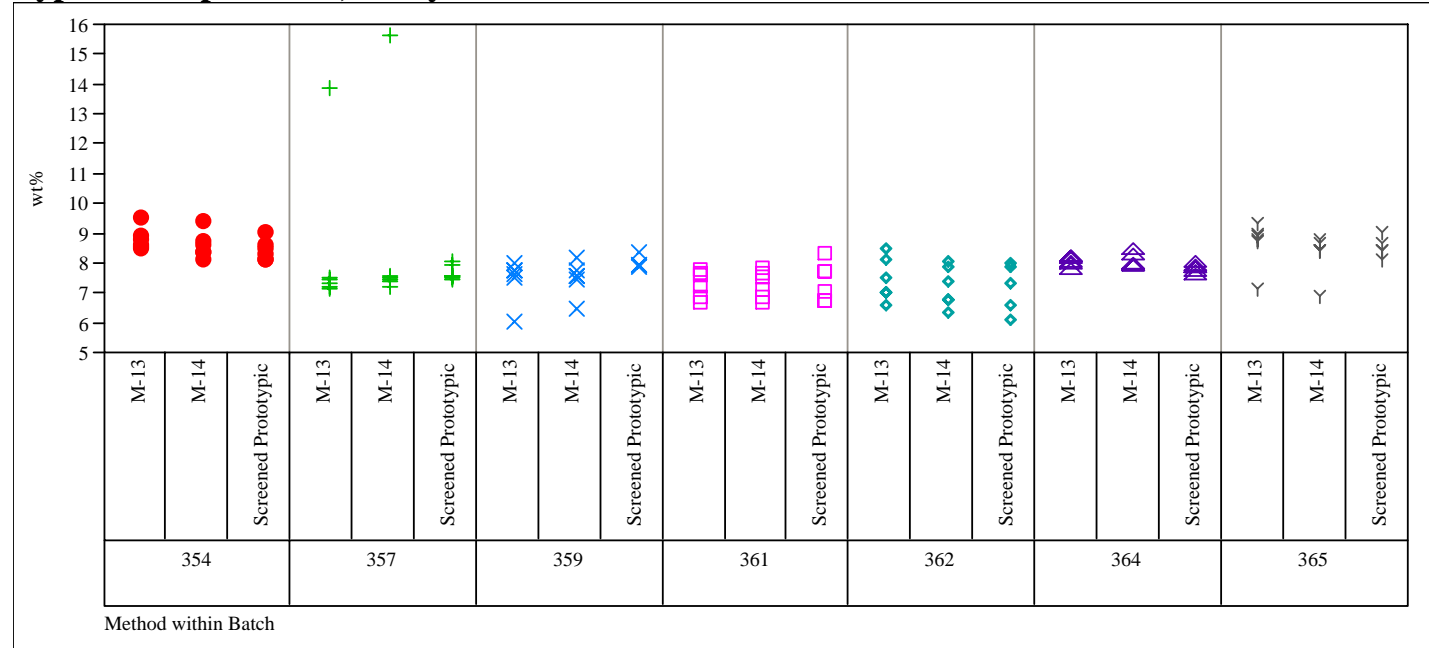

Type of Sample=SME, Analyte $=\mathrm{K}$

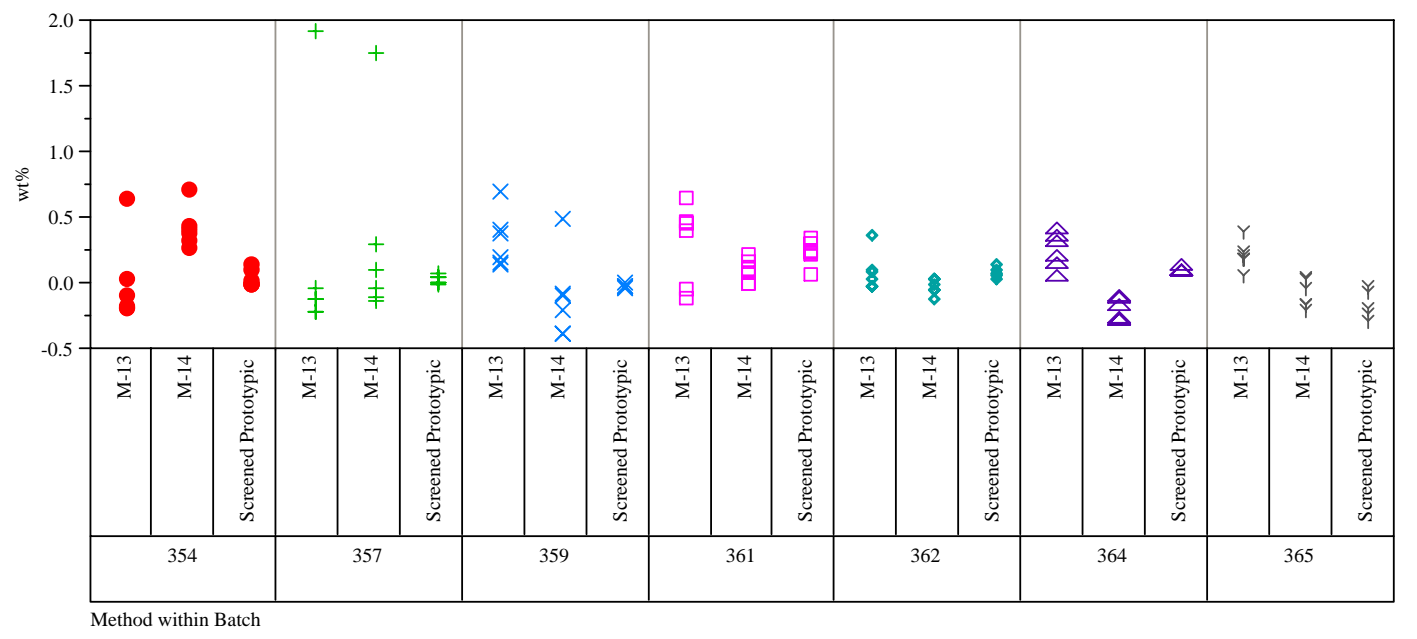

Type of Sample $=$ SME, Analyte $=\mathbf{L i}$

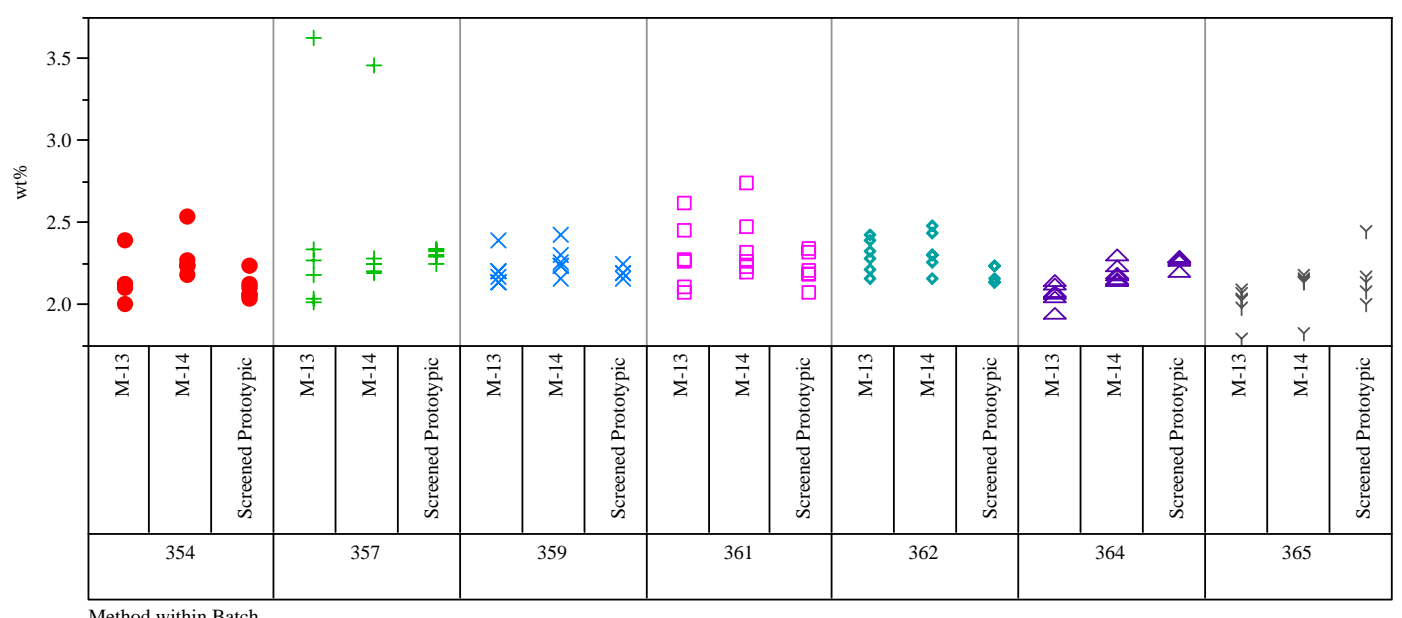

Method within Batch 
Exhibit A1. Initial Plots of Measurements by Type of Sample and by Element

Type of Sample=SME, Analyte $=M g$

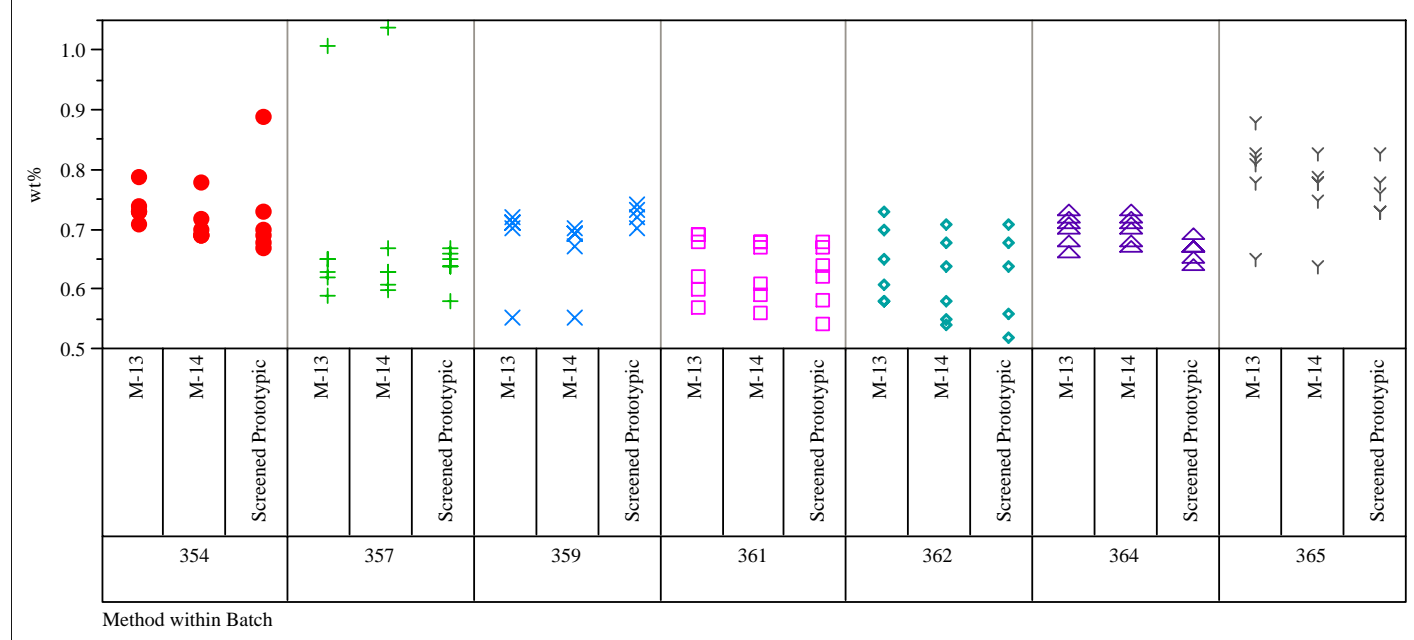

Type of Sample=SME, Analyte $=$ Mn

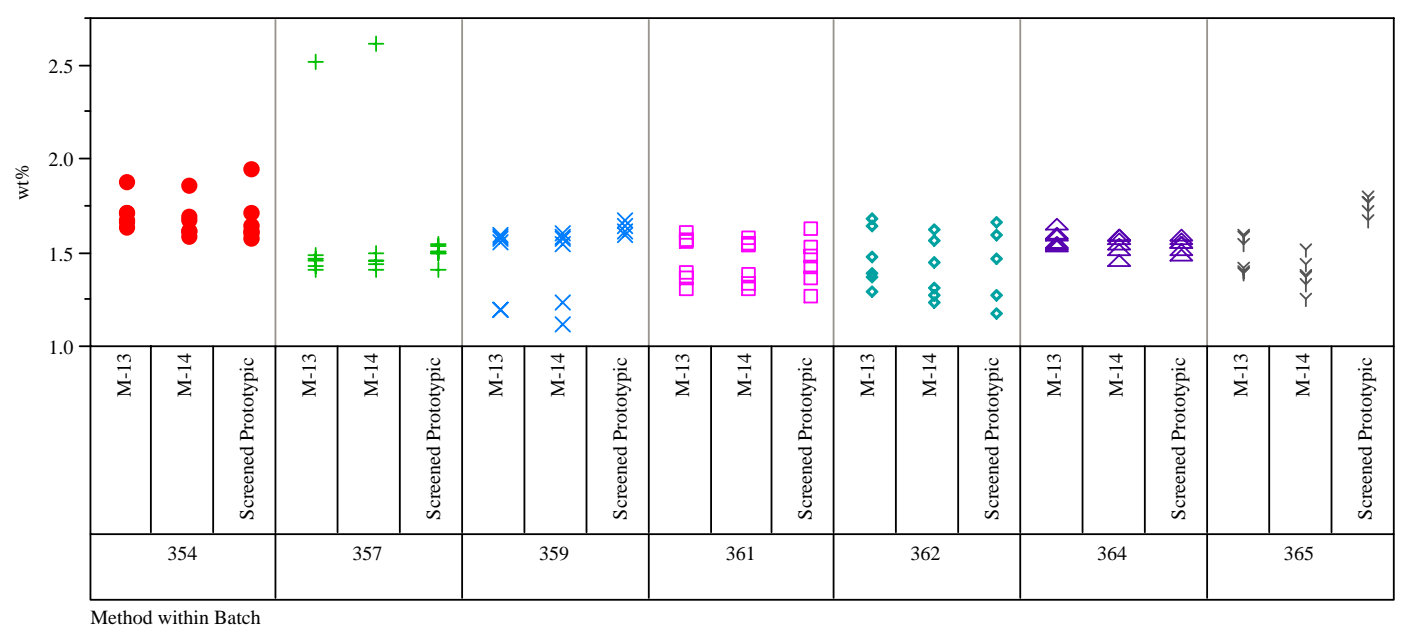

Type of Sample=SME, Analyte=Na

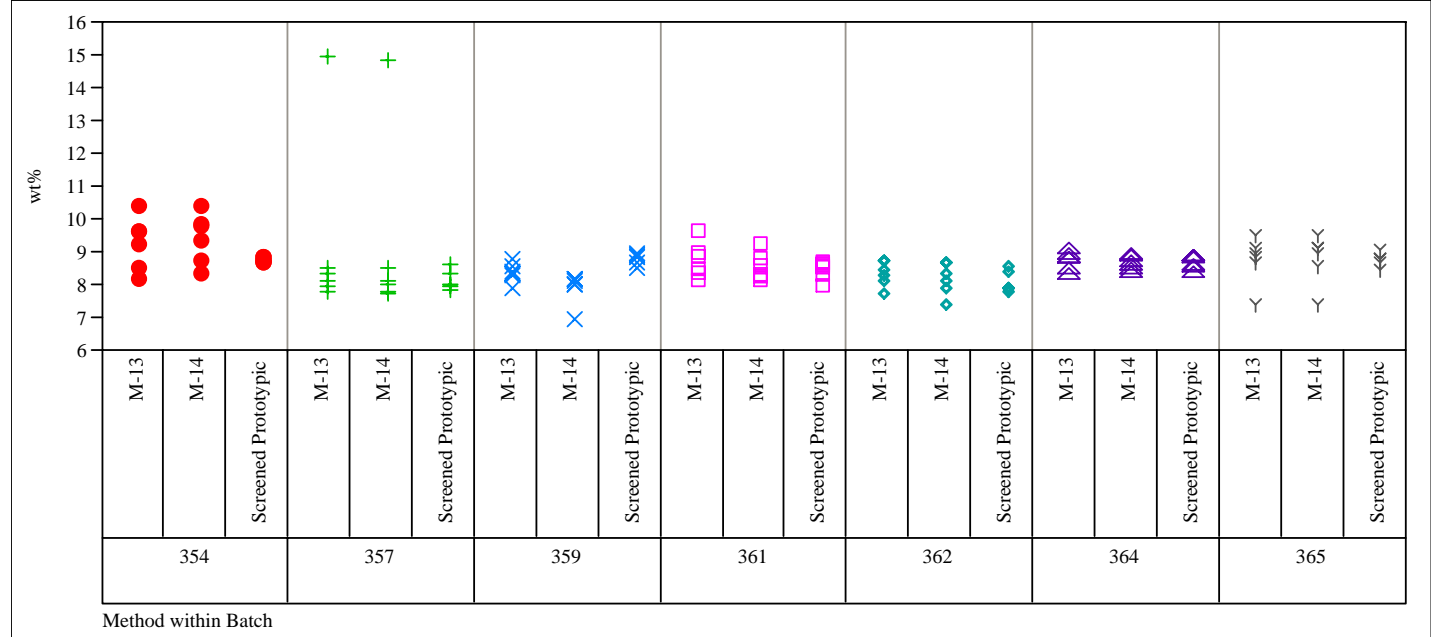


Exhibit A1. Initial Plots of Measurements by Type of Sample and by Element

Type of Sample=SME, Analyte $=\mathrm{Ni}$

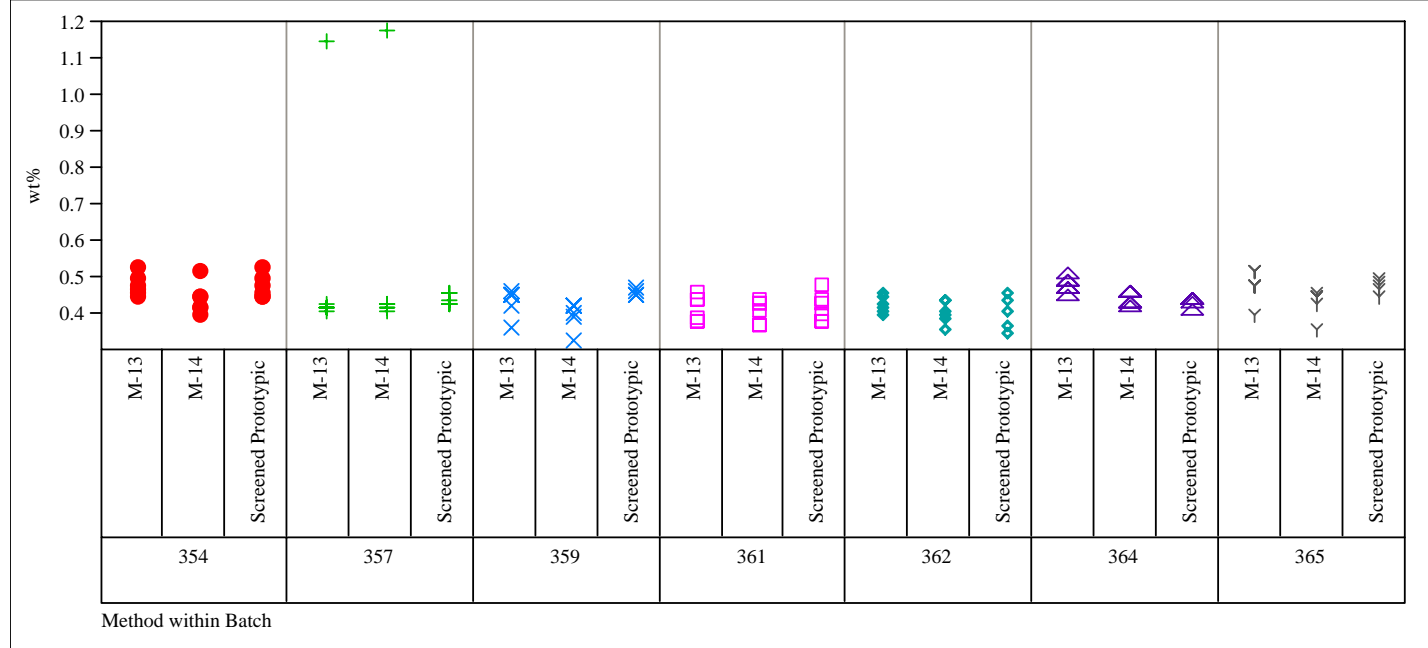

Type of Sample=SME, Analyte $=\mathrm{Si}$

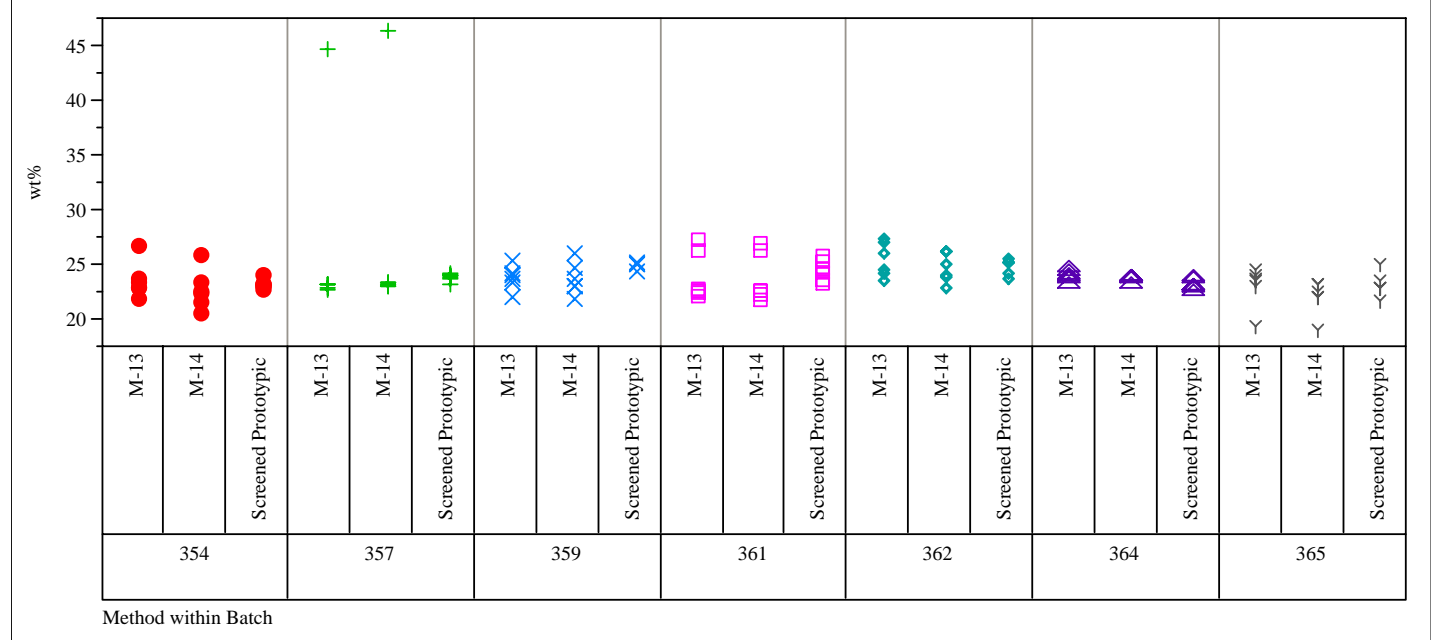

Type of Sample $=$ SME, Analyte $=\mathbf{T i}$

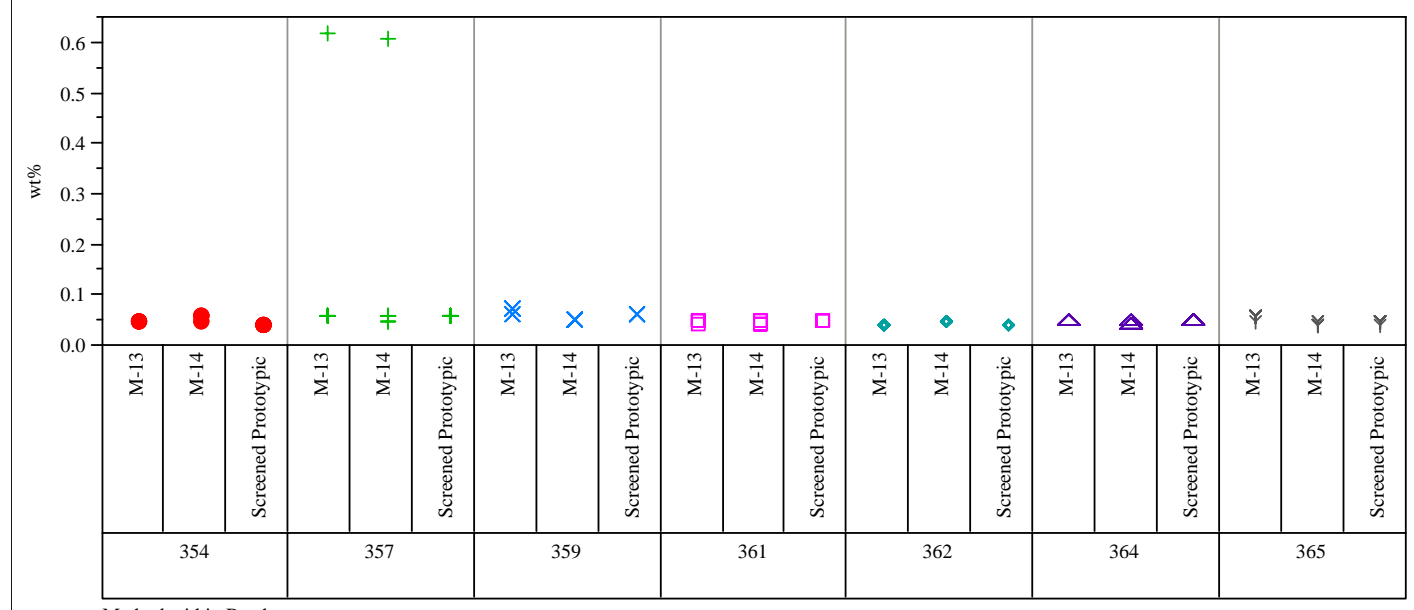

Method within Batch 
Exhibit A1. Initial Plots of Measurements by Type of Sample and by Element

Type of Sample=SME, Analyte $=\mathrm{U}$

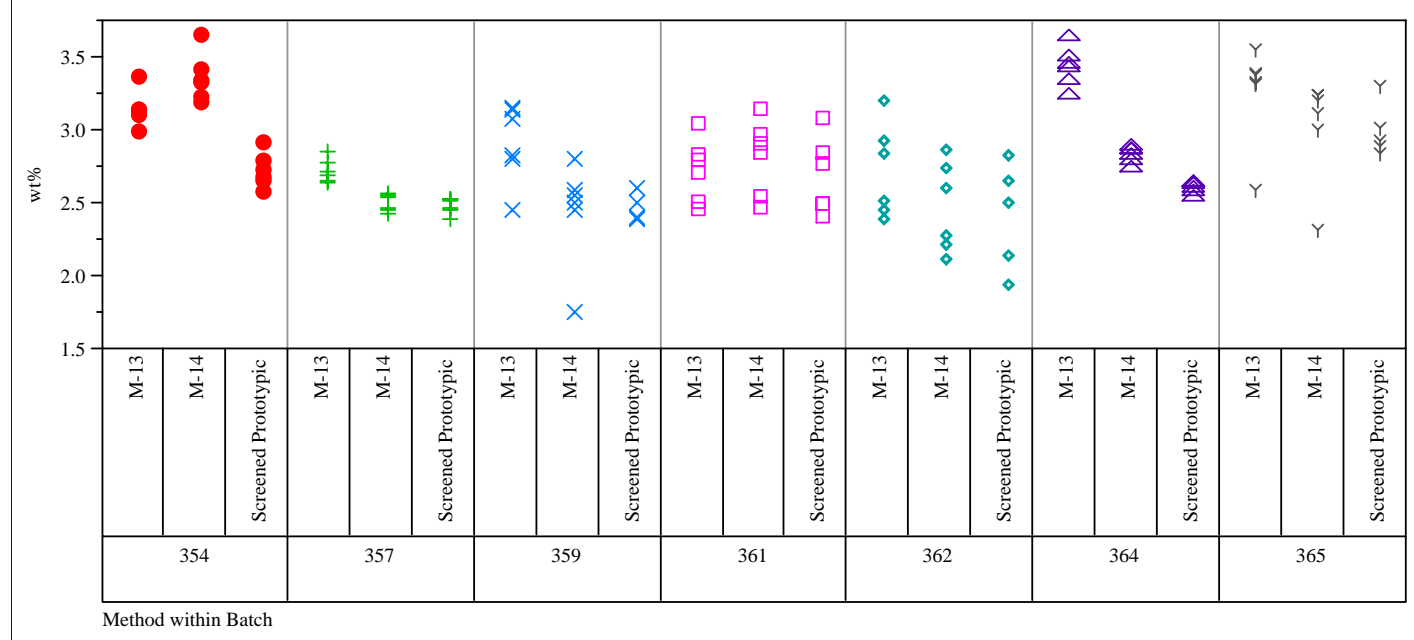

Type of Sample=SME, Analyte $=\mathrm{Zr}$

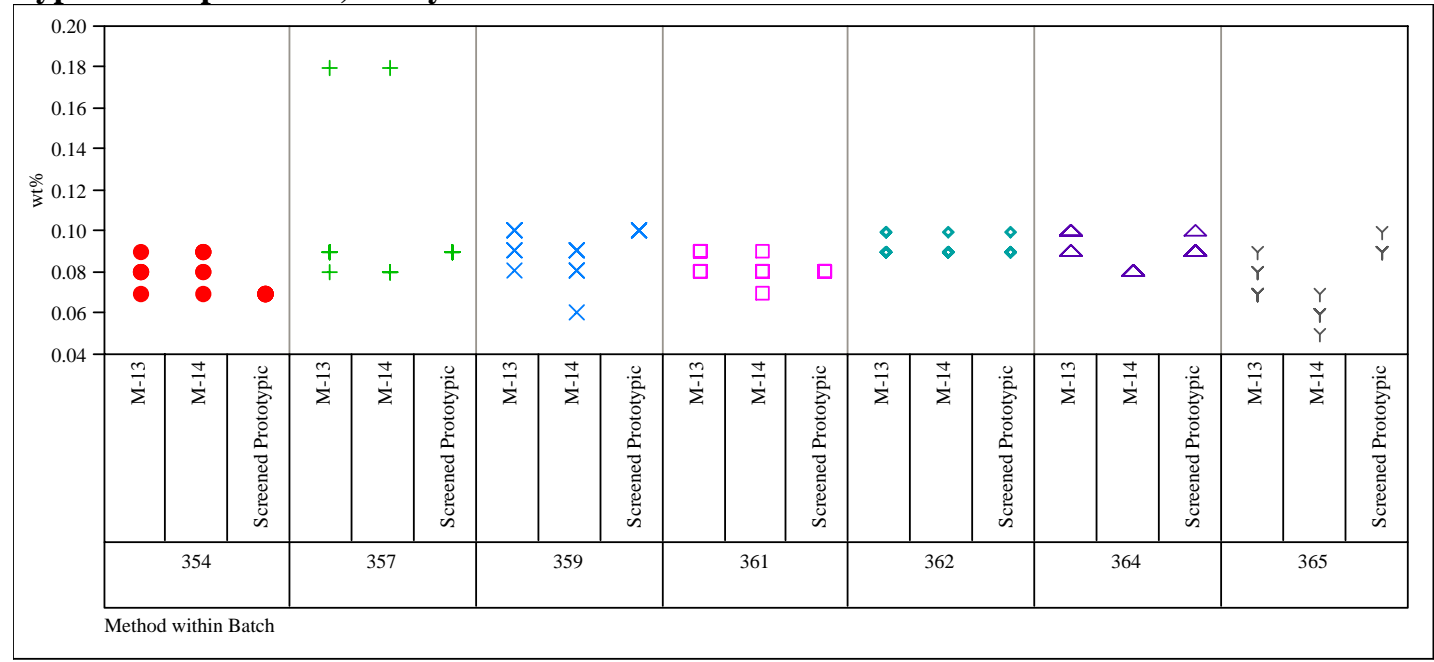

Type of Sample=ARG-1

Variability Chart for Sum of Oxides

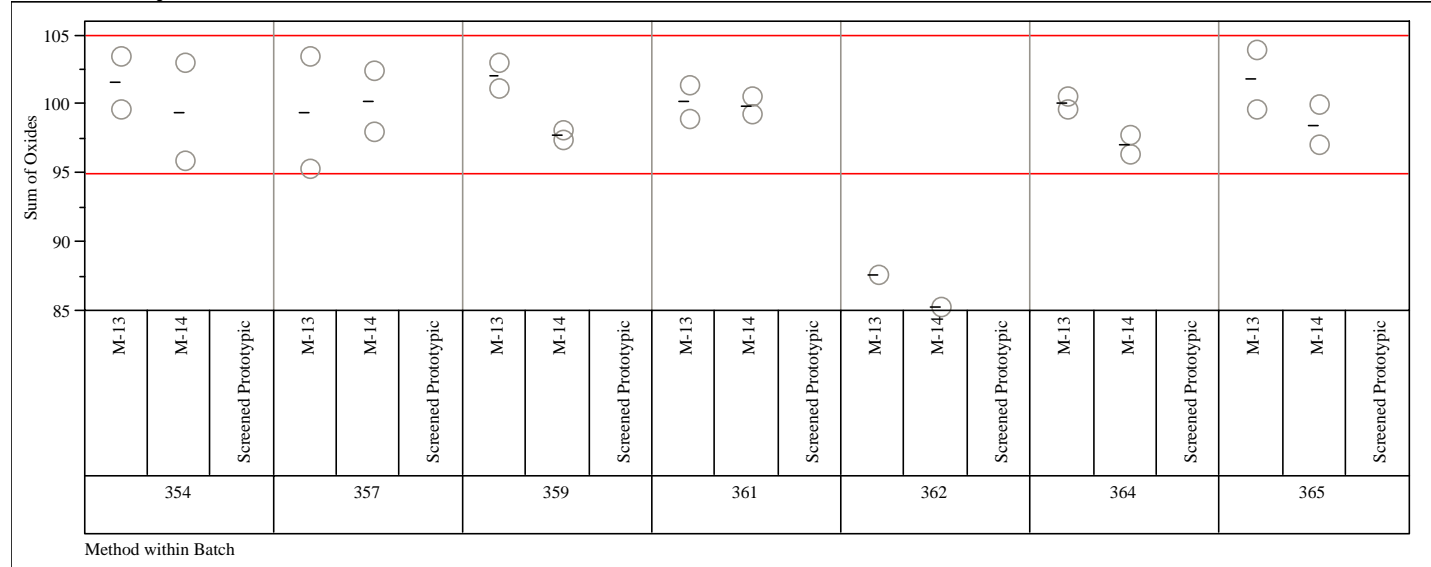


WSRC-STI-2006-00069

Revision 0

Exhibit A1. Initial Plots of Measurements by Type of Sample and by Element

Type of Sample=SME

Variability Chart for Sum of Oxides

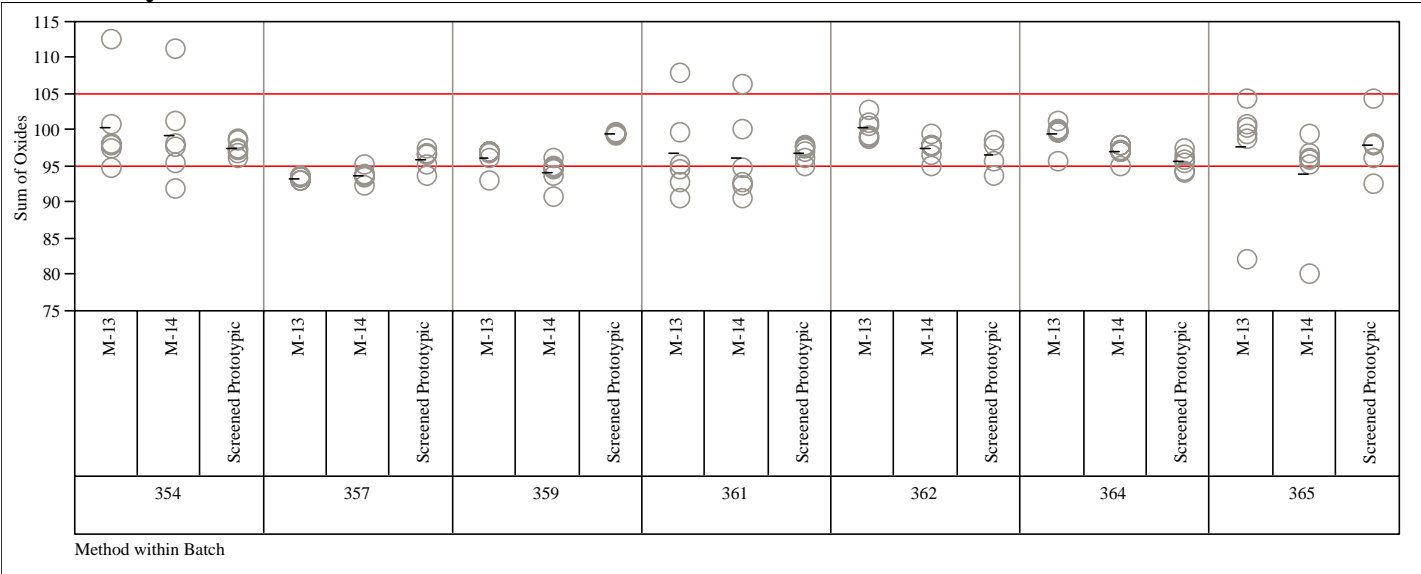


WSRC-STI-2006-00069

Revision 0

Exhibit A2. Initial Comparisons by SME Batch among M-13, M-14, and Prototypic Measurements for Each Element by Type of Sample

Type/ Analyte/UoM=ARG-1/Al/wt \% Matched Pairs

Difference: M-14-M-13

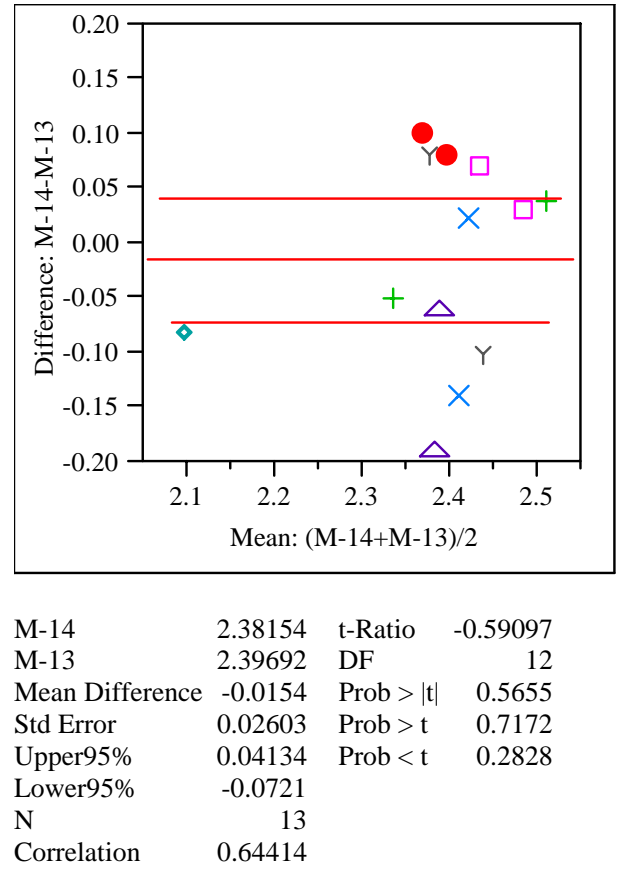

Type/ Analyte/UoM=ARG-1/B/wt\% Matched Pairs

Difference: M-14-M-13

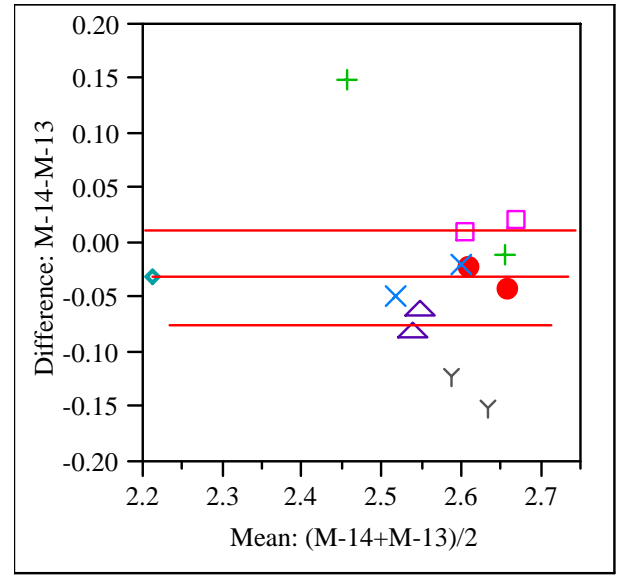

$\begin{array}{lrlr}\text { M-14 } & 2.54615 & \text { t-Ratio } & -1.52517 \\ \text { M-13 } & 2.57692 & \text { DF } & 12 \\ \text { Mean Difference } & -0.0308 & \text { Prob }>|t| & 0.1531 \\ \text { Std Error } & 0.02017 & \text { Prob }>\text { t } & 0.9234 \\ \text { Upper95\% } & 0.01319 & \text { Prob }<\text { t } & 0.0766 \\ \text { Lower95\% } & -0.0747 & & \\ \text { N } & 13 & & \\ \text { Correlation } & 0.83906 & & \end{array}$

Type/ Analyte/UoM=ARG-1/Ca/wt\% Matched Pairs

Difference: M-14-M-13

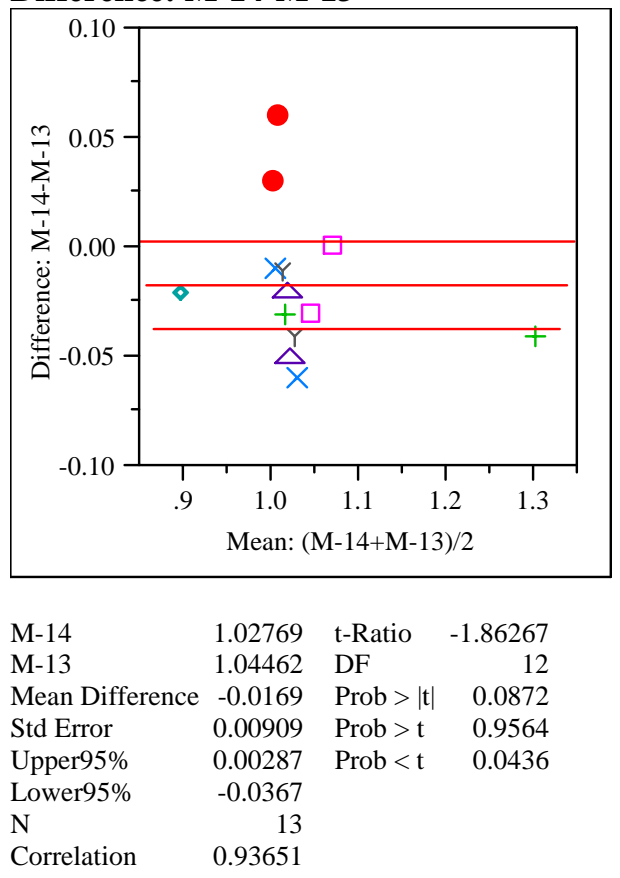

Type/ Analyte/UoM=ARG-1/Cr/wt \% Matched Pairs

Difference: M-14-M-13

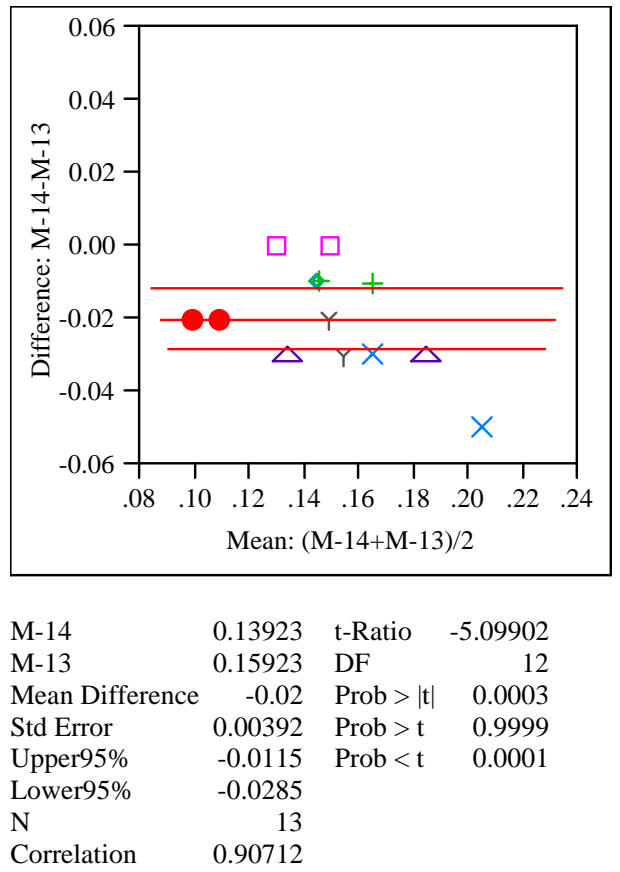


Exhibit A2. Initial Comparisons by SME Batch among M-13, M-14, and Prototypic Measurements for Each Element by Type of Sample

Type/ Analyte/UoM=ARG-1/Cu/wt\% Matched Pairs

Difference: M-14-M-13

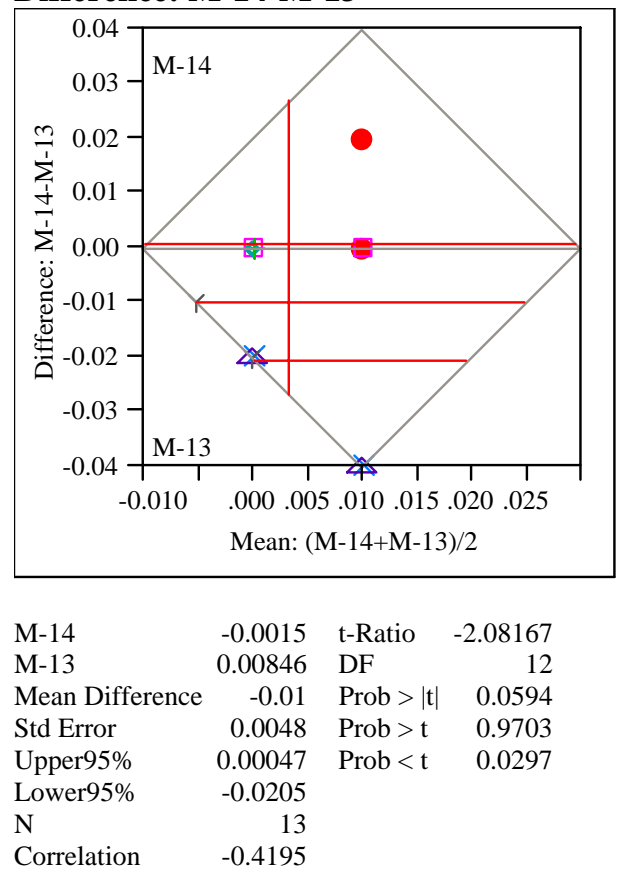

Type/ Analyte/UoM=ARG-1/Fe/wt \% Matched Pairs

Difference: M-14-M-13

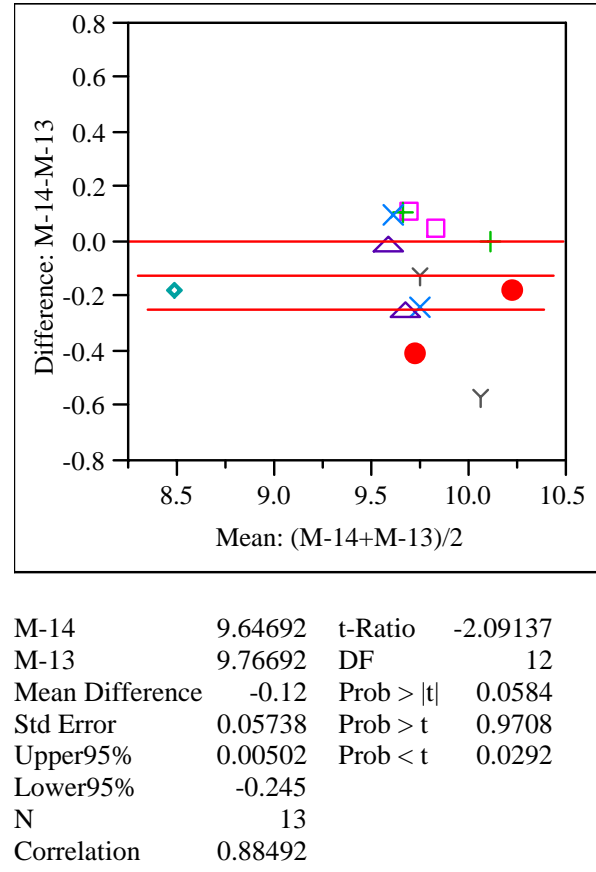

Type/ Analyte/UoM=ARG-1/K/wt \%

Matched Pairs

Difference: M-14-M-13

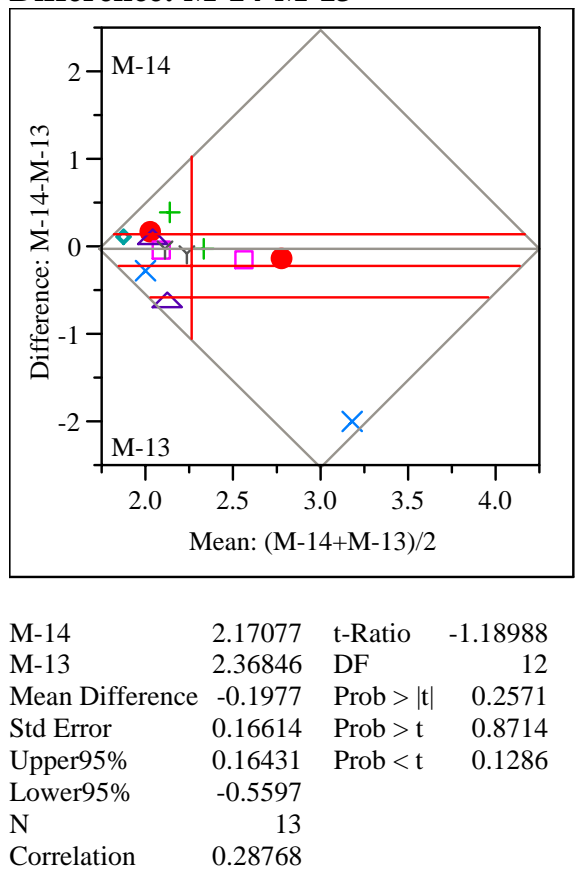

Type/ Analyte/UoM=ARG-1/Li/wt \% Matched Pairs

Difference: M-14-M-13

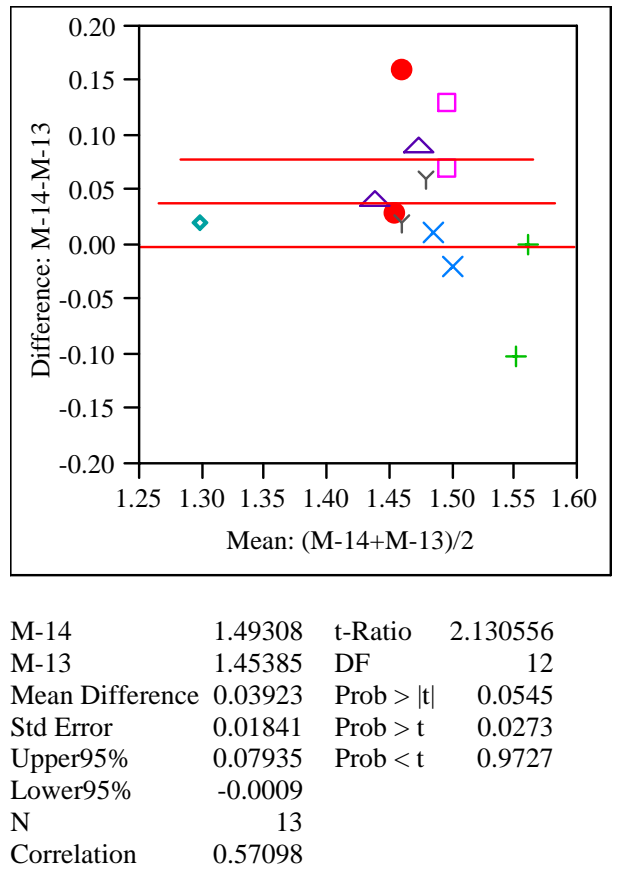


Exhibit A2. Initial Comparisons by SME Batch among M-13, M-14, and Prototypic Measurements for Each Element by Type of Sample

Type/ Analyte/UoM=ARG-1/Mg/wt \% Matched Pairs

Difference: M-14-M-13

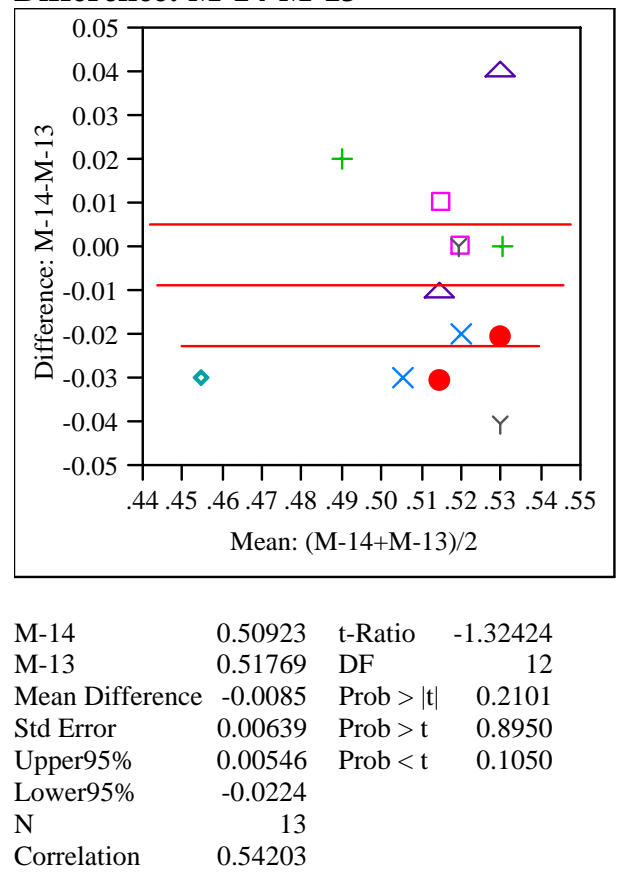

Type/ Analyte/UoM=ARG-1/Mn/wt \% Matched Pairs

Difference: M-14-M-13

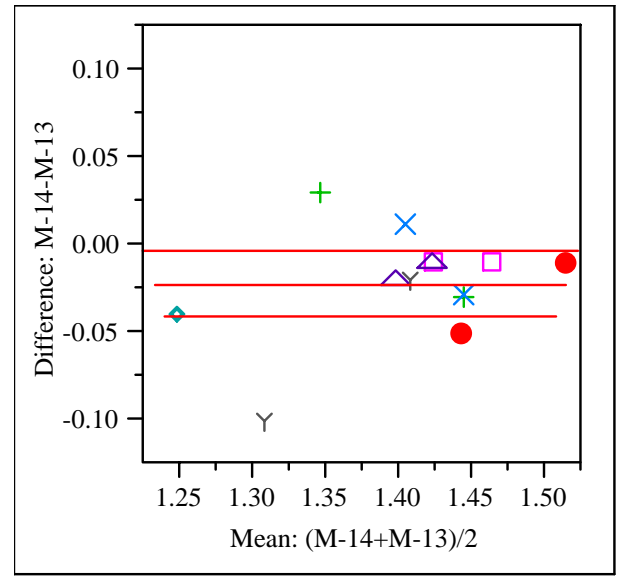

$\begin{array}{lrlr}\text { M-14 } & 1.39538 & \text { t-Ratio } & -2.58353 \\ \text { M-13 } & 1.41769 & \text { DF } & 12 \\ \text { Mean Difference } & -0.0223 & \text { Prob }>|t| & 0.0239 \\ \text { Std Error } & 0.00863 & \text { Prob }>\text { t } & 0.9880 \\ \text { Upper95\% } & -0.0035 & \text { Prob }<\text { t } & 0.0120 \\ \text { Lower95\% } & -0.0411 & & \\ \text { N } & 13 & & \\ \text { Correlation } & 0.91208 & & \end{array}$

Type/ Analyte/UoM=ARG-1/Na/wt \% Matched Pairs

Difference: M-14-M-13

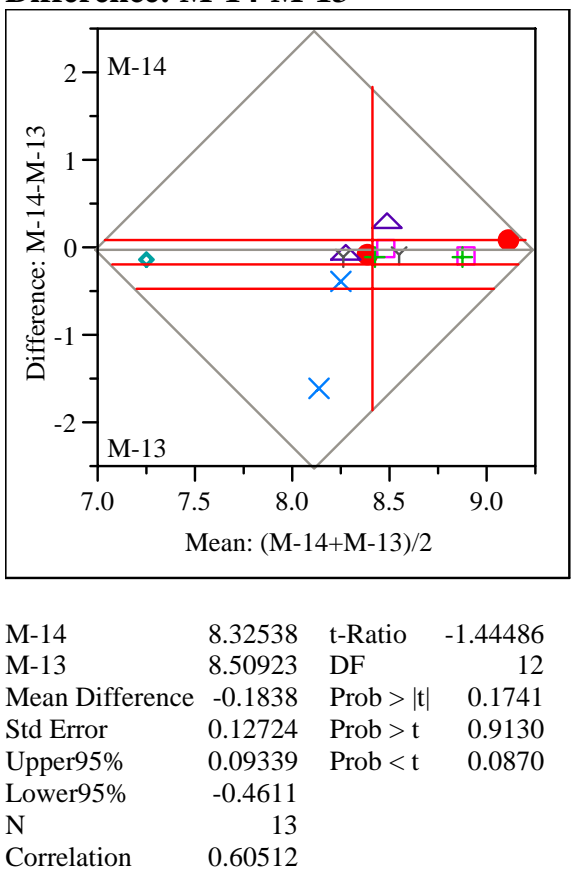

Type/ Analyte/UoM=ARG-1/Ni/wt \% Matched Pairs

Difference: M-14-M-13

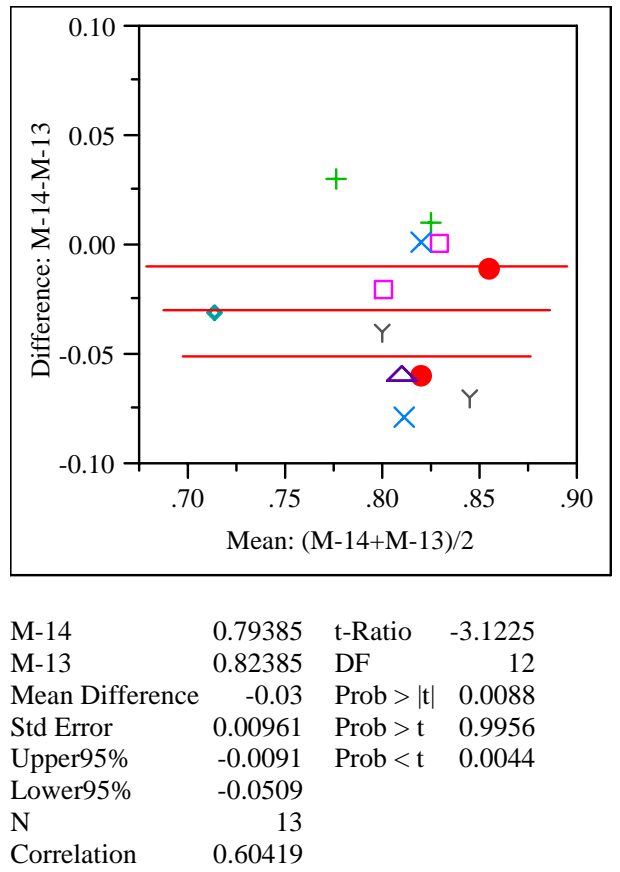


Exhibit A2. Initial Comparisons by SME Batch among M-13, M-14, and Prototypic Measurements for Each Element by Type of Sample

Type/ Analyte/UoM=ARG-1/Si/wt \% Matched Pairs

Difference: M-14-M-13

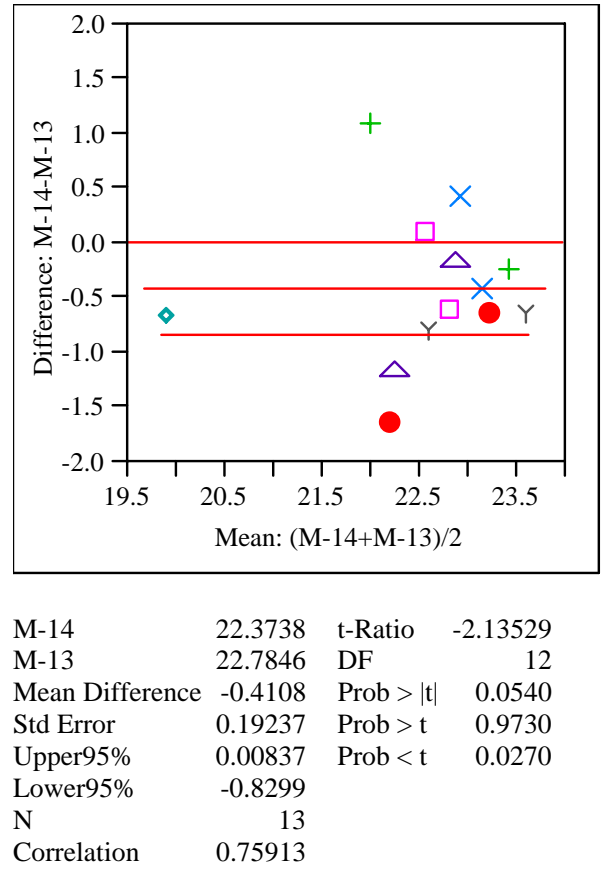

Type/ Analyte/UoM=ARG-1/Ti/wt \% Matched Pairs

Difference: M-14-M-13

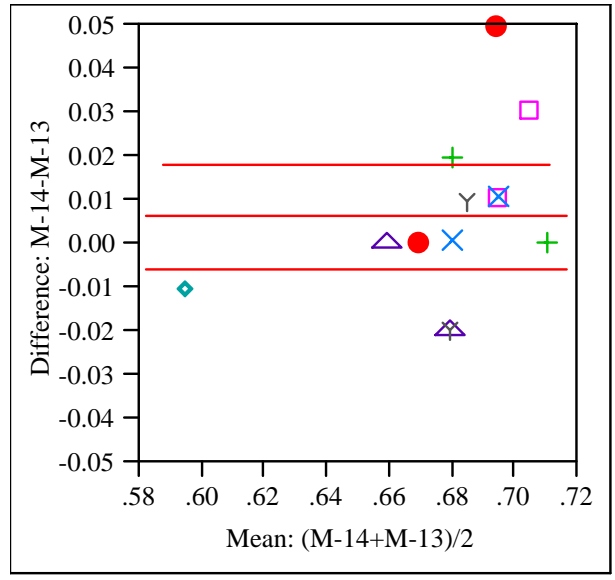

$\begin{array}{lrlr}\text { M-14 } & 0.68231 & \text { t-Ratio } & 1.144806 \\ \text { M-13 } & 0.67615 & \text { DF } & 12 \\ \text { Mean Difference } & 0.00615 & \text { Prob }>|t| & 0.2746 \\ \text { Std Error } & 0.00538 & \text { Prob }>\text { t } & 0.1373 \\ \text { Upper95\% } & 0.01787 & \text { Prob < t } & 0.8627 \\ \text { Lower95\% } & -0.0056 & & \\ \text { N } & 13 & & \\ \text { Correlation } & 0.82239 & & \end{array}$
Type/ Analyte/UoM=ARG-1/U/wt \%
Matched Pairs

Difference: M-14-M-13

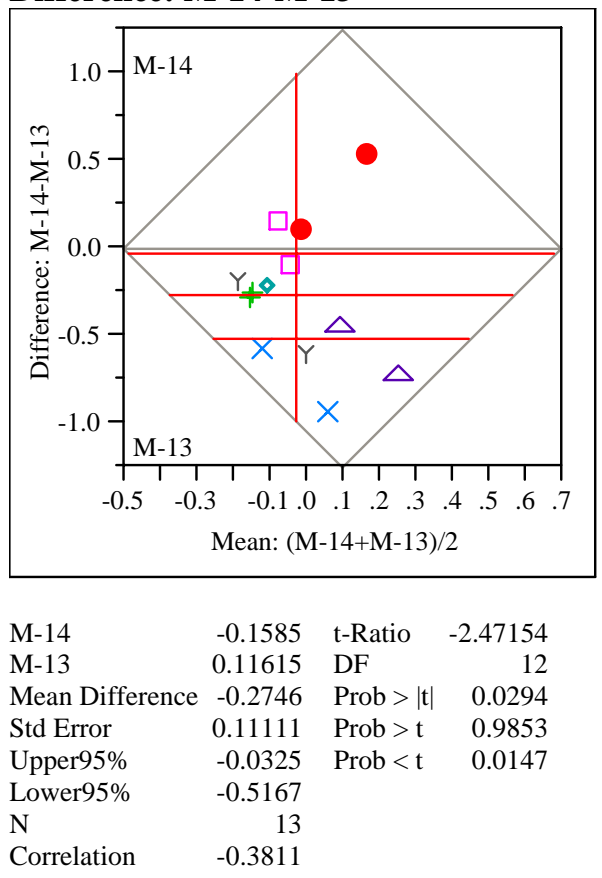

Type/ Analyte/UoM=ARG-1/Zr/wt \% Matched Pairs

Difference: M-14-M-13

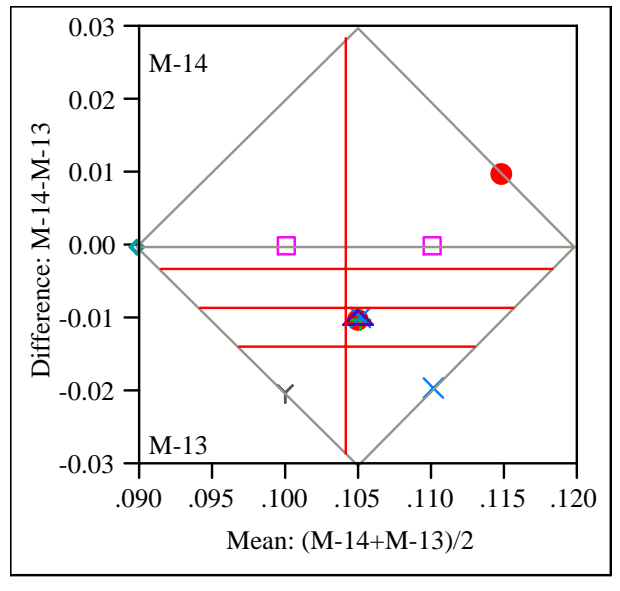

$\begin{array}{lrlr}\text { M-14 } & 0.1 & \text { t-Ratio } & -3.39467 \\ \text { M-13 } & 0.10846 & \text { DF } & 12 \\ \text { Mean Difference } & -0.0085 & \text { Prob }>|t| & 0.0053 \\ \text { Std Error } & 0.00249 & \text { Prob }>\text { t } & 0.9973 \\ \text { Upper95\% } & -0.003 & \text { Prob }<\mathrm{t} & 0.0027 \\ \text { Lower95\% } & -0.0139 & & \\ \text { N } & 13 & & \\ \text { Correlation } & 0.29637 & & \end{array}$


WSRC-STI-2006-00069

Revision 0

Exhibit A2. Initial Comparisons by SME Batch among M-13, M-14, and Prototypic Measurements for Each Element by Type of Sample

Type/ Analyte/UoM=SME/Al/wt \% Matched Pairs

Difference: M-14-M-13

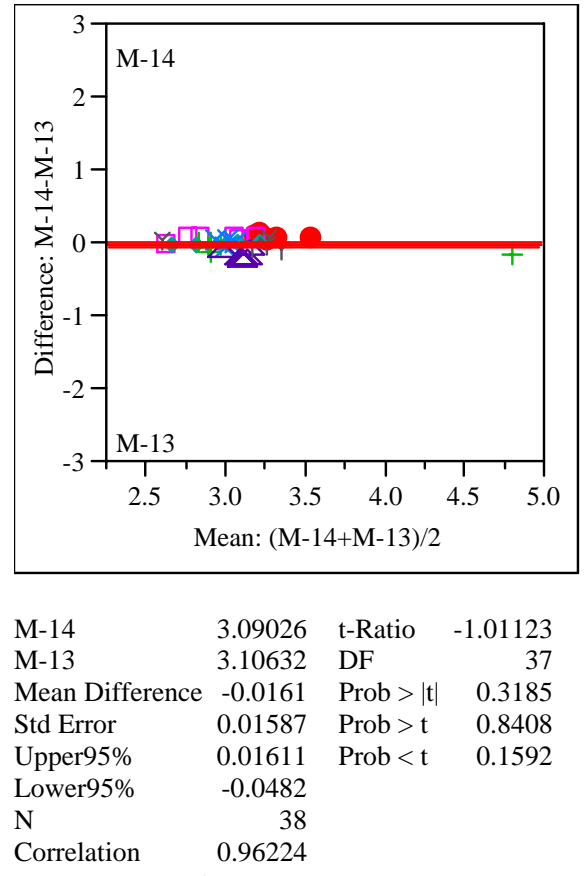

Difference: Screened Prototypic-M-13

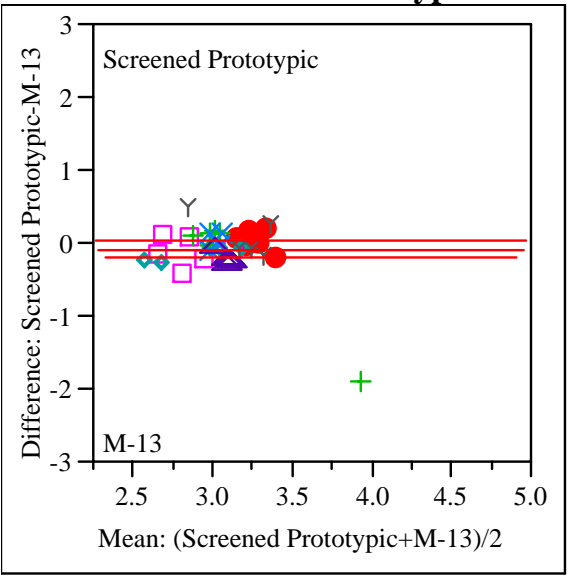

Screened Prototypic 3.02974 t-Ratio -1.34086

$\begin{array}{llll}\text { M-13 } 3.10632 & \text { DF }\end{array}$

Mean Difference $\quad-0.0766$ Prob $>|t| \quad 0.1881$

$\begin{array}{llll}\text { Std Error } & 0.05711 & \text { Prob }>t & 0.9059\end{array}$

Upper95\% $\quad 0.03914$ Prob $<\mathrm{t} \quad 0.0941$

Lower95\% $\quad-0.1923$

$\mathrm{N} \quad 38$

Correlation $\quad 0.35369$

\section{Difference: Screened Prototypic-M-14}

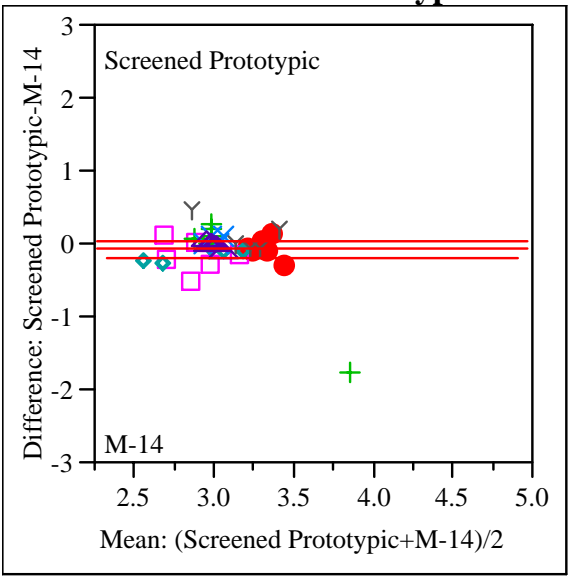

$\begin{array}{lrlr}\text { Screened Prototypic } & 3.02974 & \text { t-Ratio } & -1.13719 \\ \text { M-14 } & 3.09026 & \text { DF } & 37 \\ \text { Mean Difference } & -0.0605 & \text { Prob }>|t| & 0.2628 \\ \text { Std Error } & 0.05322 & \text { Prob }>\text { t } & 0.8686 \\ \text { Upper95\% } & 0.04732 & \text { Prob }<\text { t } & 0.1314 \\ \text { Lower95\% } & -0.1684 & & \\ \text { N } & 38 & & \\ \text { Correlation } & 0.41276 & & \end{array}$

Type/ Analyte/UoM=SME/B/wt \%

Matched Pairs

Difference: M-14-M-13

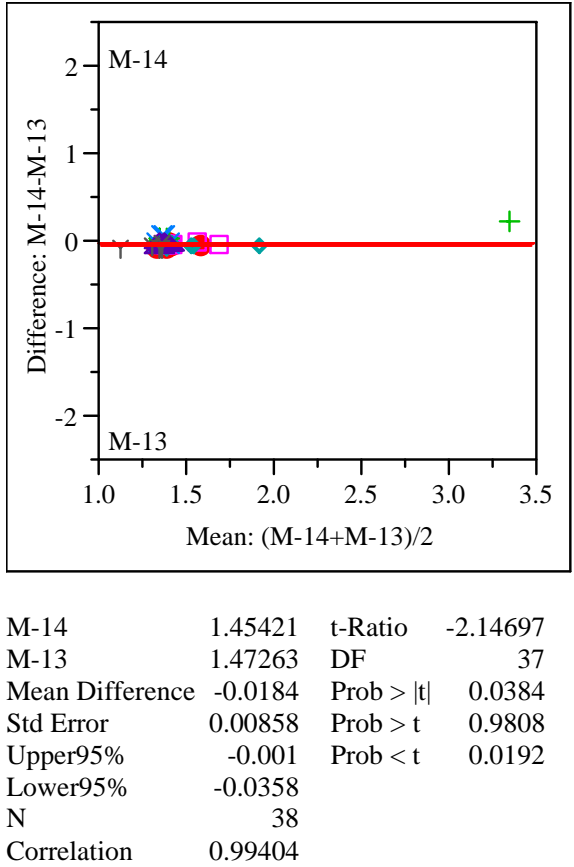


Exhibit A2. Initial Comparisons by SME Batch among M-13, M-14, and Prototypic Measurements for Each Element by Type of Sample

\section{Difference: Screened Prototypic-M-13}

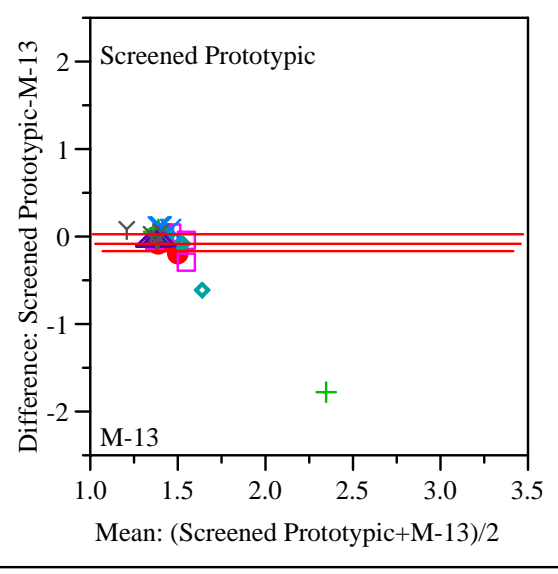

Screened Prototypic 1.40947 t-Ratio $\quad-1.25321$

M-13 1.47263 DF 37

Mean Difference $\quad-0.0632$ Prob $>|t| \quad 0.2180$

Std Error $\quad 0.0504 \quad$ Prob $>$ t 0.8910

Upper95\% $\quad 0.03896$ Prob $<\mathrm{t} \quad 0.1090$

Lower95\% $\quad-0.1653$

$\mathrm{N}$

Correlation

0.20292

\section{Difference: Screened Prototypic-M-14}

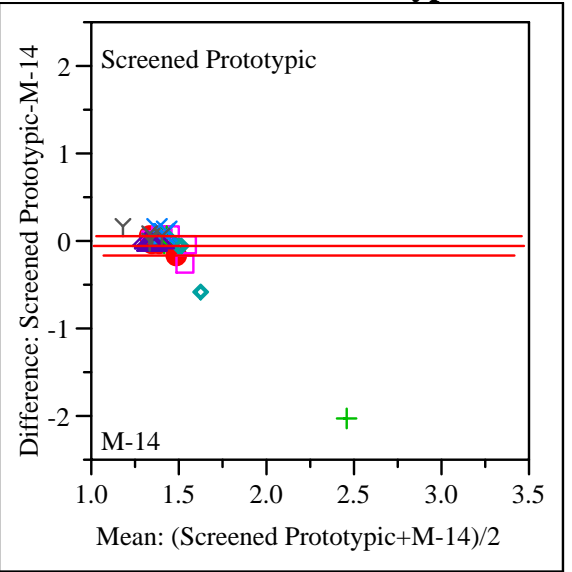

Screened Prototypic 1.40947 t-Ratio $\quad-0.79498$

M-14 1.45421 DF 37

Mean Difference $\quad-0.0447$ Prob $>|\mathrm{t}| \quad 0.4317$

$\begin{array}{llll}\text { Std Error } & 0.05627 & \text { Prob }>t & 0.7842\end{array}$

$\begin{array}{llll}\text { Upper95\% } & 0.06929 & \text { Prob }<\mathrm{t} & 0.2158\end{array}$

Lower95\% $\quad-0.1588$

$\mathrm{N} \quad 38$

Correlation $\quad 0.22806$

\section{Type/ Analyte/UoM=SME/Ca/wt \% Matched Pairs \\ Difference: M-14-M-13}

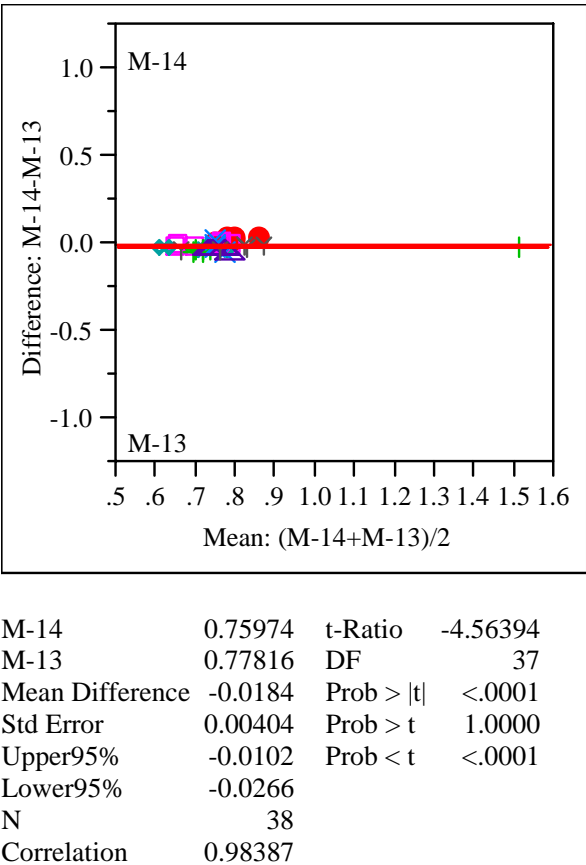

Difference: Screened Prototypic-M-13

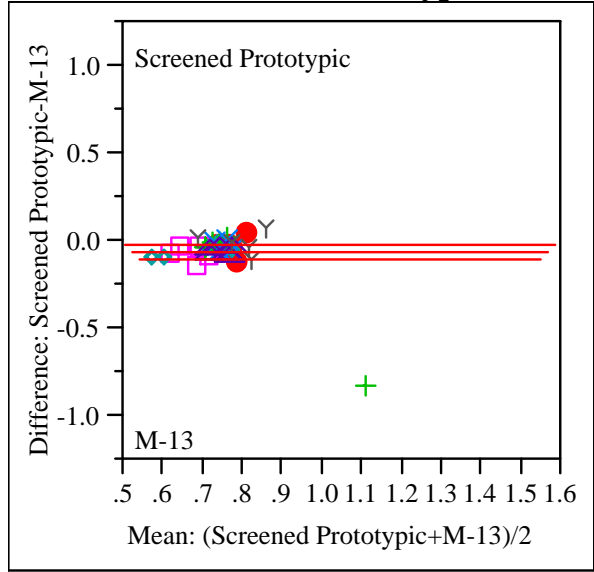

$\begin{array}{lrlr}\text { Screened Prototypic } & 0.71737 & \text { t-Ratio } & -2.79041 \\ \text { M-13 } & 0.77816 & \text { DF } & 37 \\ \text { Mean Difference } & -0.0608 & \text { Prob }>|t| & 0.0083 \\ \text { Std Error } & 0.02179 & \text { Prob }>\text { t } & 0.9959 \\ \text { Upper95\% } & -0.0166 & \text { Prob }<\text { t } & 0.0041 \\ \text { Lower95\% } & -0.1049 & & \\ \text { N } & 38 & & \\ \text { Correlation } & 0.27577 & & \end{array}$


Exhibit A2. Initial Comparisons by SME Batch among M-13, M-14, and Prototypic Measurements for Each Element by Type of Sample

\section{Difference: Screened Prototypic-M-14}

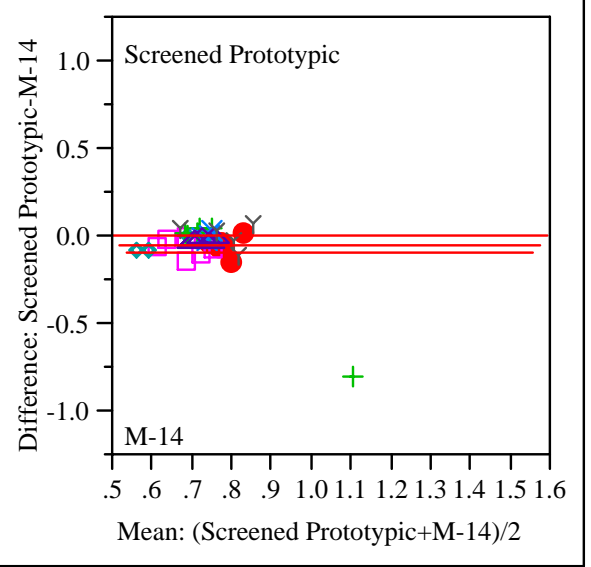

Screened Prototypic 0.71737 t-Ratio $\quad-1.91799$

M-14 0.75974 DF 37

Mean Difference $\quad-0.0424$ Prob $>|t| \quad 0.0629$

Std Error $\quad 0.02209 \quad$ Prob $>\mathrm{t} \quad 0.9686$

Upper95\% $\quad 0.00239$ Prob $<\mathrm{t} \quad 0.0314$

Lower95\% $\quad-0.0871$

$\mathrm{N}$

Correlation

0.29065

Type/ Analyte/UoM=SME/Cr/wt \%

Matched Pairs

Difference: M-14-M-13

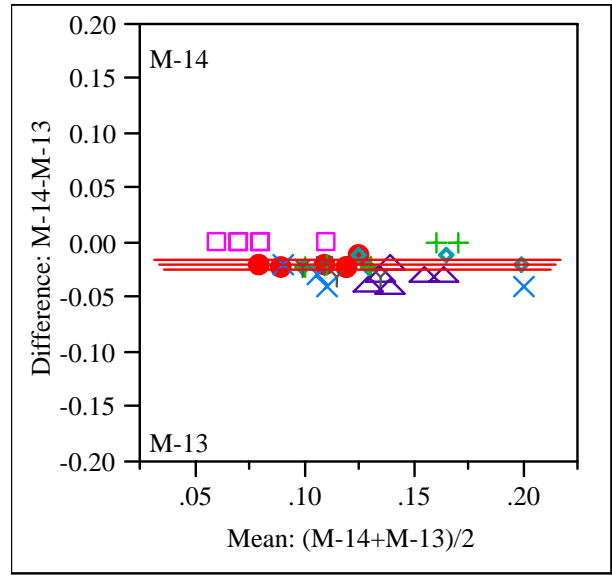

$\begin{array}{lrlr}\text { M-14 } & 0.11105 & \text { t-Ratio } & -9.33364 \\ \text { M-13 } & 0.12974 & \text { DF } & 37 \\ \text { Mean Difference } & -0.0187 & \text { Prob }>|t| & <.0001 \\ \text { Std Error } & 0.002 & \text { Prob }>\text { t } & 1.0000 \\ \text { Upper95\% } & -0.0146 & \text { Prob }<\text { t } & <.0001 \\ \text { Lower95\% } & -0.0227 & & \\ \text { N } & 38 & & \\ \text { Correlation } & 0.94187 & & \end{array}$

\section{Difference: Screened Prototypic-M-13}

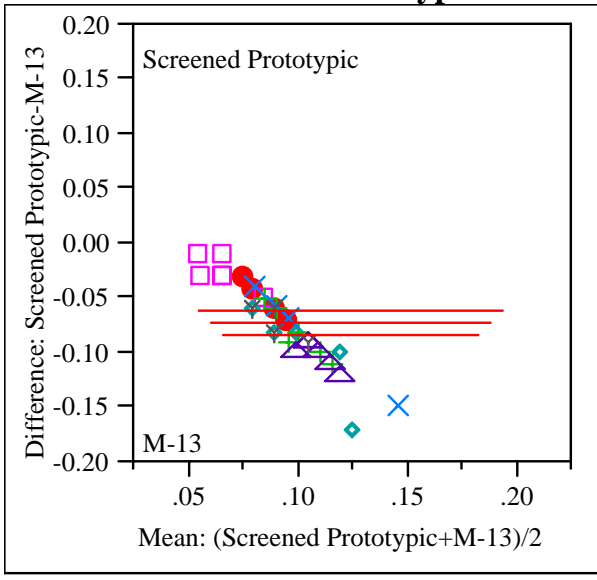

$\begin{array}{lrlr}\text { Screened Prototypic } & 0.05711 & \text { t-Ratio } & -12.9341 \\ \text { M-13 } & 0.12974 & \text { DF } & 37 \\ \text { Mean Difference } & -0.0726 & \text { Prob }>|t| & <.0001 \\ \text { Std Error } & 0.00562 & \text { Prob }>\text { t } & 1.0000 \\ \text { Upper95\% } & -0.0613 & \text { Prob }<\text { t } & <.0001 \\ \text { Lower95\% } & -0.084 & & \\ \text { N } & 38 & & \\ \text { Correlation } & 0.30625 & & \end{array}$

Difference: Screened Prototypic-M-14

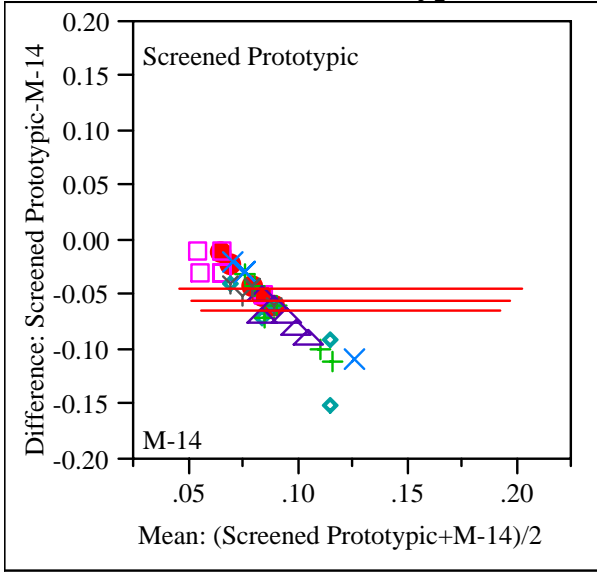

Screened Prototypic 0.05711 t-Ratio $\quad-10.8268$

M-14 0.11105 DF 37

Mean Difference $\quad-0.0539$ Prob $>|t|<.0001$

$\begin{array}{llll}\text { Std Error } & 0.00498 & \text { Prob }>\text { t } & 1.0000\end{array}$

Upper95\% $\quad-0.0439$ Prob $<\mathrm{t} \quad<.0001$

Lower95\% $\quad-0.064$

$\mathrm{N} \quad 38$

Correlation $\quad 0.2375$ 
WSRC-STI-2006-00069

Revision 0

Exhibit A2. Initial Comparisons by SME Batch among M-13, M-14, and Prototypic Measurements for Each Element by Type of Sample

Type/ Analyte/UoM=SME/Cu/wt \%

Matched Pairs

Difference: M-14-M-13

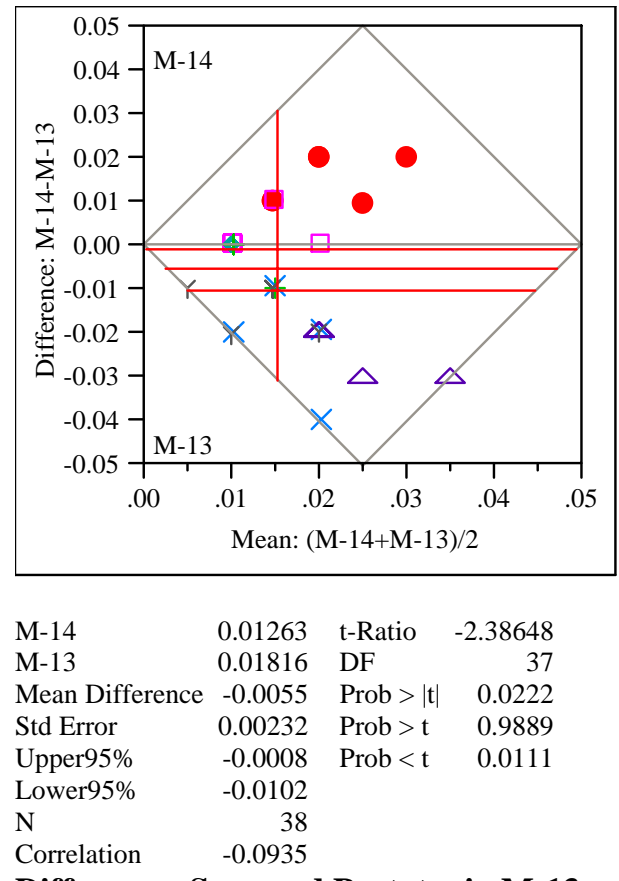

Difference: Screened Prototypic-M-13

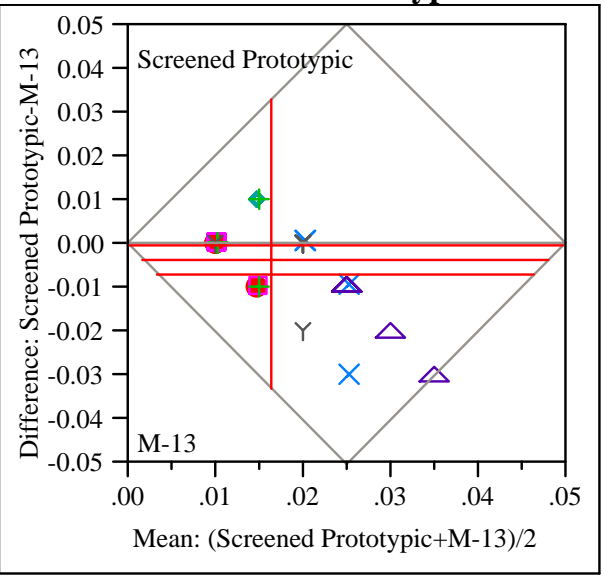

Screened Prototypic 0.01474 t-Ratio $\quad-2.12174$

M-13 0.01816 DF 37

Mean Difference $\quad-0.0034$ Prob $>|t| \quad 0.0406$

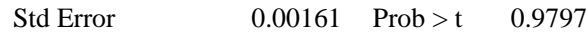

Upper95\% $\quad-0.0002$ Prob $<$ t 0.0203

Lower95\% $\quad-0.0067$

$\mathrm{N} \quad 38$

Correlation $\quad 0.36803$

\section{Difference: Screened Prototypic-M-14}

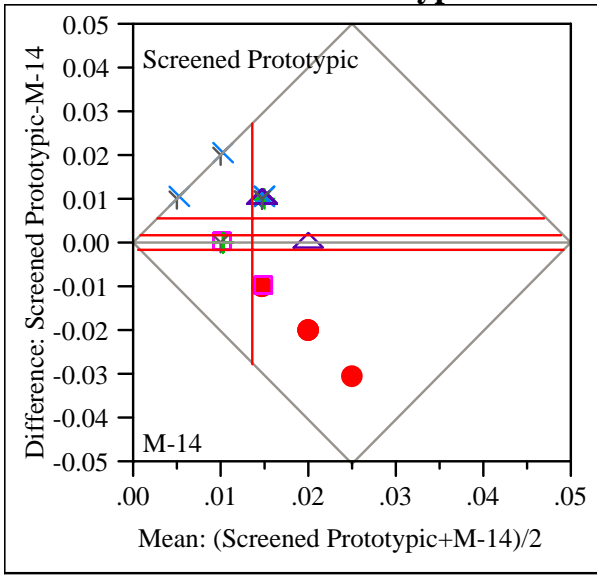

$\begin{array}{lrlr}\text { Screened Prototypic } & 0.01474 & \text { t-Ratio } & 1.135676 \\ \text { M-14 } & 0.01263 & \text { DF } & 37 \\ \text { Mean Difference } & 0.00211 & \text { Prob }>|t| & 0.2634 \\ \text { Std Error } & 0.00185 & \text { Prob }>\text { t } & 0.1317 \\ \text { Upper95\% } & 0.00586 & \text { Prob }<\text { t } & 0.8683 \\ \text { Lower95\% } & -0.0017 & & \\ \text { N } & 38 & & \\ \text { Correlation } & -0.3563 & & \end{array}$

Type/ Analyte/UoM=SME/Fe/wt \%

Matched Pairs

Difference: M-14-M-13

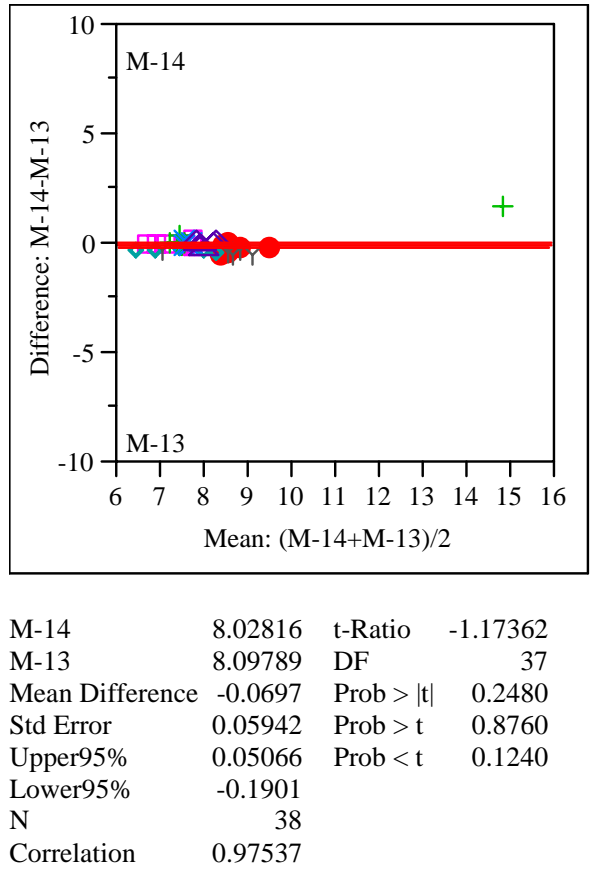


Exhibit A2. Initial Comparisons by SME Batch among M-13, M-14, and Prototypic Measurements for Each Element by Type of Sample

\section{Difference: Screened Prototypic-M-13}

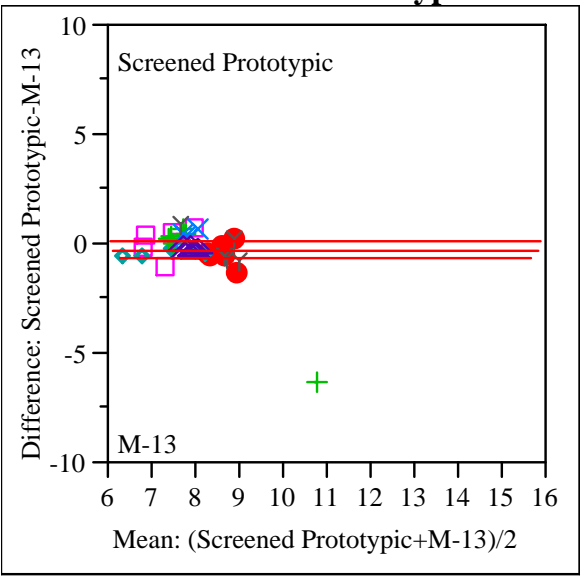

Screened Prototypic 7.86947 t-Ratio $\quad-1.25545$

M-13 8.09789 DF 37

Mean Difference $\quad-0.2284$ Prob $>|t| \quad 0.2172$

Std Error $\quad 0.18194 \quad$ Prob $>$ t $\quad 0.8914$

Upper95\% $\quad 0.14023$ Prob $<\mathrm{t} \quad 0.1086$

Lower95\% $\quad-0.5971$

$\mathrm{N}$

Correlation

0.4031

\section{Difference: Screened Prototypic-M-14}

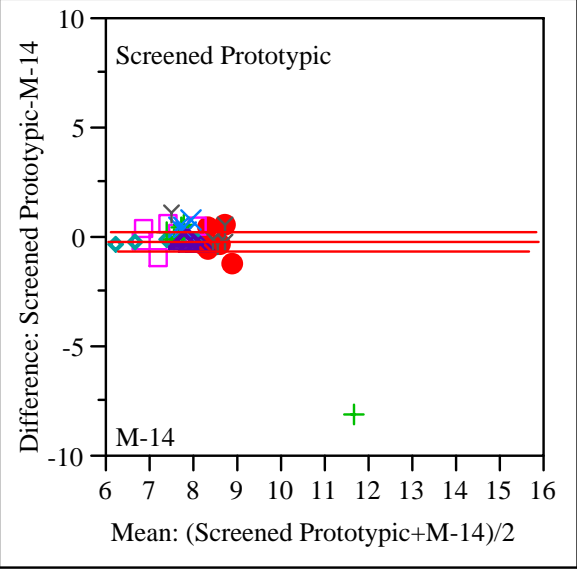

Screened Prototypic 7.86947 t-Ratio $\quad-0.70199$

M-14

Mean Difference

Std Error

Upper95\%

Lower95\%

$\mathrm{N}$

8.02816

$-0.1587 \quad$ Prob $>|\mathrm{t}| \quad 0.4871$

$0.22605 \quad$ Prob $>\mathrm{t} \quad 0.7565$

0.29934 Prob $<\mathrm{t} \quad 0.2435$

$-0.6167$

38

0.28511
Type/ Analyte/UoM=SME/K/wt \%

Matched Pairs

Difference: M-14-M-13

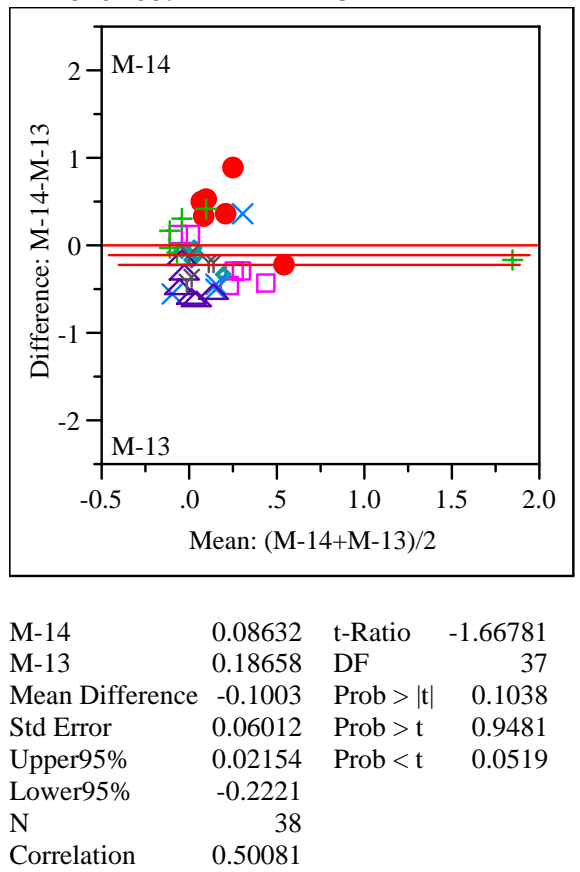

Difference: Screened Prototypic-M-13

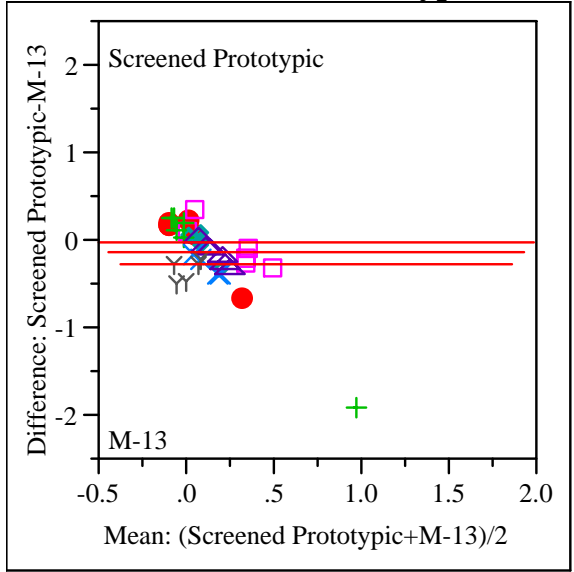

$\begin{array}{lrlr}\text { Screened Prototypic } & 0.05053 & \text { t-Ratio } & -2.18099 \\ \text { M-13 } & 0.18658 & \text { DF } & 37 \\ \text { Mean Difference } & -0.1361 & \text { Prob }>|t| & 0.0356 \\ \text { Std Error } & 0.06238 & \text { Prob }>\text { t } & 0.9822 \\ \text { Upper95\% } & -0.0097 & \text { Prob }<\text { t } & 0.0178 \\ \text { Lower95\% } & -0.2624 & & \\ \text { N } & 38 & & \\ \text { Correlation } & 0.08505 & & \end{array}$ 
Exhibit A2. Initial Comparisons by SME Batch among M-13, M-14, and Prototypic Measurements for Each Element by Type of Sample

\section{Difference: Screened Prototypic-M-14}

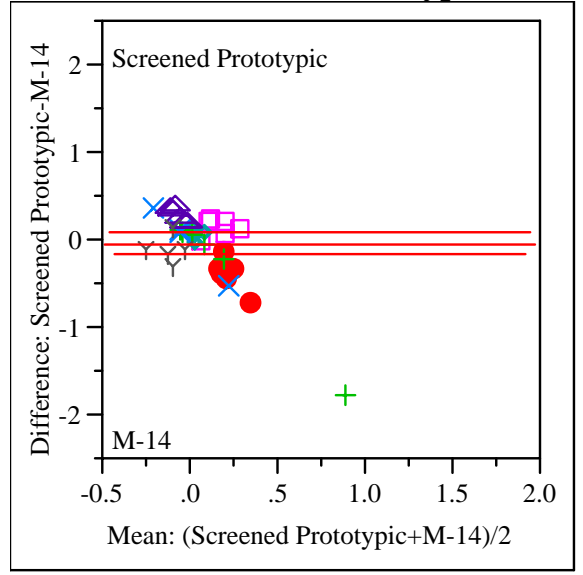

Screened Prototypic 0.05053 t-Ratio $\quad-0.57144$

M-14 0.08632 DF 37

Mean Difference $\quad-0.0358$ Prob $>|t| \quad 0.5712$

Std Error $\quad 0.06263 \quad$ Prob $>\mathrm{t} \quad 0.7144$

Upper95\% $\quad 0.09111$ Prob $<\mathrm{t} \quad 0.2856$

Lower95\% $\quad-0.1627$

$\mathrm{N}$

Correlation

0.02108

\section{Type/ Analyte/UoM=SME/Li/wt \%}

Matched Pairs

Difference: M-14-M-13

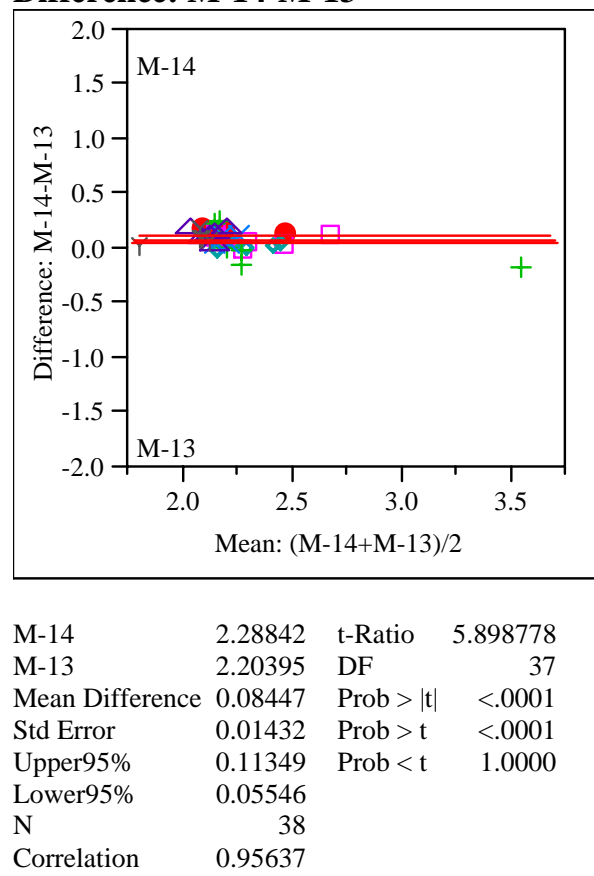

\section{Difference: Screened Prototypic-M-13}

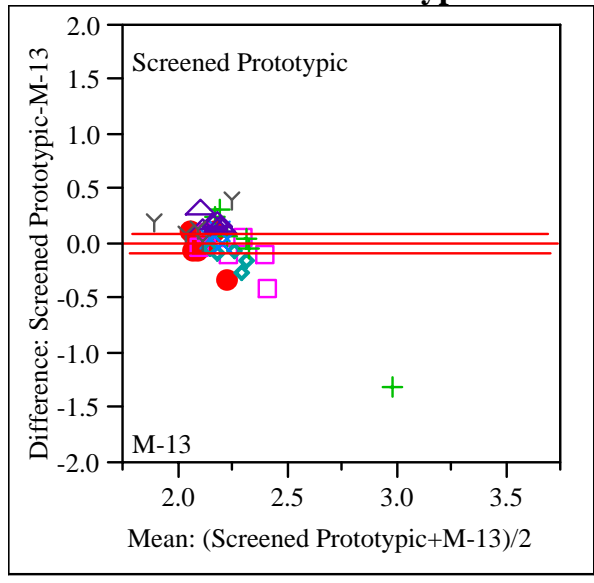

$\begin{array}{lrlr}\text { Screened Prototypic } & 2.21342 & \text { t-Ratio } & 0.210762 \\ \text { M-13 } & 2.20395 & \text { DF } & 37 \\ \text { Mean Difference } & 0.00947 & \text { Prob }>|t| & 0.8342 \\ \text { Std Error } & 0.04495 & \text { Prob }>\text { t } & 0.4171 \\ \text { Upper95\% } & 0.10055 & \text { Prob }<\text { t } & 0.5829 \\ \text { Lower95\% } & -0.0816 & & \\ \text { N } & 38 & & \\ \text { Correlation } & 0.25322 & & \end{array}$

\section{Difference: Screened Prototypic-M-14}

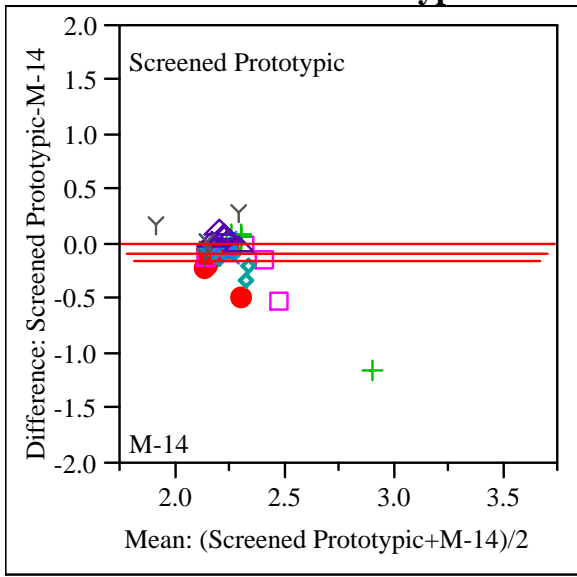

$\begin{array}{lrlr}\text { Screened Prototypic } & 2.21342 & \text { t-Ratio } & -1.93158 \\ \text { M-14 } & 2.28842 & \text { DF } & 37 \\ \text { Mean Difference } & -0.075 & \text { Prob }>|t| & 0.0611 \\ \text { Std Error } & 0.03883 & \text { Prob }>\text { t } & 0.9695 \\ \text { Upper95\% } & 0.00367 & \text { Prob }<\text { t } & 0.0305 \\ \text { Lower95\% } & -0.1537 & & \\ \text { N } & 38 & & \\ \text { Correlation } & 0.24365 & & \end{array}$


WSRC-STI-2006-00069

Revision 0

Exhibit A2. Initial Comparisons by SME Batch among M-13, M-14, and Prototypic Measurements for Each Element by Type of Sample

Type/ Analyte/UoM=SME/Mg/wt\% Matched Pairs

Difference: M-14-M-13

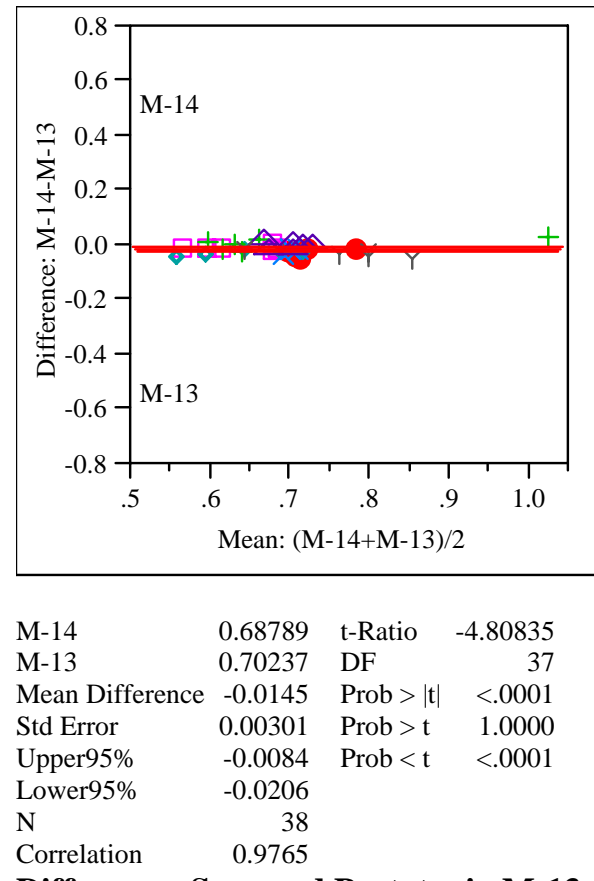

Difference: Screened Prototypic-M-13

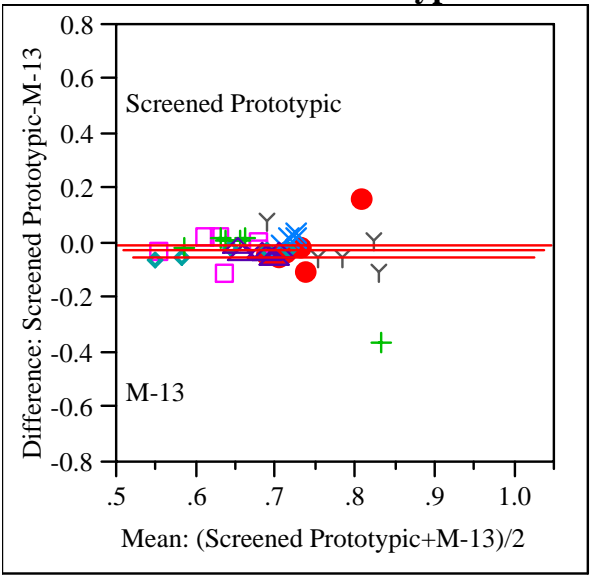

Screened Prototypic 0.67763 t-Ratio $\quad-2.0702$

$\begin{array}{llll}\text { M-13 } & 0.70237 & \text { DF } & 37\end{array}$

Mean Difference $\quad-0.0247$ Prob $>|\mathrm{t}| \quad 0.0455$

$\begin{array}{llll}\text { Std Error } \quad 0.01195 & \text { Prob }>\text { t } & 0.9773\end{array}$

Upper95\% $\quad-0.0005$ Prob $<\mathrm{t} \quad 0.0227$

Lower95\% $\quad-0.0489$

$\mathrm{N} \quad 38$

Correlation $\quad 0.57334$

\section{Difference: Screened Prototypic-M-14}

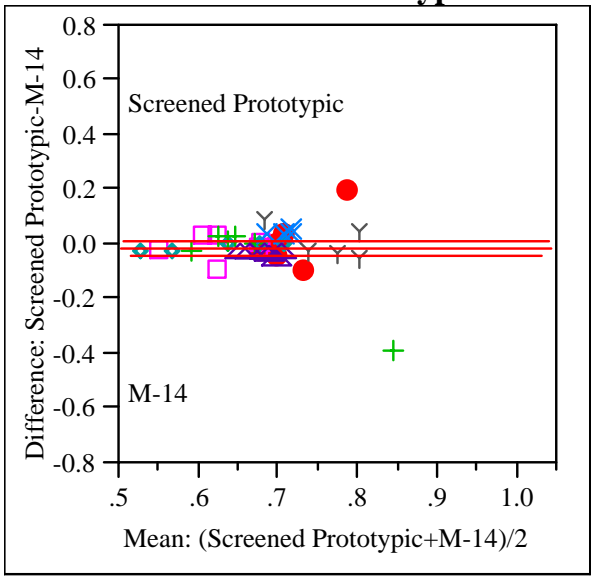

$\begin{array}{lrlr}\text { Screened Prototypic } & 0.67763 & \text { t-Ratio } & -0.78278 \\ \text { M-14 } & 0.68789 & \text { DF } & 37 \\ \text { Mean Difference } & -0.0103 & \text { Prob }>|t| & 0.4387 \\ \text { Std Error } & 0.01311 & \text { Prob }>\text { t } & 0.7806 \\ \text { Upper95\% } & 0.0163 & \text { Prob }<\text { t } & 0.2194 \\ \text { Lower95\% } & -0.0368 & & \\ \text { N } & 38 & & \\ \text { Correlation } & 0.48918 & & \end{array}$

Type/ Analyte/UoM=SME/Mn/wt \%

Matched Pairs

Difference: M-14-M-13

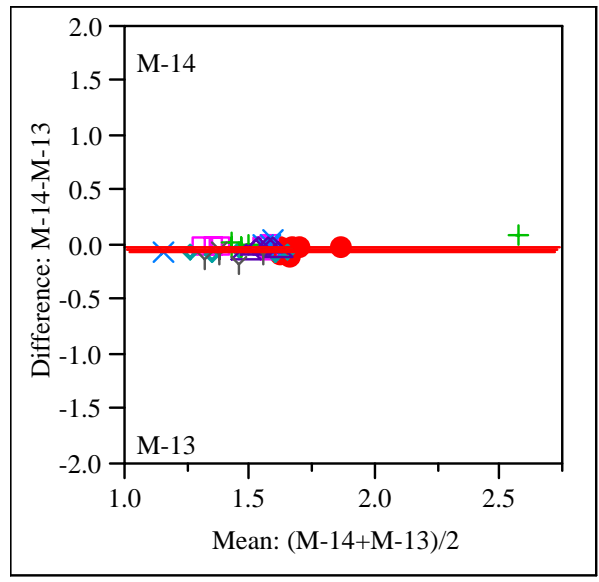

$\begin{array}{lrlr}\text { M-14 } & 1.52158 & \text { t-Ratio } & -4.2376 \\ \text { M-13 } & 1.555 & \text { DF } & 37 \\ \text { Mean Difference } & -0.0334 & \text { Prob }>|t| & 0.0001 \\ \text { Std Error } & 0.00789 & \text { Prob }>\text { t } & 0.9999 \\ \text { Upper95\% } & -0.0174 & \text { Prob }<\mathrm{t} & <.0001 \\ \text { Lower95\% } & -0.0494 & & \\ \text { N } & 38 & & \\ \text { Correlation } & 0.9809 & & \end{array}$


WSRC-STI-2006-00069

Revision 0

Exhibit A2. Initial Comparisons by SME Batch among M-13, M-14, and Prototypic Measurements for Each Element by Type of Sample

\section{Difference: Screened Prototypic-M-13}

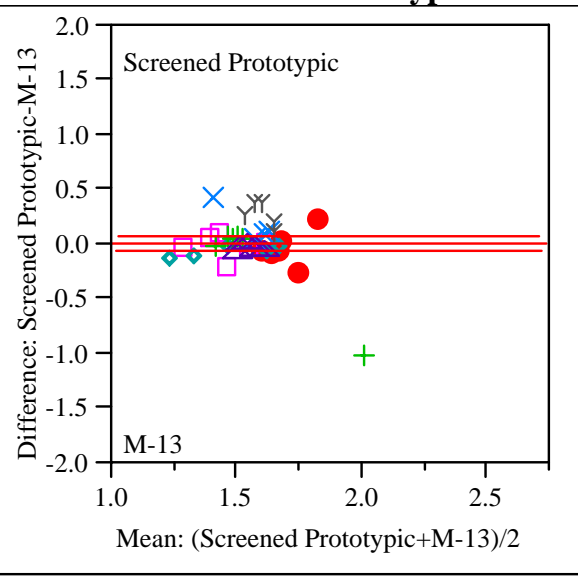

Screened Prototypic 1.56632 t-Ratio 0.307174

M-13

Mean Difference 0.01132 Prob $>|\mathrm{t}| \quad 0.7604$

Std Error $\quad 0.03684 \quad$ Prob $>\mathrm{t} \quad 0.3802$

Upper95\% $\quad 0.08596$ Prob $<\mathrm{t} \quad 0.6198$

Lower95\% $\quad-0.0633$

$\mathrm{N}$

Correlation

0.24699

\section{Difference: Screened Prototypic-M-14}

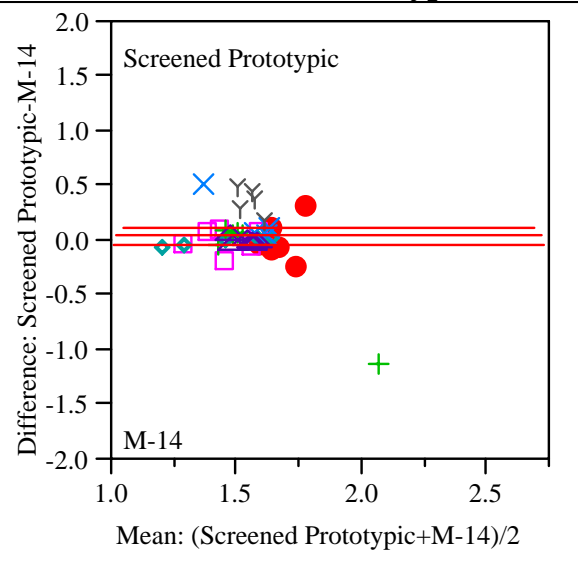

Screened Prototypic 1.56632 t-Ratio 1.06427

$\mathrm{M}-14$

1.52158 DF 37

Mean Difference $\quad 0.04474$ Prob $>|t| \quad 0.2941$

$\begin{array}{llll}\text { Std Error } & 0.04204 & \text { Prob }>t & 0.1471\end{array}$

Upper95\% $\quad 0.12991$ Prob $<\mathrm{t} \quad 0.8529$

Lower95\% $\quad-0.0404$

N

Correlation
Type/ Analyte/UoM=SME/Na/wt $\%$

Matched Pairs

Difference: M-14-M-13

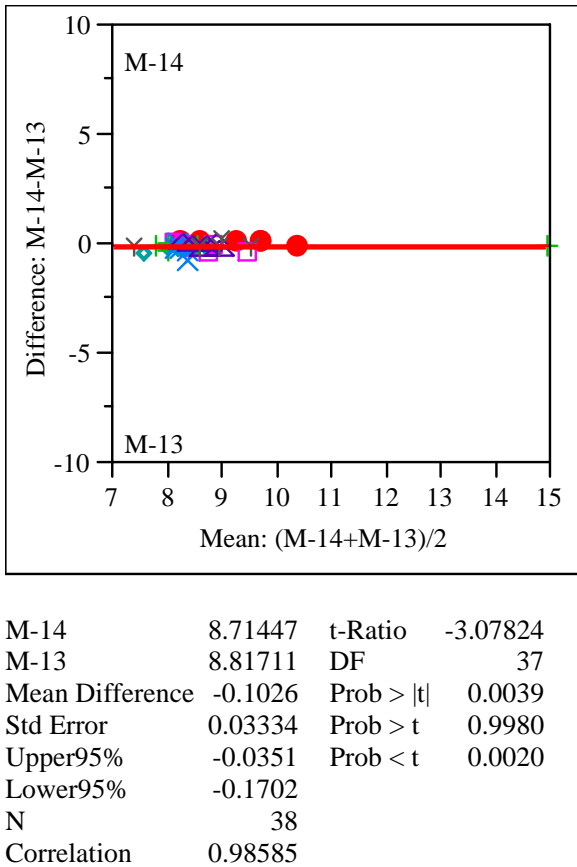

Difference: Screened Prototypic-M-13

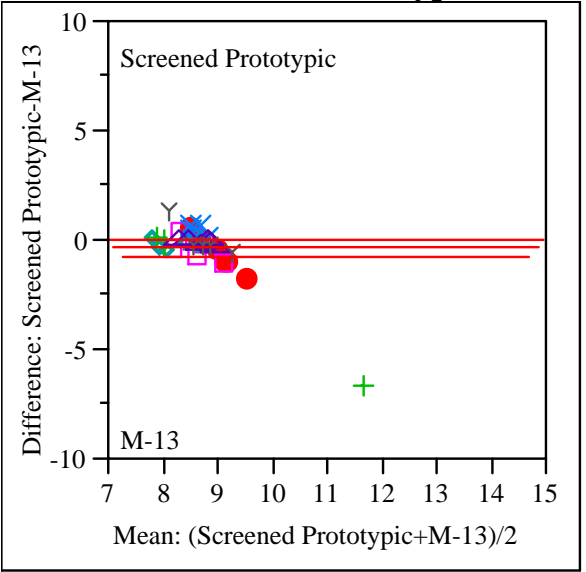

$\begin{array}{lrlr}\text { Screened Prototypic } & 8.53263 & \text { t-Ratio } & -1.48665 \\ \text { M-13 } & 8.81711 & \text { DF } & 37 \\ \text { Mean Difference } & -0.2845 & \text { Prob }>|t| & 0.1456 \\ \text { Std Error } & 0.19135 & \text { Prob }>\text { t } & 0.9272 \\ \text { Upper95\% } & 0.10324 & \text { Prob }<\text { t } & 0.0728 \\ \text { Lower95\% } & -0.6722 & & \\ \text { N } & 38 & & \\ \text { Correlation } & 0.15509 & & \end{array}$


Exhibit A2. Initial Comparisons by SME Batch among M-13, M-14, and Prototypic Measurements for Each Element by Type of Sample

\section{Difference: Screened Prototypic-M-14}

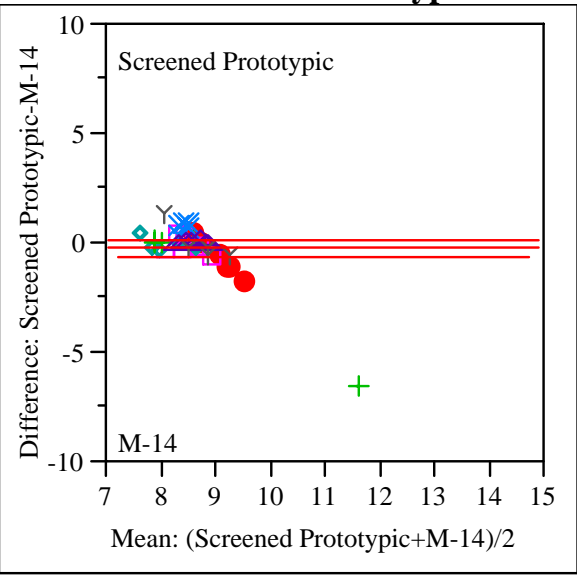

Screened Prototypic 8.53263 t-Ratio $\quad-0.9293$

M-14

8.71447 DF 37

Mean Difference $\quad-0.1818 \quad$ Prob $>|t| \quad 0.3588$

Std Error $\quad 0.19568 \quad$ Prob $>\mathrm{t} \quad 0.8206$

$\begin{array}{llll}\text { Upper95\% } & 0.21464 & \text { Prob }<\mathrm{t} & 0.1794\end{array}$

Lower95\% $\quad-0.5783$

$\mathrm{N}$

Correlation

0.1814

Type/ Analyte/UoM=SME/Ni/wt \%

Matched Pairs

Difference: M-14-M-13

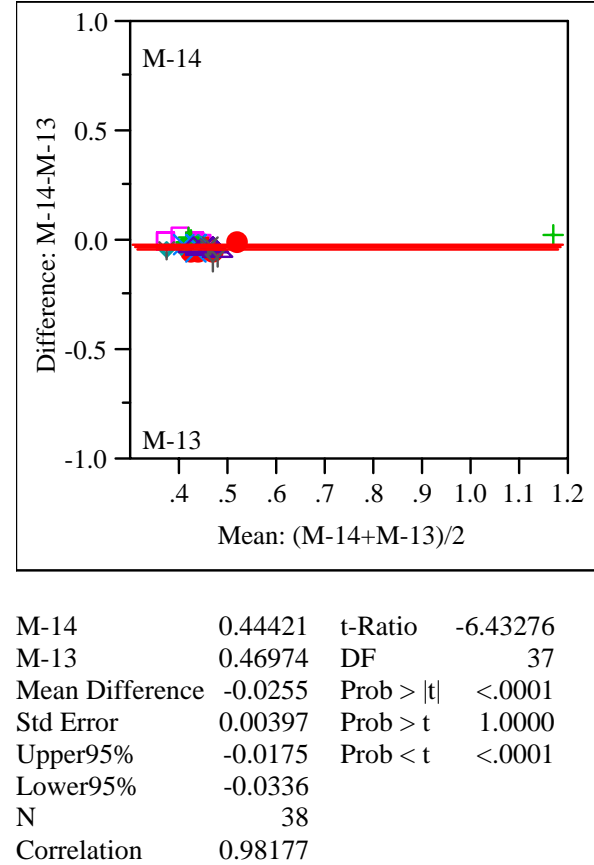

Correlation $\quad 0.98177$

\section{Difference: Screened Prototypic-M-13}

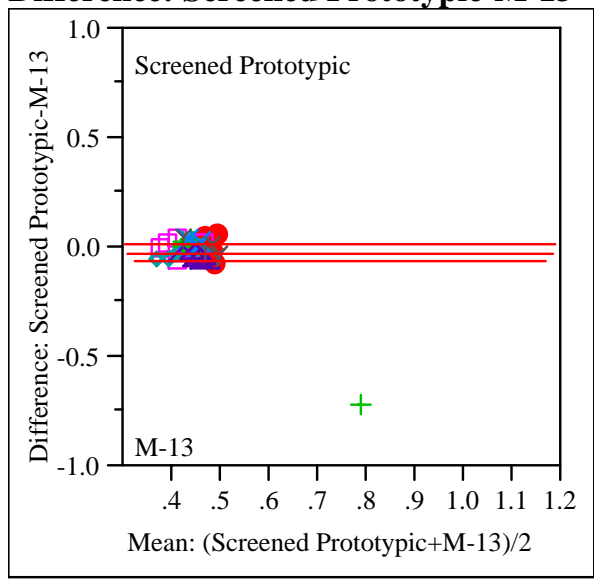

$\begin{array}{lrlr}\text { Screened Prototypic } & 0.44421 & \text { t-Ratio } & -1.29947 \\ \text { M-13 } & 0.46974 & \text { DF } & 37 \\ \text { Mean Difference } & -0.0255 & \text { Prob }>|t| & 0.2018 \\ \text { Std Error } & 0.01964 & \text { Prob }>\text { t } & 0.8991 \\ \text { Upper95\% } & 0.01428 & \text { Prob }<\text { t } & 0.1009 \\ \text { Lower95\% } & -0.0653 & & \\ \text { N } & 38 & & \\ \text { Correlation } & 0.11715 & & \end{array}$

Difference: Screened Prototypic-M-14

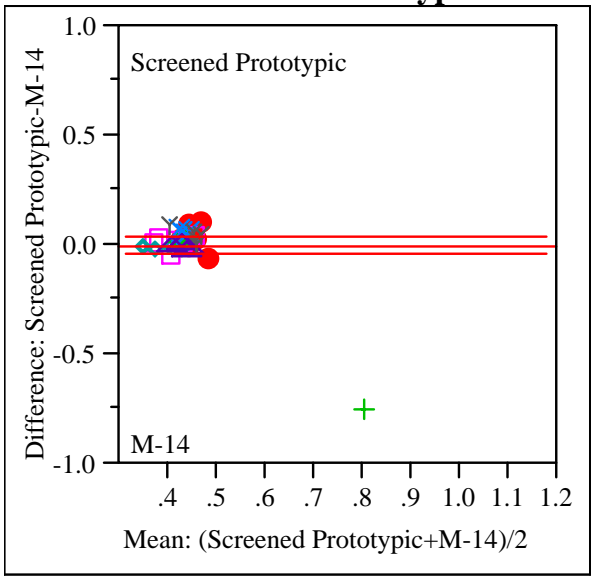

M-14 0.44421 DF 37

Mean Difference $\quad 1.5 \mathrm{e}-18$ Prob $>|\mathrm{t}| \quad 1.0000$

Std Error

0.02113 Prob $>\mathrm{t} \quad 0.5000$

Upper95\%

0.04281 Prob $<\mathrm{t} \quad 0.5000$

Lower95\%

$-0.0428$

$\mathrm{N}$

Correlation 
Exhibit A2. Initial Comparisons by SME Batch among M-13, M-14, and Prototypic Measurements for Each Element by Type of Sample

Type/ Analyte/UoM=SME/Si/wt \% Matched Pairs

Difference: M-14-M-13

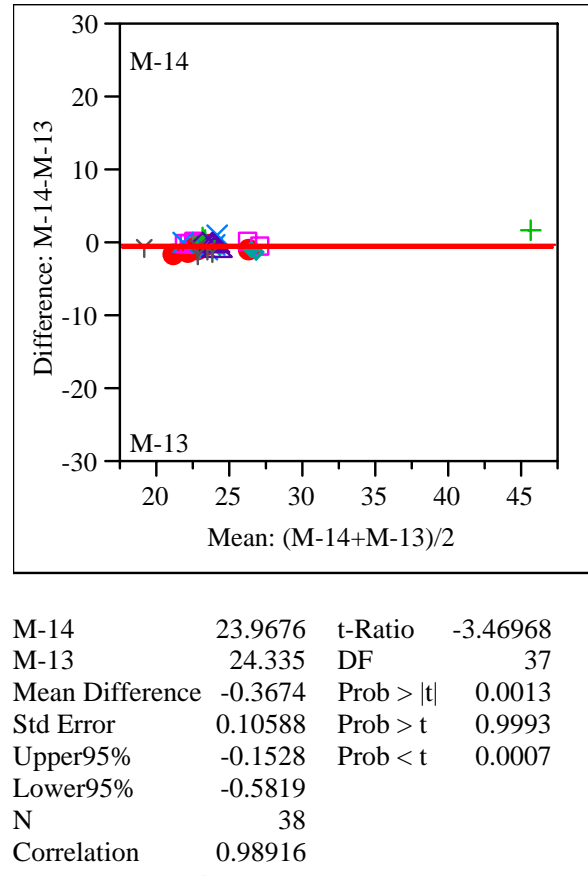

Difference: Screened Prototypic-M-13

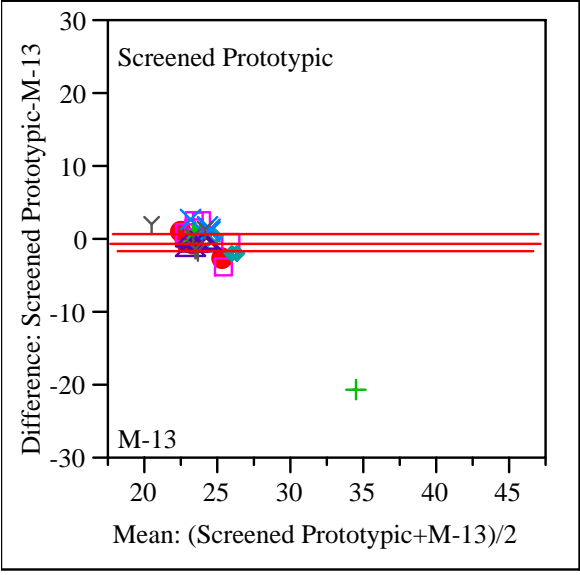

Screened Prototypic 23.9063 t-Ratio $\quad-0.72539$

M-13

fference

Std Error

Upper95\%

Lower95\%

$\mathrm{N}$

Correlation
24.335 DF 37

-0.4287 Prob $>|\mathrm{t}| \quad 0.4728$

$0.59097 \quad$ Prob $>\mathrm{t} \quad 0.7636$

0.76873 Prob $<\mathrm{t} \quad 0.2364$

$-1.6261$

0.23339

\section{Difference: Screened Prototypic-M-14}

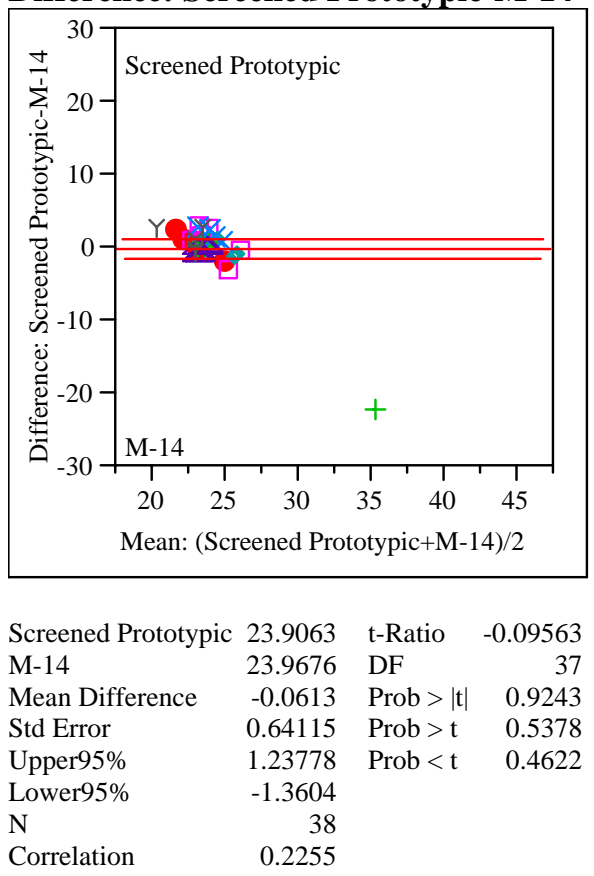

Type/ Analyte/UoM=SME/Ti/wt \% Matched Pairs

Difference: M-14-M-13

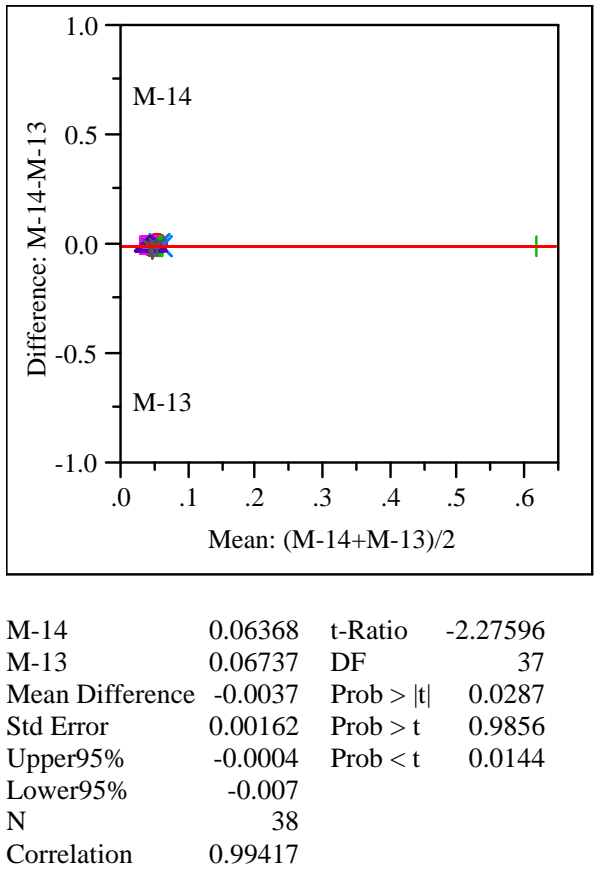


WSRC-STI-2006-00069

Revision 0

Exhibit A2. Initial Comparisons by SME Batch among M-13, M-14, and Prototypic Measurements for Each Element by Type of Sample

\section{Difference: Screened Prototypic-M-13}

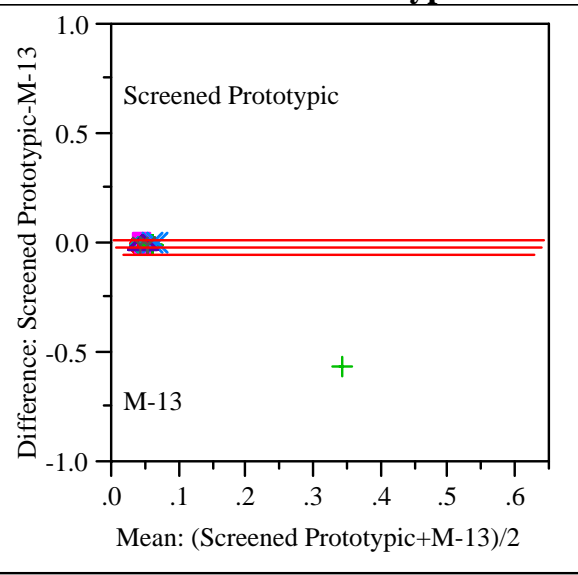

Screened Prototypic 0.04947 t-Ratio $\quad-1.21932$

M-13 0.06737 DF 37

Mean Difference $\quad-0.0179$ Prob $>|t| \quad 0.2304$

Std Error $\quad 0.01468 \quad$ Prob $>\mathrm{t} \quad 0.8848$

Upper95\% $\quad 0.01184$ Prob $<\mathrm{t} \quad 0.1152$

Lower95\% $\quad-0.0476$

$\mathrm{N}$

Correlation

0.29076

\section{Difference: Screened Prototypic-M-14}

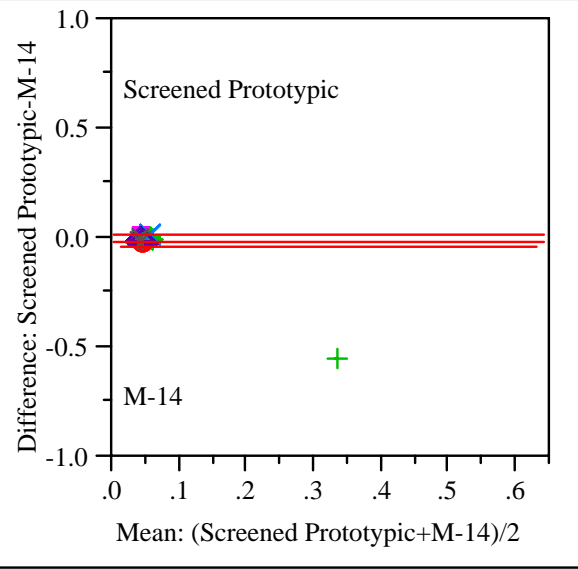

Screened Prototypic 0.04947 t-Ratio $\quad-0.97491$

M-14

0.06368

Mean Difference $\quad-0.0142$ Prob $>|t| \quad 0.3359$

Std Error

Upper95\%

Lower95\%

0.01458 Prob $>\mathrm{t} \quad 0.8320$

Correlation
0.01532 Prob $<\mathrm{t} \quad 0.1680$

$-0.0437$

0.22608
Type/ Analyte/UoM=SME/U/wt \%
Matched Pairs

Difference: M-14-M-13

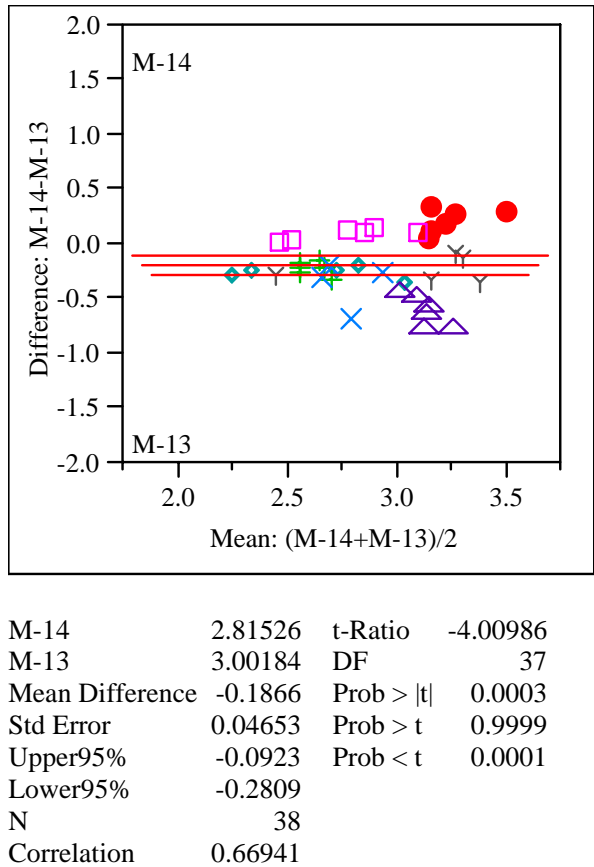

Difference: Screened Prototypic-M-13

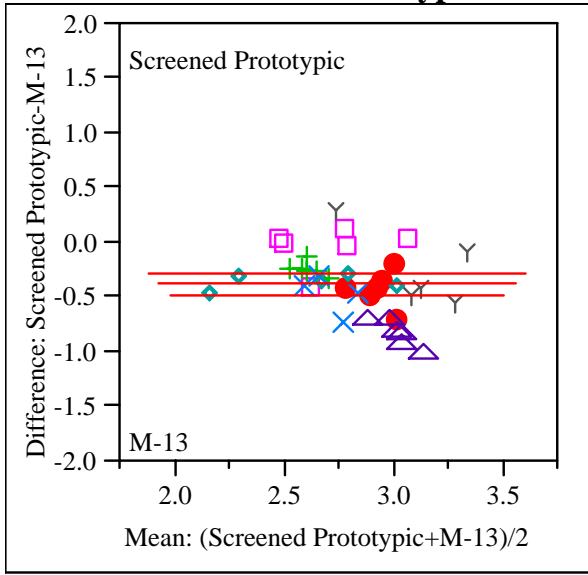

$\begin{array}{lrlr}\text { Screened Prototypic } & 2.63026 & \text { t-Ratio } & -7.81457 \\ \text { M-13 } & 3.00184 & \text { DF } & 37 \\ \text { Mean Difference } & -0.3716 & \text { Prob }>|t| & <.0001 \\ \text { Std Error } & 0.04755 & \text { Prob }>\text { t } & 1.0000 \\ \text { Upper95\% } & -0.2752 & \text { Prob }<\text { t } & <.0001 \\ \text { Lower95\% } & -0.4679 & & \\ \text { N } & 38 & & \\ \text { Correlation } & 0.54611 & & \end{array}$


Exhibit A2. Initial Comparisons by SME Batch among M-13, M-14, and Prototypic Measurements for Each Element by Type of Sample

\section{Difference: Screened Prototypic-M-14}

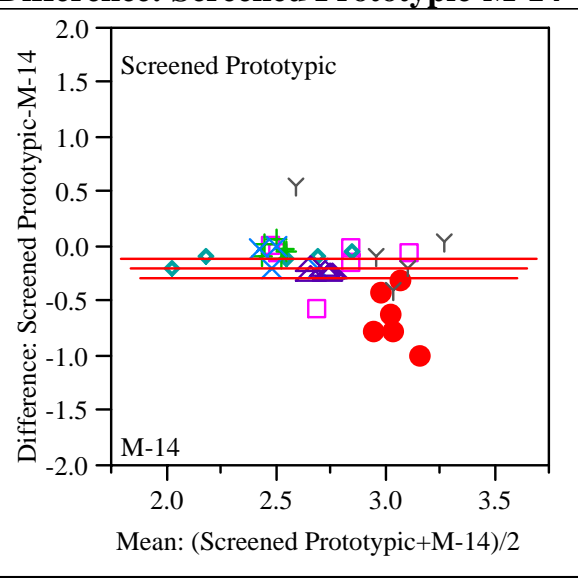

Screened Prototypic 2.63026 t-Ratio $\quad-4.16951$

M-14 2.81526 DF 37

Mean Difference $\quad-0.185$ Prob $>|t| \quad 0.0002$

Std Error $\quad 0.04437 \quad$ Prob $>\mathrm{t} \quad 0.9999$

Upper95\% $\quad-0.0951$ Prob $<\mathrm{t} \quad<.0001$

Lower95\% $\quad-0.2749$

$\mathrm{N}$

Correlation

0.65803

Type/ Analyte/UoM=SME/Zr/wt\%

Matched Pairs

Difference: M-14-M-13

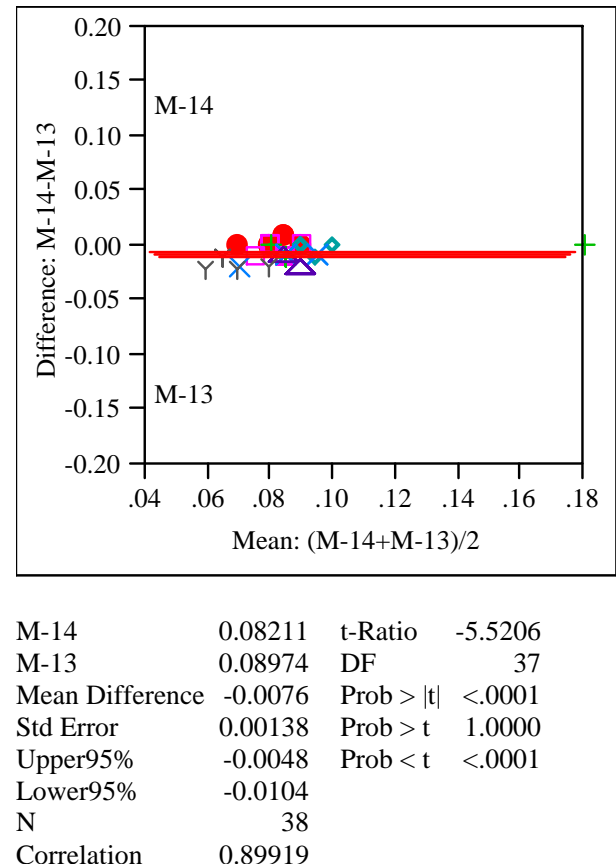

\section{Difference: Screened Prototypic-M-13}

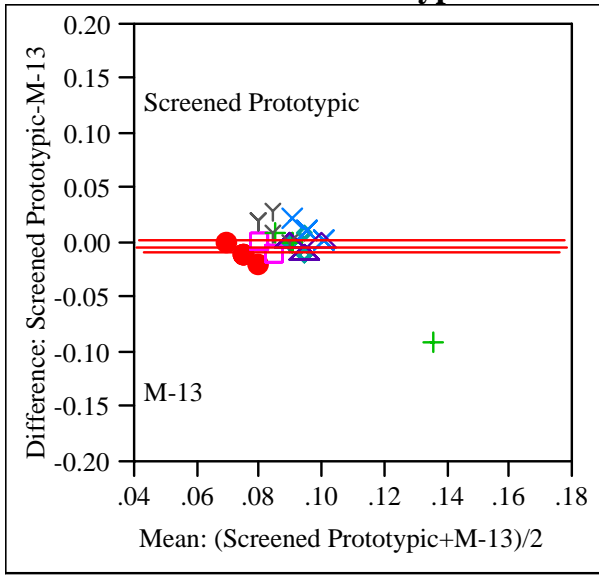

$\begin{array}{lrlr}\text { Screened Prototypic } & 0.08737 & \text { t-Ratio } & -0.80778 \\ \text { M-13 } & 0.08974 & \text { DF } & 37 \\ \text { Mean Difference } & -0.0024 & \text { Prob }>|t| & 0.4244 \\ \text { Std Error } & 0.00293 & \text { Prob }>\text { t } & 0.7878 \\ \text { Upper95\% } & 0.00357 & \text { Prob }<\text { t } & 0.2122 \\ \text { Lower95\% } & -0.0083 & & \\ \text { N } & 38 & & \\ \text { Correlation } & 0.2311 & & \end{array}$

Difference: Screened Prototypic-M-14

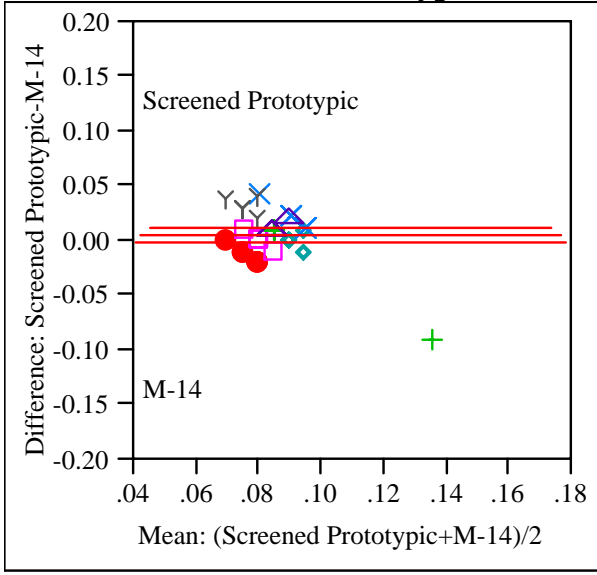

Screened Prototypic 0.08737 t-Ratio 1.464982

M-14

0.08211 DF

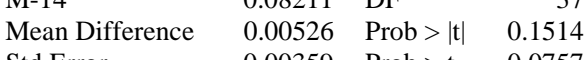

Std Error

$\begin{array}{lll}0.00359 & \text { Prob }>\mathrm{t} & 0.0757 \\ 0.01254 & \text { Prob }<\mathrm{t} & 0.9243\end{array}$

Upper95\%

$\begin{array}{lr}\text { Lower95\% } & -0.002 \\ \mathrm{~N} & 38\end{array}$

Correlation $\quad-0.0411$ 
Exhibit A3. Initial Comparisons by SME Batch among M-13, M-14, and Prototypic Measurements for Each Element by Type of Sample after Screening

Type/ Analyte/UoM=ARG-1/Al/wt \% Matched Pairs

Difference: M-14-M-13

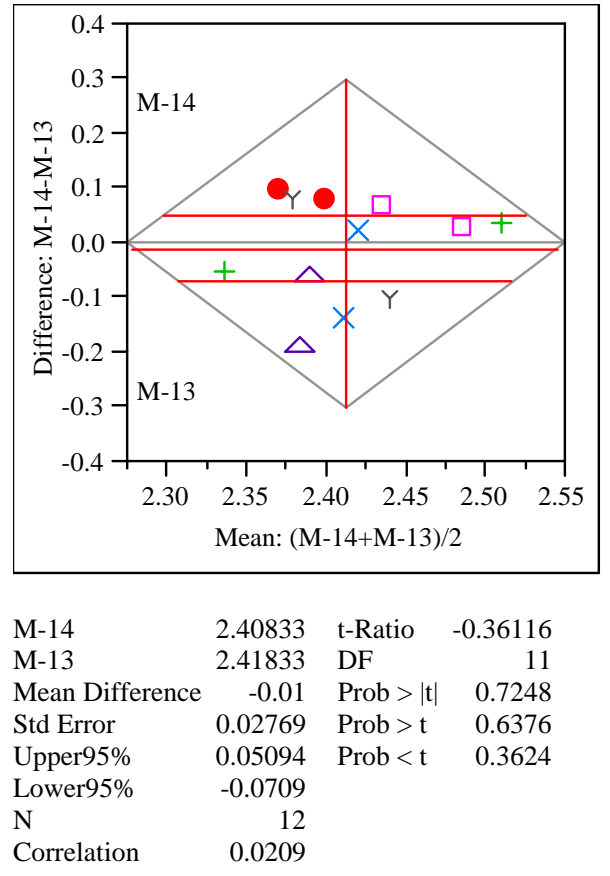

Type/ Analyte/UoM=ARG-1/B/wt\% Matched Pairs

Difference: M-14-M-13

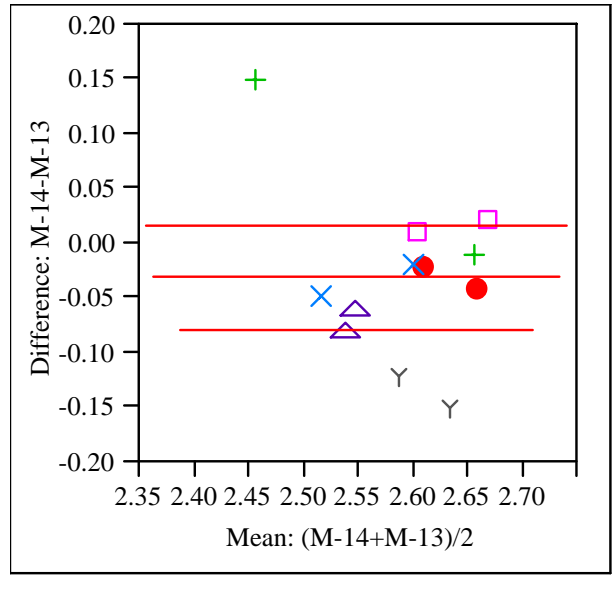

$\begin{array}{lrlr}\text { M-14 } & 2.575 & \text { t-Ratio } & -1.40588 \\ \text { M-13 } & 2.60583 & \text { DF } & 11 \\ \text { Mean Difference } & -0.0308 & \text { Prob > t } \mid & 0.1874 \\ \text { Std Error } & 0.02193 & \text { Prob }>\text { t } & 0.9063 \\ \text { Upper95\% } & 0.01744 & \text { Prob < t } & 0.0937 \\ \text { Lower95\% } & -0.0791 & & \\ \text { N } & 12 & & \\ \text { Correlation } & 0.51337 & & \end{array}$

Type/ Analyte/UoM=ARG-1/Ca/wt\% Matched Pairs

Difference: M-14-M-13

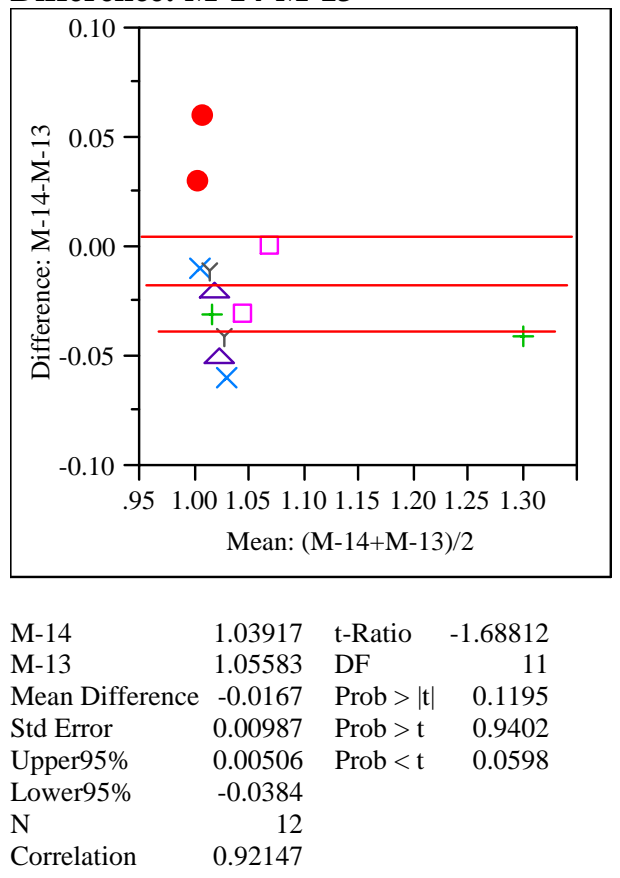

Type/ Analyte/UoM=ARG-1/Cr/wt \% Matched Pairs

Difference: M-14-M-13

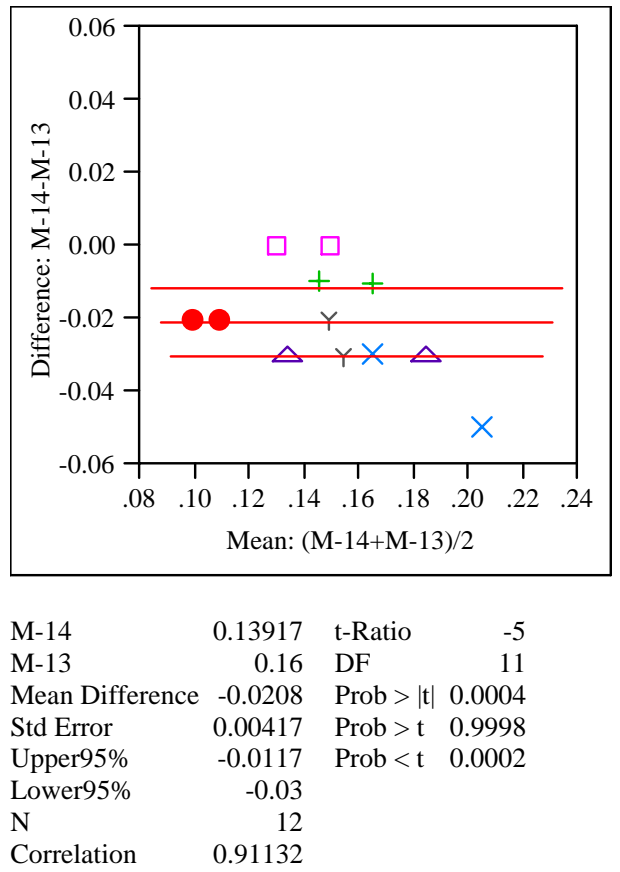


Exhibit A3. Initial Comparisons by SME Batch among M-13, M-14, and Prototypic Measurements for Each Element by Type of Sample after Screening

Type/ Analyte/UoM=ARG-1/Cu/wt\% Matched Pairs

Difference: M-14-M-13

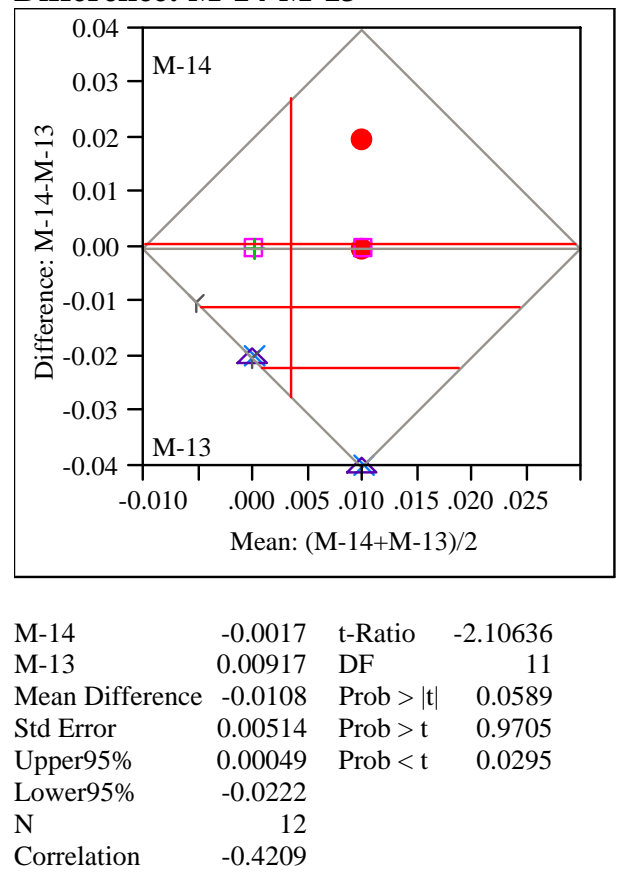

Type/ Analyte/UoM=ARG-1/Fe/wt \% Matched Pairs

Difference: M-14-M-13

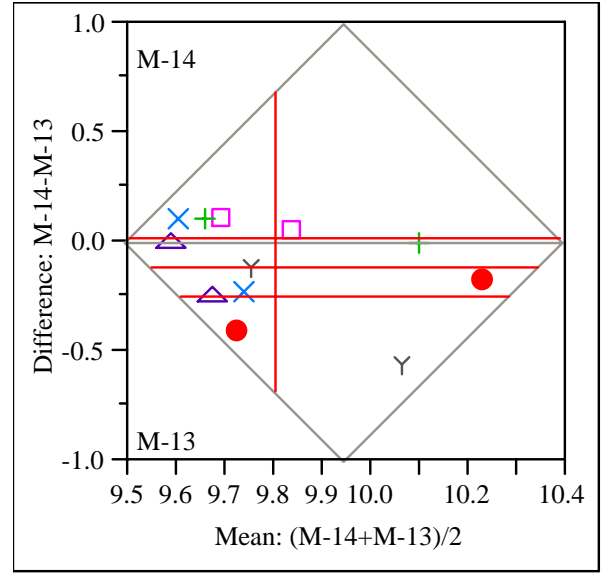

$\begin{array}{lrlr}\text { M-14 } & 9.75 & \text { t-Ratio } & -1.8619 \\ \text { M-13 } & 9.86583 & \text { DF } & 11 \\ \text { Mean Difference } & -0.1158 & \text { Prob }>|t| & 0.0895 \\ \text { Std Error } & 0.06221 & \text { Prob }>\text { t } & 0.9552 \\ \text { Upper95\% } & 0.0211 & \text { Prob }<\text { t } & 0.0448 \\ \text { Lower95\% } & -0.2528 & & \\ \text { N } & 12 & & \\ \text { Correlation } & 0.61238 & & \end{array}$

Type/ Analyte/UoM=ARG-1/K/wt \% Matched Pairs

Difference: M-14-M-13

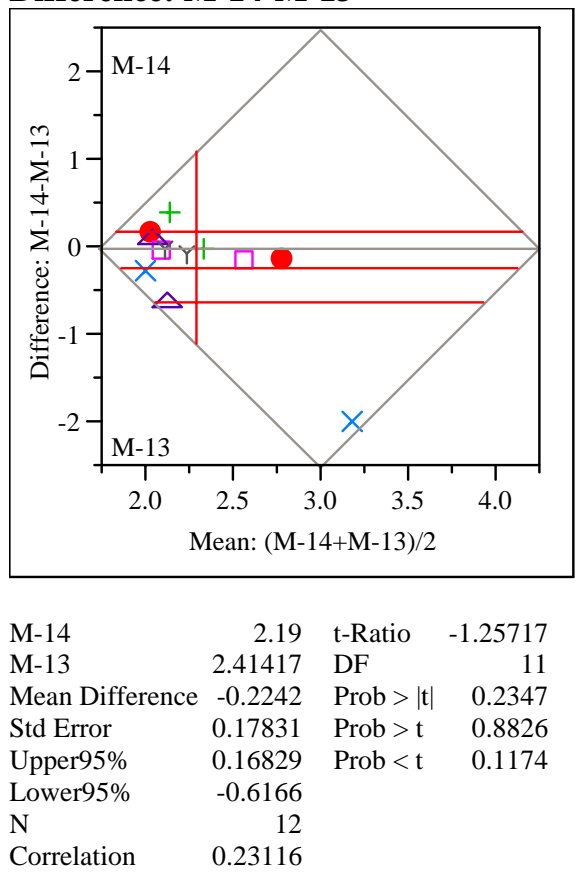

Type/ Analyte/UoM=ARG-1/Li/wt \% Matched Pairs

Difference: M-14-M-13

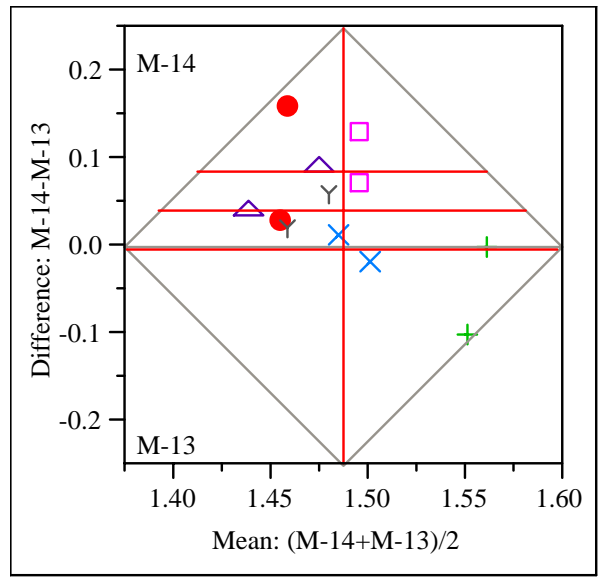

$\begin{array}{lrlr}\text { M-14 } & 1.50833 & \text { t-Ratio } & 2.047654 \\ \text { M-13 } & 1.4675 & \text { DF } & 11 \\ \text { Mean Difference } & 0.04083 & \text { Prob }>|t| & 0.0652 \\ \text { Std Error } & 0.01994 & \text { Prob }>\text { t } & 0.0326 \\ \text { Upper95\% } & 0.08472 & \text { Prob }<\text { t } & 0.9674 \\ \text { Lower95\% } & -0.0031 & & \\ \text { N } & 12 & & \\ \text { Correlation } & 0.05769 & & \end{array}$


Exhibit A3. Initial Comparisons by SME Batch among M-13, M-14, and Prototypic Measurements for Each Element by Type of Sample after Screening

Type/ Analyte/UoM=ARG-1/Mg/wt\% Matched Pairs

Difference: M-14-M-13

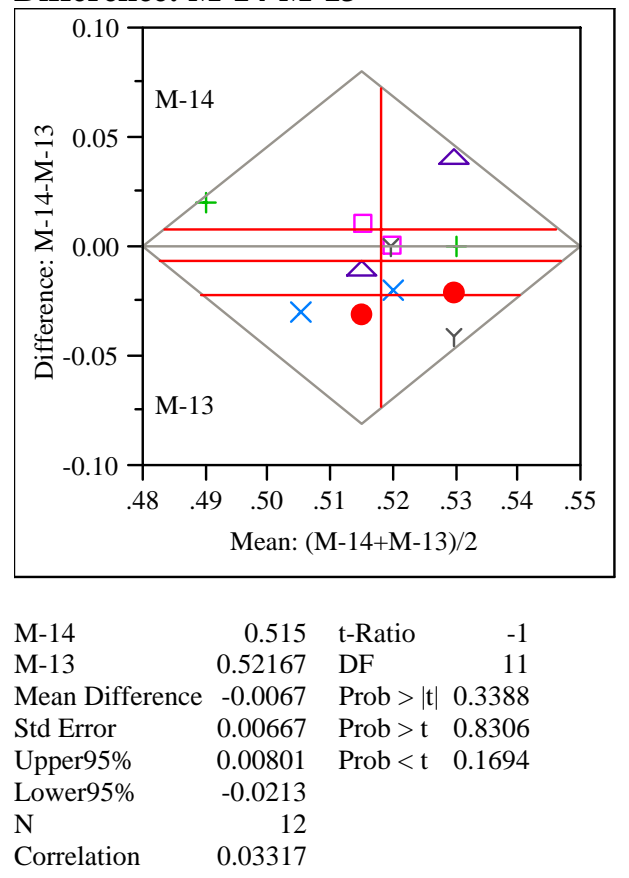

Type/ Analyte/UoM=ARG-1/Mn/wt\% Matched Pairs

Difference: M-14-M-13

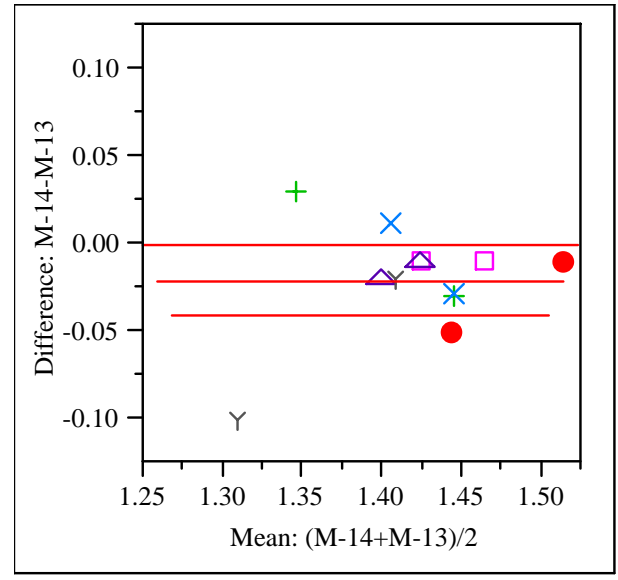

$\begin{array}{lrlr}\text { M-14 } & 1.40917 & \text { t-Ratio } & -2.25251 \\ \text { M-13 } & 1.43 & \text { DF } & 11 \\ \text { Mean Difference } & -0.0208 & \text { Prob }>|t| & 0.0457 \\ \text { Std Error } & 0.00925 & \text { Prob }>\text { t } & 0.9772 \\ \text { Upper95\% } & -0.0005 & \text { Prob }<\mathrm{t} & 0.0228 \\ \text { Lower95\% } & -0.0412 & & \\ \text { N } & 12 & & \\ \text { Correlation } & 0.84363 & & \end{array}$

Type/ Analyte/UoM=ARG-1/Na/wt \% Matched Pairs

Difference: M-14-M-13

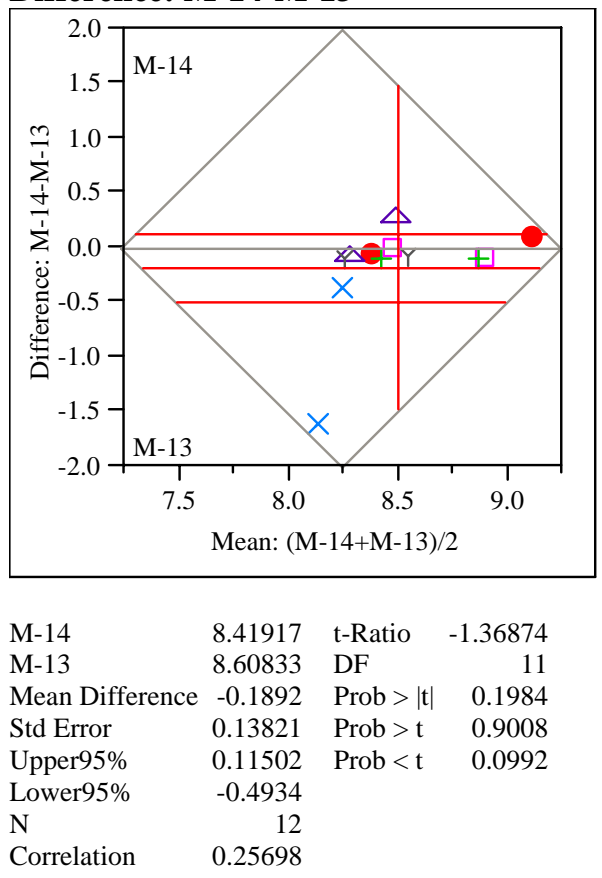

Type/ Analyte/UoM=ARG-1/Ni/wt \% Matched Pairs

Difference: M-14-M-13

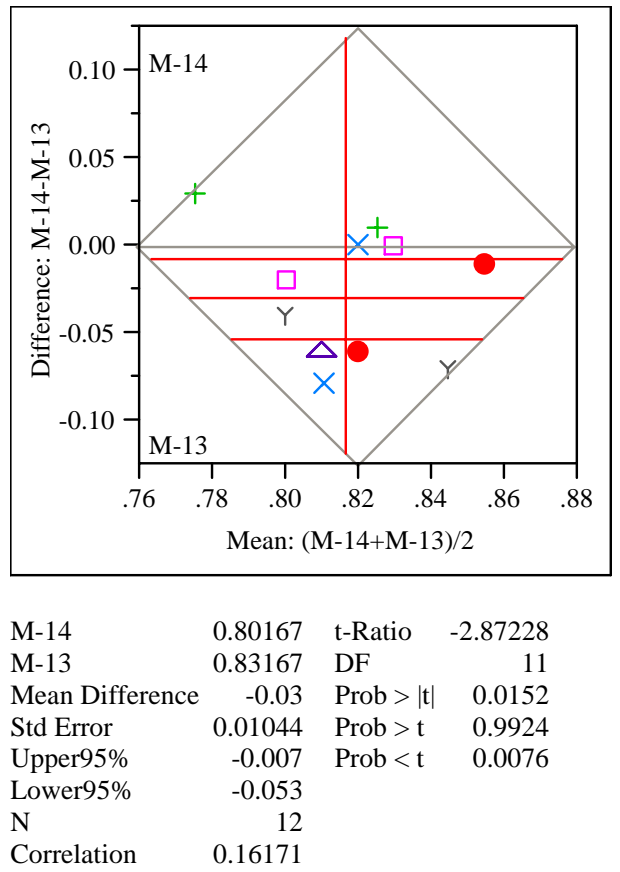


Exhibit A3. Initial Comparisons by SME Batch among M-13, M-14, and Prototypic Measurements for Each Element by Type of Sample after Screening

Type/ Analyte/UoM=ARG-1/Si/wt \% Matched Pairs

Difference: M-14-M-13

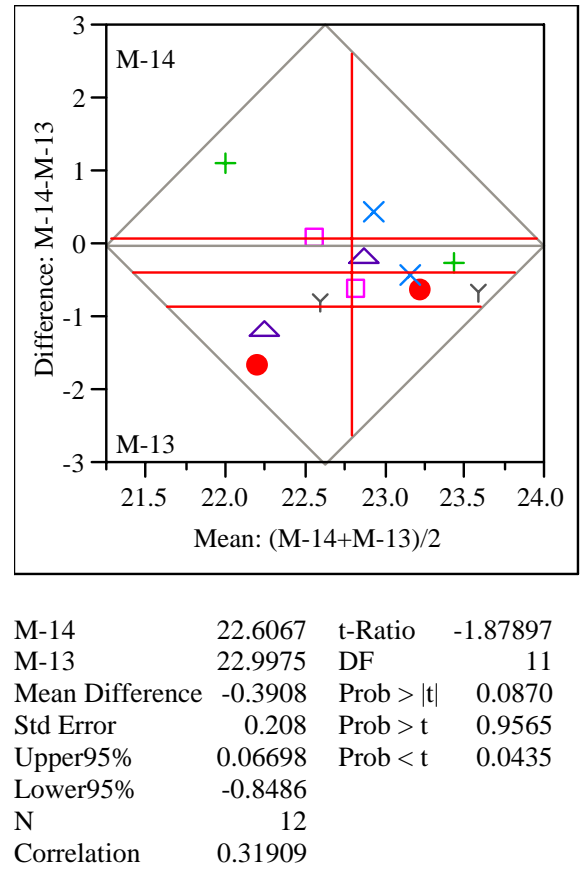

Type/ Analyte/UoM=ARG-1/Ti/wt \% Matched Pairs

Difference: M-14-M-13

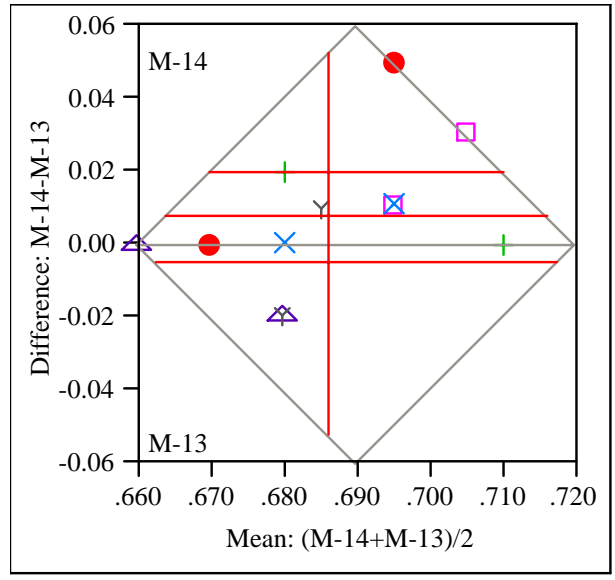

$\begin{array}{lrlr}\text { M-14 } & 0.69 & \text { t-Ratio } & 1.325668 \\ \text { M-13 } & 0.6825 & \text { DF } & 11 \\ \text { Mean Difference } & 0.0075 & \text { Prob > t } \mid & 0.2118 \\ \text { Std Error } & 0.00566 & \text { Prob }>\text { t } & 0.1059 \\ \text { Upper95\% } & 0.01995 & \text { Prob < t } & 0.8941 \\ \text { Lower95\% } & -0.005 & & \\ \text { N } & 12 & & \\ \text { Correlation } & 0.39318 & & \end{array}$

Type/ Analyte/UoM=ARG-1/U/wt\% Matched Pairs

Difference: M-14-M-13

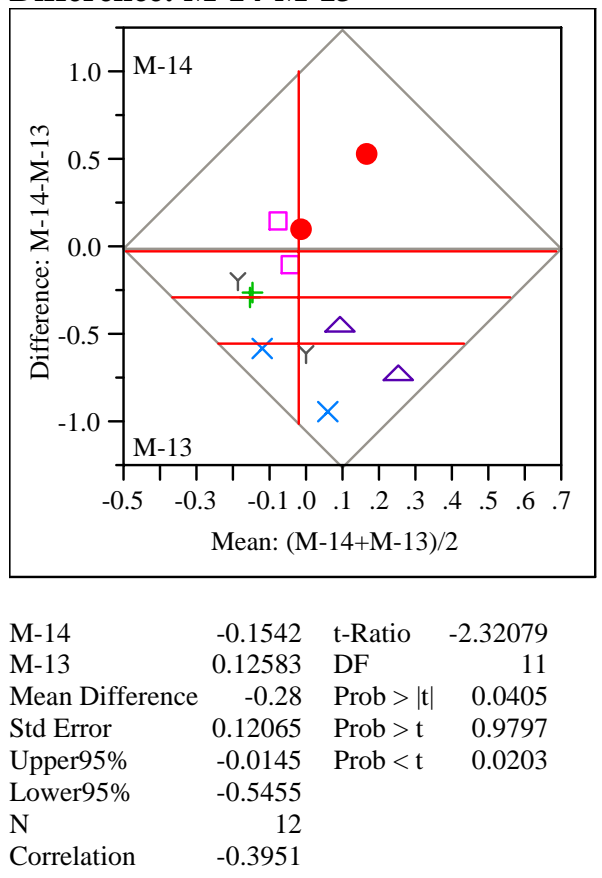

Type/ Analyte/UoM=ARG-1/Zr/wt \% Matched Pairs

Difference: M-14-M-13

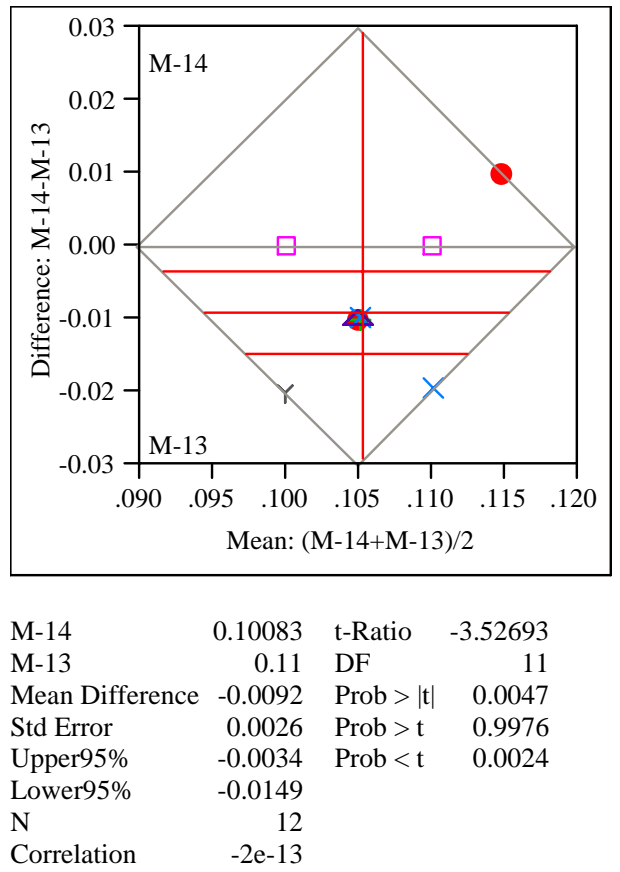


Exhibit A3. Initial Comparisons by SME Batch among M-13, M-14, and Prototypic Measurements for Each Element by Type of Sample after Screening

Type/ Analyte/UoM=SME/Al/wt \% Matched Pairs

Difference: M-14-M-13

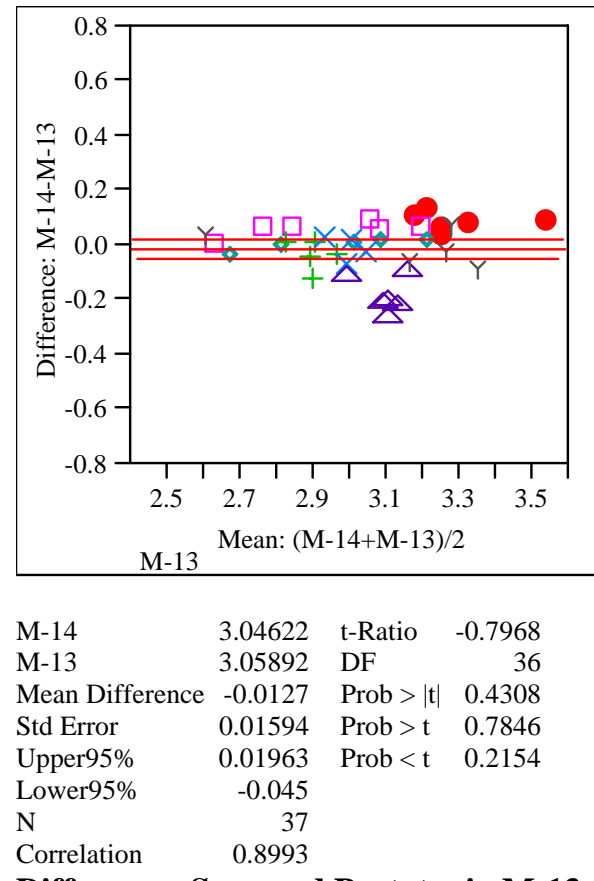

Difference: Screened Prototypic-M-13

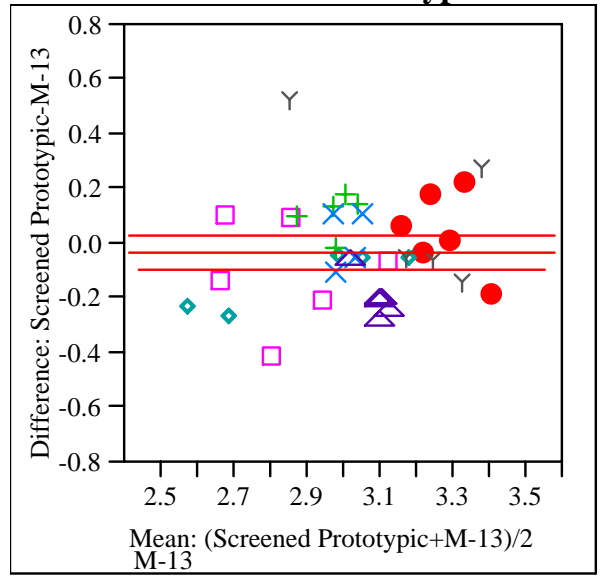

Screened Prototypic 3.03108 t-Ratio $\quad-0.91025$

M-13 3.05892 DF 36

Mean Difference $\quad-0.0278$ Prob $>|\mathrm{t}| \quad 0.3687$

$\begin{array}{llll}\text { Std Error } & 0.03058 & \text { Prob }>t & 0.8156\end{array}$

Upper95\% $\quad 0.03419$ Prob $<\mathrm{t} \quad 0.1844$

Lower95\% $\quad-0.0899$

$\mathrm{N} \quad 37$

Correlation $\quad 0.65749$
Difference: Screened Prototypic-M-14

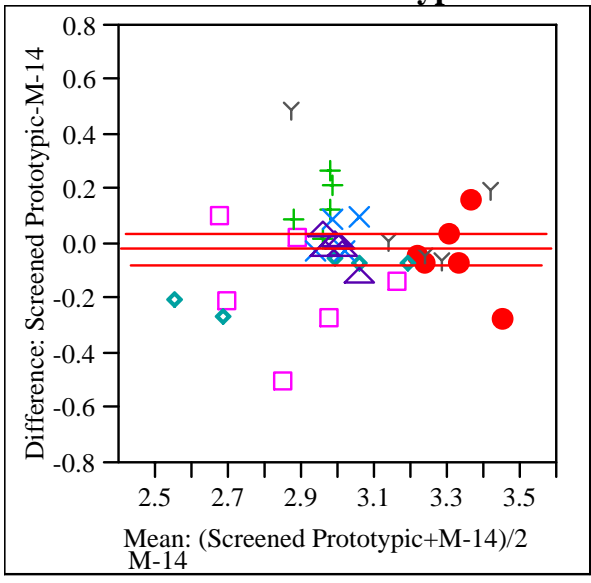

Screened Prototypic 3.03108 t-Ratio $\quad-0.53003$

M-14 3.04622 DF 36

Mean Difference $\quad-0.0151 \quad$ Prob $>|t| \quad 0.5993$

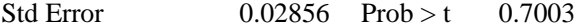

Upper95\% $\quad 0.04278$ Prob $<\mathrm{t} \quad 0.2997$

Lower95\% $\quad-0.073$

$\begin{array}{lr}\mathrm{N} & 37 \\ \text { Correlation } & 0.7086\end{array}$

Type/ Analyte/UoM=SME/B/wt \%

Matched Pairs

Difference: M-14-M-13

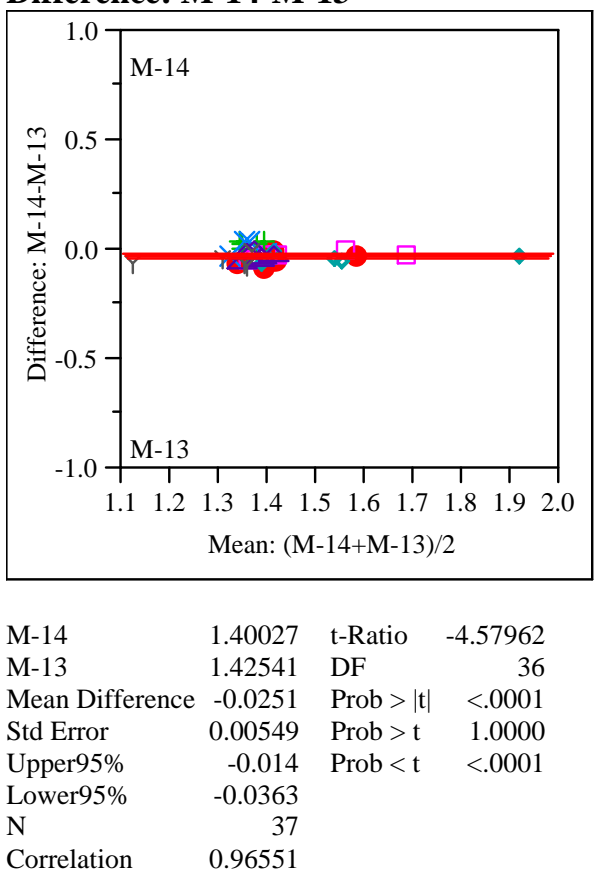


Exhibit A3. Initial Comparisons by SME Batch among M-13, M-14, and Prototypic Measurements for Each Element by Type of Sample after Screening

\section{Difference: Screened Prototypic-M-13}

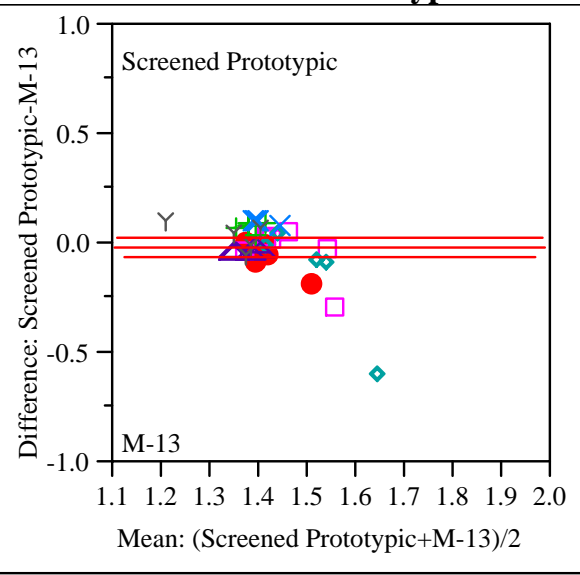

Screened Prototypic 1.40838 t-Ratio $\quad-0.8167$

M-13 1.42541 DF 36

Mean Difference $\quad-0.017$ Prob $>|t| \quad 0.4195$

Std Error $\quad 0.02085 \quad$ Prob $>$ t 0.7903

$\begin{array}{llll}\text { Upper95\% } & 0.02526 & \text { Prob }<\mathrm{t} & 0.2097\end{array}$

Lower95\% $\quad-0.0593$

$\mathrm{N}$

Correlation

0.22604

Difference: Screened Prototypic-M-14

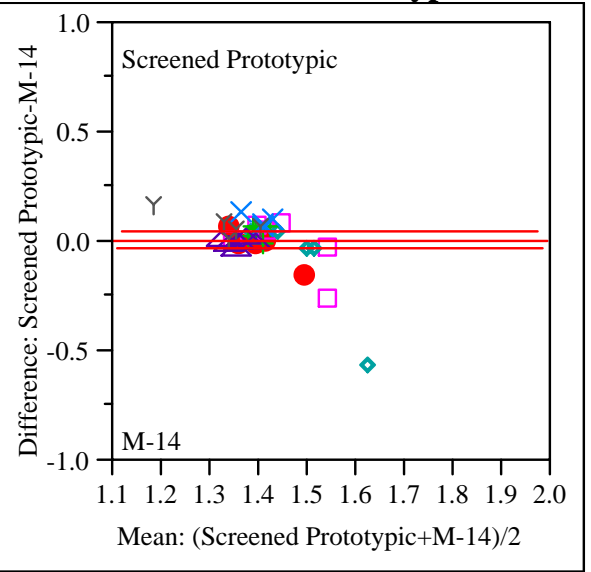

Screened Prototypic 1.40838 t-Ratio 0.407953

$\begin{array}{llll}\text { M-14 } & 1.40027 & \text { DF } & 36\end{array}$

Mean Difference $\quad 0.00811 \quad$ Prob $>|t| \quad 0.6857$

Std Error $\quad 0.01988 \quad$ Prob $>t \quad 0.3429$

Upper95\% $\quad 0.04842$ Prob $<\mathrm{t} \quad 0.6571$

Lower95\% $\quad-0.0322$

$\mathrm{N} \quad 37$

Correlation $\quad 0.32022$
Type/ Analyte/UoM=SME/Ca/wt \%

Matched Pairs

Difference: M-14-M-13

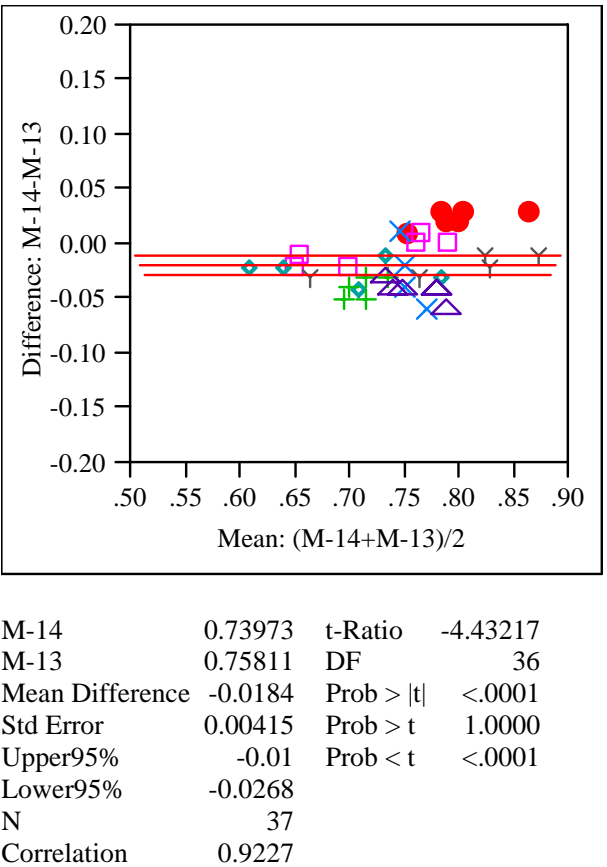

Difference: Screened Prototypic-M-13

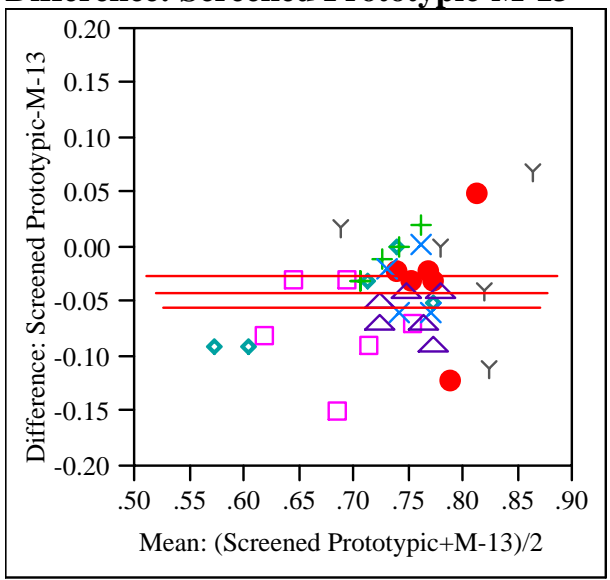

$\begin{array}{lrlr}\text { Screened Prototypic } & 0.71784 & \text { t-Ratio } & -5.35608 \\ \text { M-13 } & 0.75811 & \text { DF } & 36 \\ \text { Mean Difference } & -0.0403 & \text { Prob }>|t| & <.0001 \\ \text { Std Error } & 0.00752 & \text { Prob }>\text { t } & 1.0000 \\ \text { Upper95\% } & -0.025 & \text { Prob }<\text { t } & <.0001 \\ \text { Lower95\% } & -0.0555 & & \\ \text { N } & 37 & & \\ \text { Correlation } & 0.76431 & & \end{array}$


Exhibit A3. Initial Comparisons by SME Batch among M-13, M-14, and Prototypic Measurements for Each Element by Type of Sample after Screening

Difference: Screened Prototypic-M-14

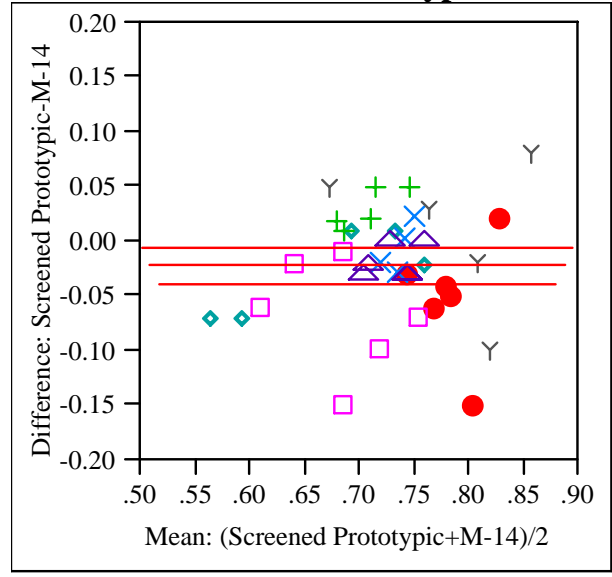

Screened Prototypic 0.71784 t-Ratio $\quad-2.5711$

M-14 0.73973 DF 36

Mean Difference $\quad-0.0219$ Prob $>|t| c 0.0144$

Std Error $\quad 0.00851 \quad$ Prob $>\mathrm{t} \quad 0.9928$

Upper95\% $\quad-0.0046$ Prob < $\quad 0.0072$

Lower95\% $\quad-0.0392$

$\mathrm{N}$

Correlation

0.71185

Type/ Analyte/UoM=SME/Cr/wt\%

Matched Pairs

Difference: M-14-M-13

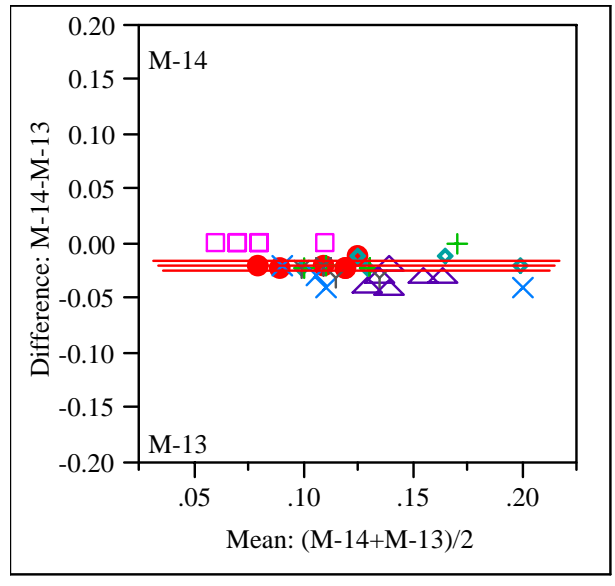

$\begin{array}{lrlr}\text { M-14 } & 0.10973 & \text { t-Ratio } & -9.64206 \\ \text { M-13 } & 0.12892 & \text { DF } & 36 \\ \text { Mean Difference } & -0.0192 & \text { Prob }>|t| & <.0001 \\ \text { Std Error } & 0.00199 & \text { Prob }>\text { t } & 1.0000 \\ \text { Upper95\% } & -0.0152 & \text { Prob }<\text { t } & <.0001 \\ \text { Lower95\% } & -0.0232 & & \\ \text { N } & 37 & & \\ \text { Correlation } & 0.94684 & & \end{array}$

\section{Difference: Screened Prototypic-M-13}

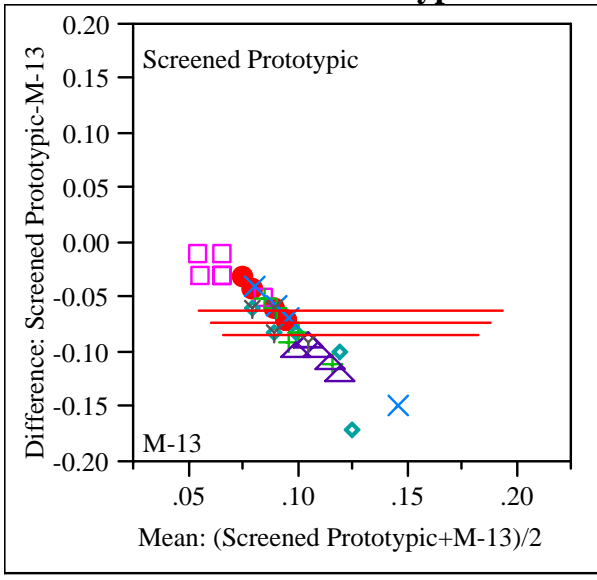

$\begin{array}{lrlr}\text { Screened Prototypic } & 0.05703 & \text { t-Ratio } & -12.5704 \\ \text { M-13 } & 0.12892 & \text { DF } & 36 \\ \text { Mean Difference } & -0.0719 & \text { Prob }>|t| & <.0001 \\ \text { Std Error } & 0.00572 & \text { Prob }>\text { t } & 1.0000 \\ \text { Upper95\% } & -0.0603 & \text { Prob }<\text { t } & <.0001 \\ \text { Lower95\% } & -0.0835 & & \\ \text { N } & 37 & & \\ \text { Correlation } & 0.29969 & & \end{array}$

\section{Difference: Screened Prototypic-M-14}

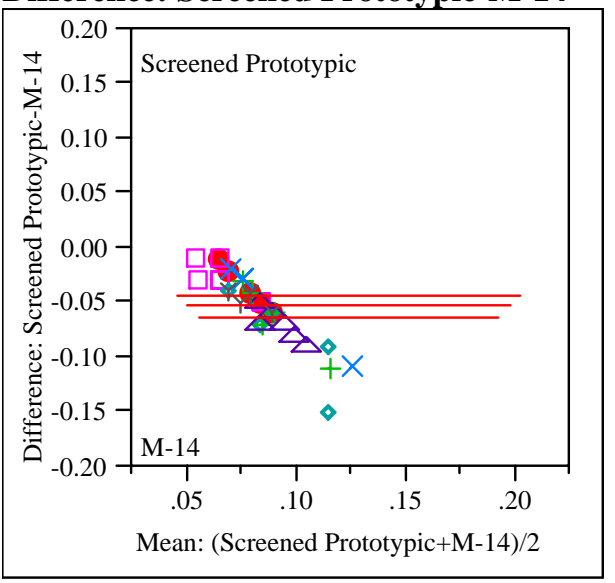

$\begin{array}{lrlr}\text { Screened Prototypic } & 0.05703 & \text { t-Ratio } & -10.632 \\ \text { M-14 } & 0.10973 & \text { DF } & 36 \\ \text { Mean Difference } & -0.0527 & \text { Prob }>|t| & <.0001 \\ \text { Std Error } & 0.00496 & \text { Prob }>\text { t } & 1.0000 \\ \text { Upper95\% } & -0.0426 & \text { Prob }<\text { t } & <.0001 \\ \text { Lower95\% } & -0.0628 & & \\ \text { N } & 37 & & \\ \text { Correlation } & 0.22674 & & \end{array}$


Exhibit A3. Initial Comparisons by SME Batch among M-13, M-14, and Prototypic Measurements for Each Element by Type of Sample after Screening

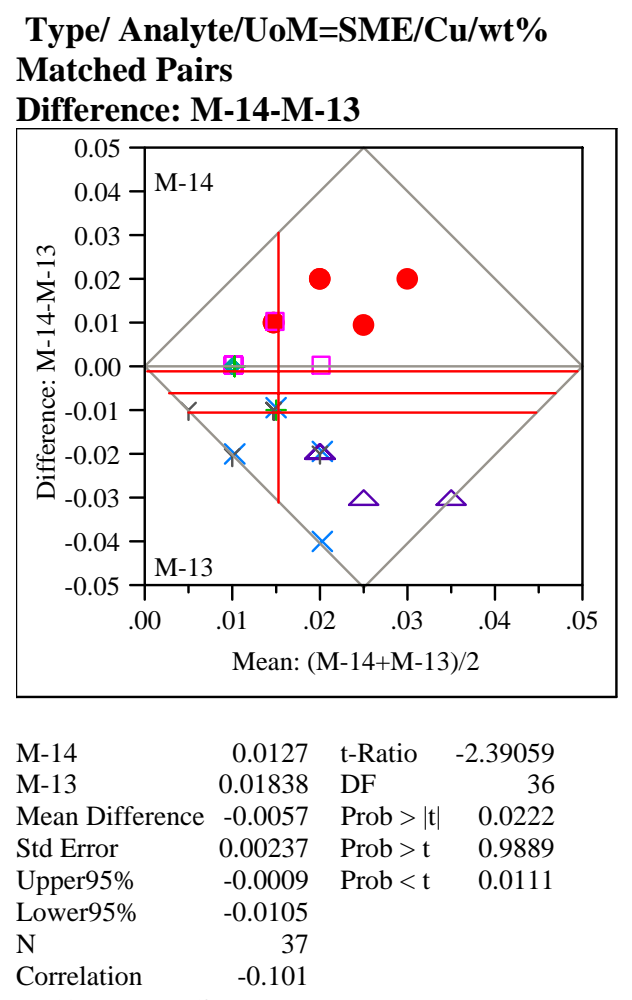

Difference: Screened Prototypic-M-13

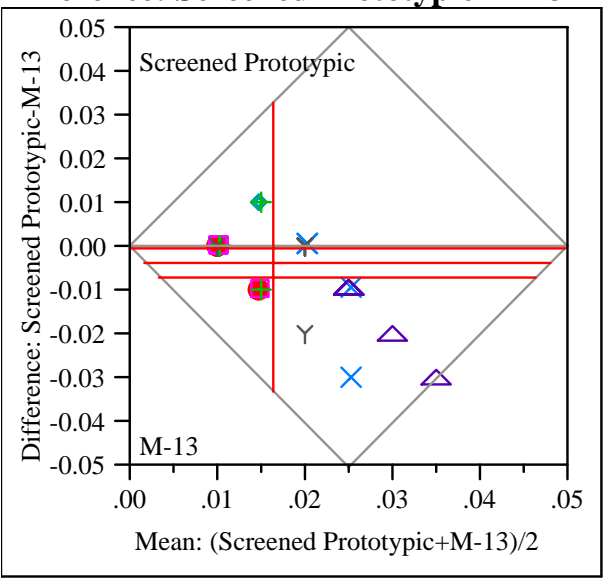

$\begin{array}{lrlr}\text { Screened Prototypic } & 0.01486 & \text { t-Ratio } & -2.12447 \\ \text { M-13 } & 0.01838 & \text { DF } & 36 \\ \text { Mean Difference } & -0.0035 & \text { Prob }>|t| & 0.0406 \\ \text { Std Error } & 0.00165 & \text { Prob }>\text { t } & 0.9797 \\ \text { Upper95\% } & -0.0002 & \text { Prob }<\text { t } & 0.0203 \\ \text { Lower95\% } & -0.0069 & & \\ \text { N } & 37 & & \\ \text { Correlation } & 0.3553 & & \end{array}$

\section{Difference: Screened Prototypic-M-14}

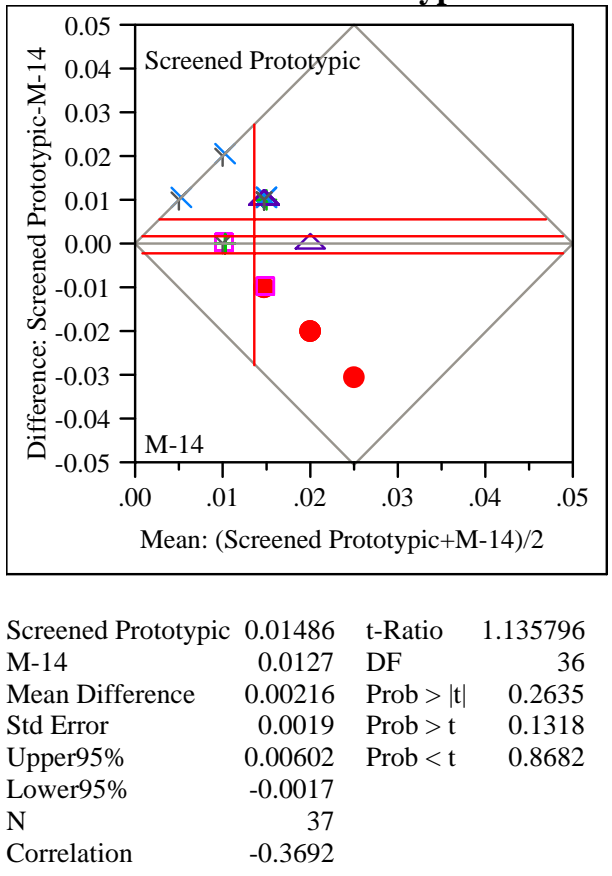

Type/ Analyte/UoM=SME/Fe/wt \% Matched Pairs

Difference: M-14-M-13

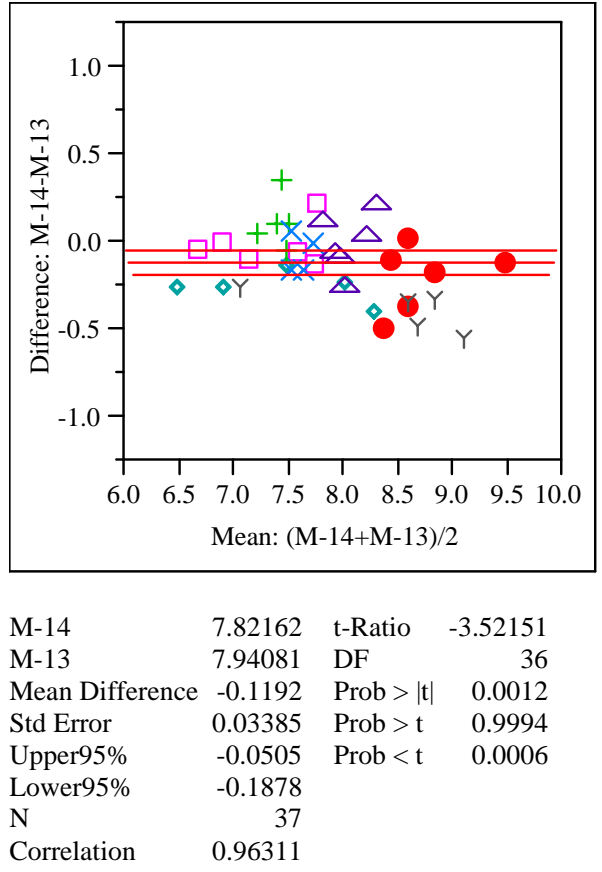


Exhibit A3. Initial Comparisons by SME Batch among M-13, M-14, and Prototypic Measurements for Each Element by Type of Sample after Screening

\section{Difference: Screened Prototypic-M-13}

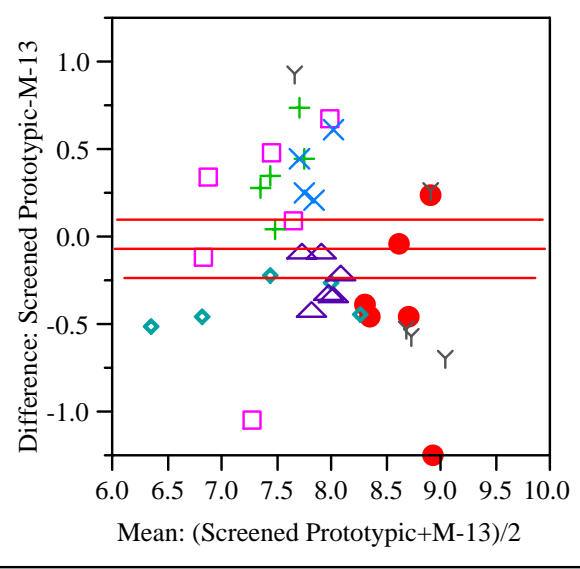

Screened Prototypic 7.87622 t-Ratio $\quad-0.79438$

M-13 7.94081 DF 36

Mean Difference $\quad-0.0646$ Prob $>|t| \quad 0.4322$

Std Error $\quad 0.08131 \quad$ Prob $>\mathrm{t} \quad 0.7839$

Upper95\% $\quad 0.10032$ Prob $<\mathrm{t} \quad 0.2161$

Lower95\% $\quad-0.2295$

$\mathrm{N}$

Correlation

0.75493

\section{Difference: Screened Prototypic-M-14}

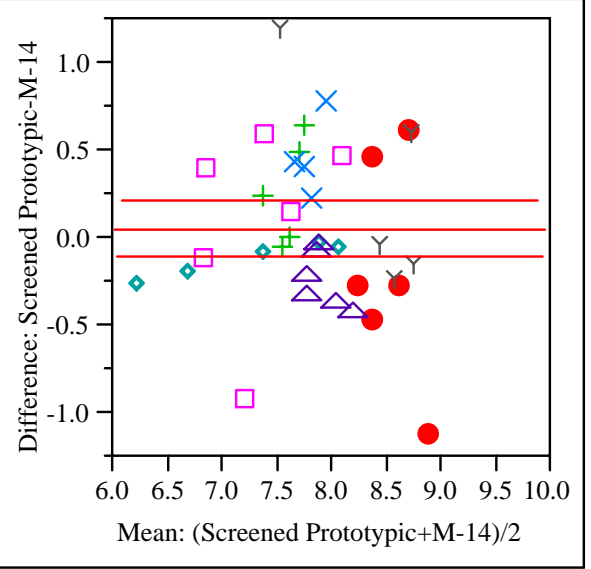

Screened Prototypic 7.87622 t-Ratio 0.709394

M-14 7.82162 DF 36

Mean Difference 0.05459 Prob $>|\mathrm{t}| \quad 0.4826$

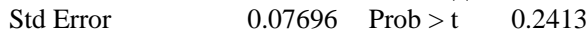

$\begin{array}{llll}\text { Upper95\% } & 0.21068 & \text { Prob }<\mathrm{t} & 0.7587\end{array}$

Lower95\% $\quad-0.1015$

$\mathrm{N}$

-0.1015
37

Correlation

0.74557

\section{Type/ Analyte/UoM=SME/K/wt \% Matched Pairs \\ Difference: M-14-M-13}

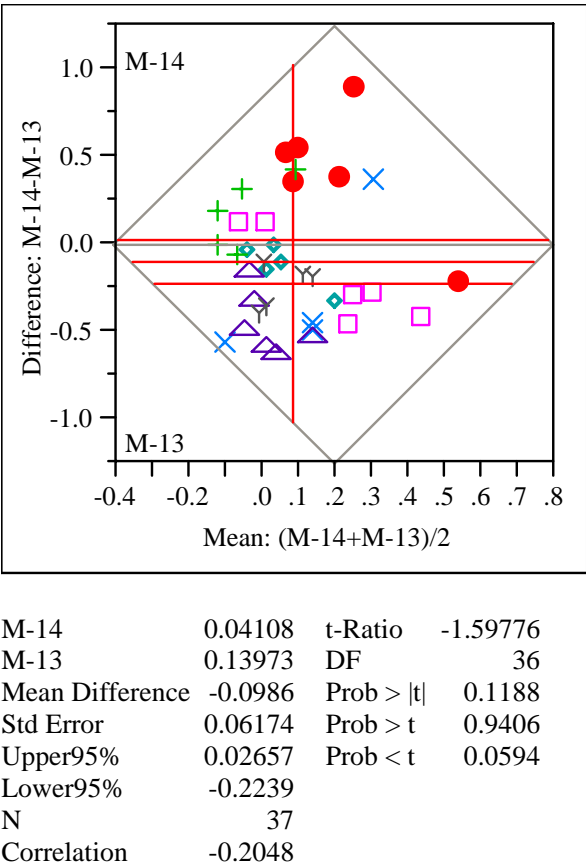

Difference: Screened Prototypic-M-13

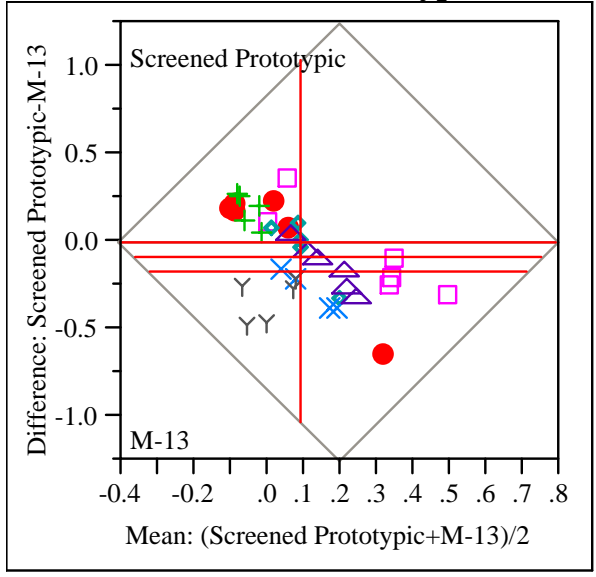

$\begin{array}{lrlr}\text { Screened Prototypic } & 0.05162 & \text { t-Ratio } & -2.14885 \\ \text { M-13 } & 0.13973 & \text { DF } & 36 \\ \text { Mean Difference } & -0.0881 & \text { Prob > t } \mid & 0.0384 \\ \text { Std Error } & 0.041 & \text { Prob }>\text { t } & 0.9808 \\ \text { Upper95\% } & -0.005 & \text { Prob < t } & 0.0192 \\ \text { Lower95\% } & -0.1713 & & \\ \text { N } & 37 & & \\ \text { Correlation } & 0.19903 & & \end{array}$


Exhibit A3. Initial Comparisons by SME Batch among M-13, M-14, and Prototypic Measurements for Each Element by Type of Sample after Screening

\section{Difference: Screened Prototypic-M-14}

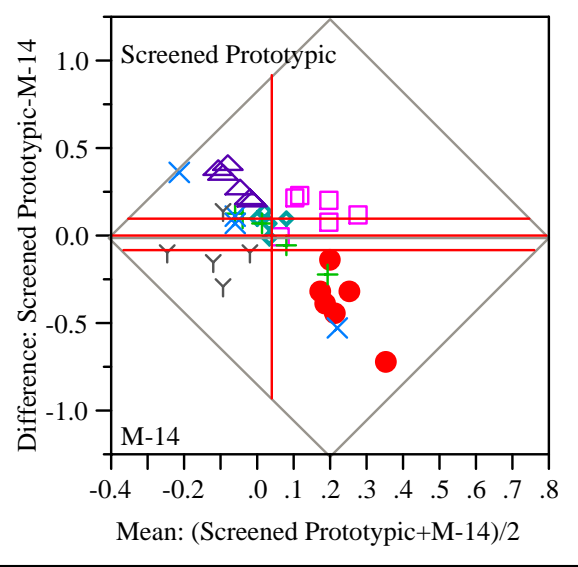

Screened Prototypic 0.05162 t-Ratio 0.243439

M-14 0.04108 DF 36

Mean Difference $\quad 0.01054$ Prob $>|t| \quad 0.8090$

Std Error $\quad 0.0433 \quad$ Prob $>$ t $\quad 0.4045$

Upper95\% $\quad 0.09835$ Prob $<\mathrm{t} \quad 0.5955$

Lower95\% $\quad-0.0773$

$\mathrm{N}$

Correlation

0.0948

\section{Type/ Analyte/UoM=SME/Li/wt \%}

Matched Pairs

Difference: M-14-M-13

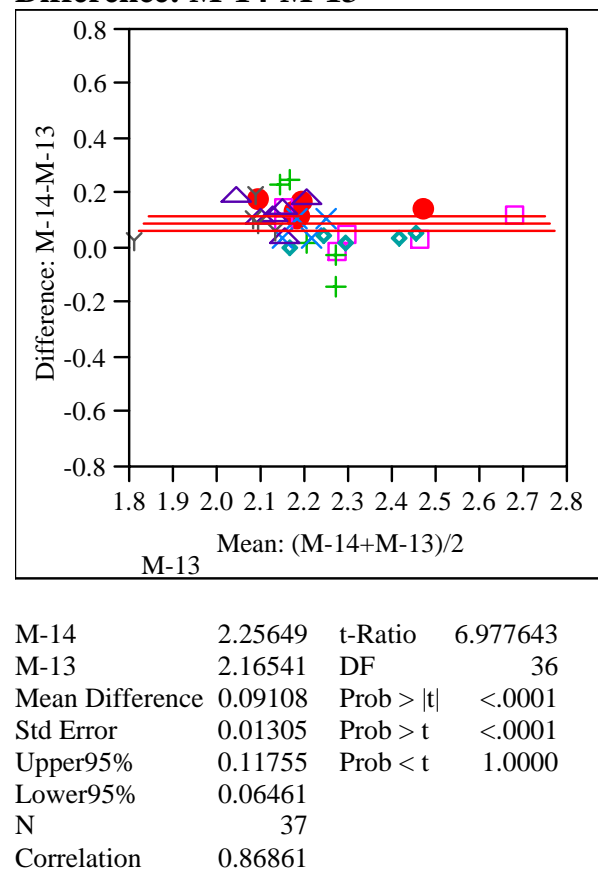

Difference: Screened Prototypic-M-13

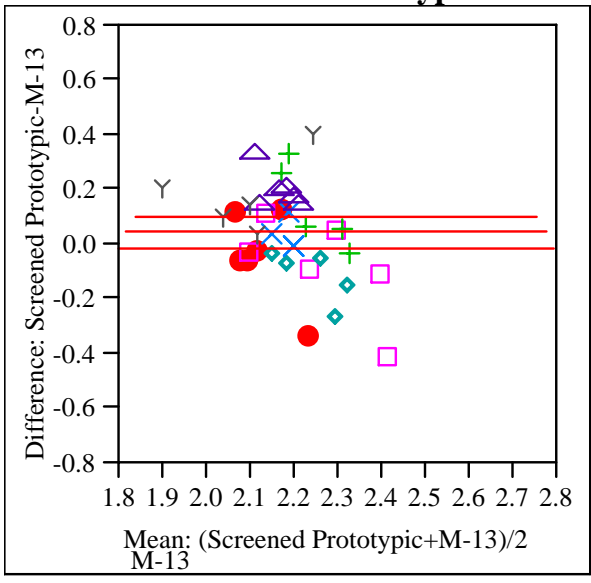

Screened Prototypic 2.21027 t-Ratio 1.575803

M-13

2.16541 DF

0.04486 Prob $>|\mathrm{t}| \quad 0.1238$

0.02847 Prob $>\mathrm{t} \quad 0.0619$

Std Error

Upper95\%

0.9381

Lower95\%

$-0.0129$

$\mathrm{N}$

Correlation

0.16539

\section{Difference: Screened Prototypic-M-14}

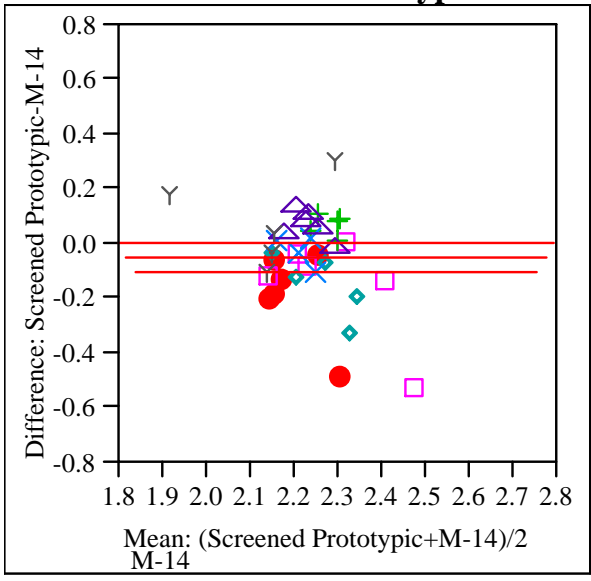

Screened Prototypic 2.21027 t-Ratio -1.72613

M-14

2.25649

$-0.0462$

0.02677

Std Error

0.00808

$-0.1005$

Lower95\%

37

Correlation $\quad 0.14722$
DF 36

Prob $>|t| \quad 0.0929$

$\begin{array}{ll}\text { Prob }>t & 0.9536 \\ \text { Prob }<\mathrm{t} & 0.0464\end{array}$ 
Exhibit A3. Initial Comparisons by SME Batch among M-13, M-14, and Prototypic Measurements for Each Element by Type of Sample after Screening

Type/ Analyte/UoM=SME/Mg/wt \% Matched Pairs

Difference: M-14-M-13

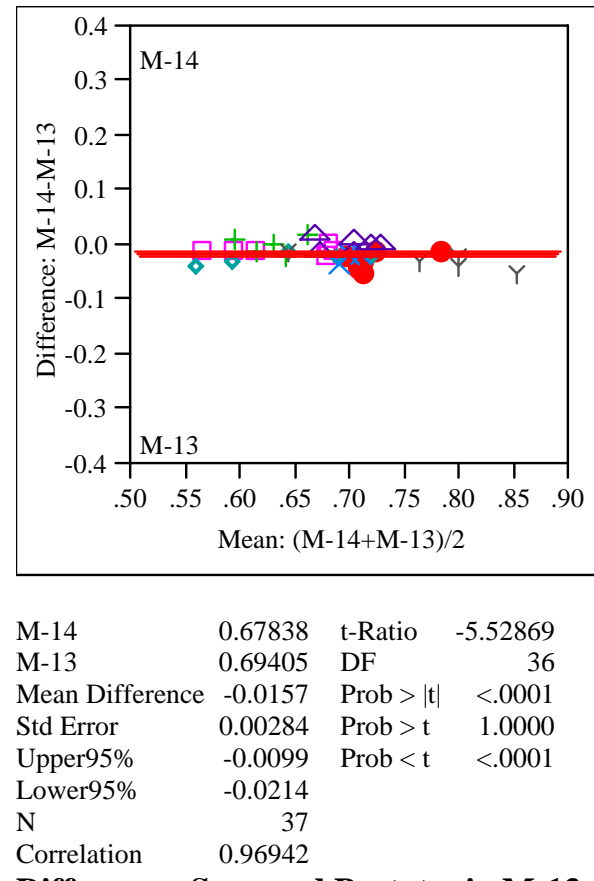

Difference: Screened Prototypic-M-13

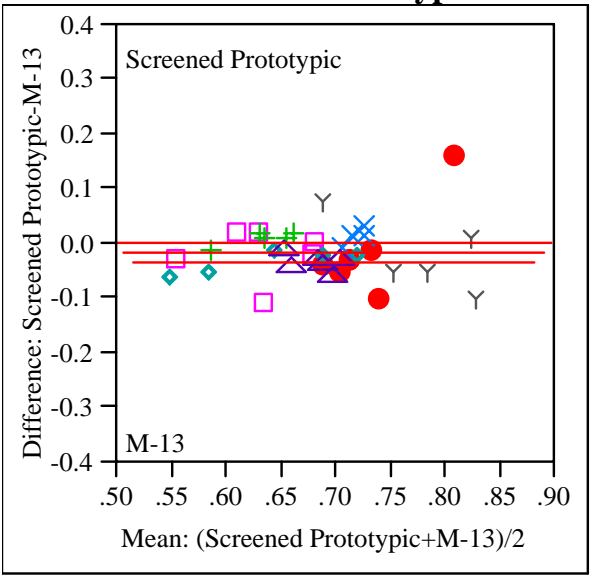

Screened Prototypic 0.67838 t-Ratio $\quad-1.95877$

M-13 0.69405 DF 36

Mean Difference $\quad-0.0157$ Prob $>|t| \quad 0.0579$

Std Error

Upper95\%

Lower95\%

$\mathrm{N}$

Correlation

0.00055 Prob $<\mathrm{t} \quad 0.0290$

$-0.0319$

37

0.76727

\section{Difference: Screened Prototypic-M-14}

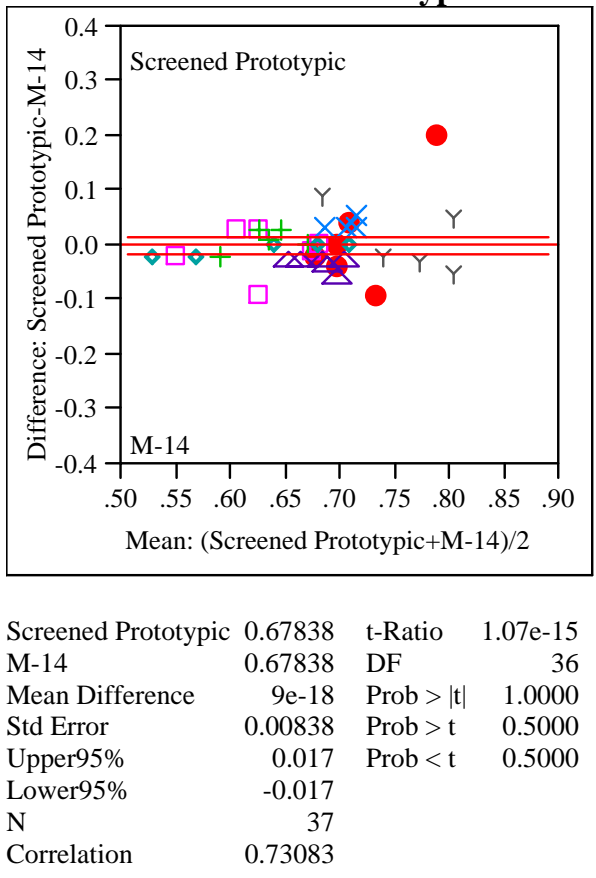

Type/ Analyte/UoM=SME/Mn/wt\% Matched Pairs

Difference: M-14-M-13

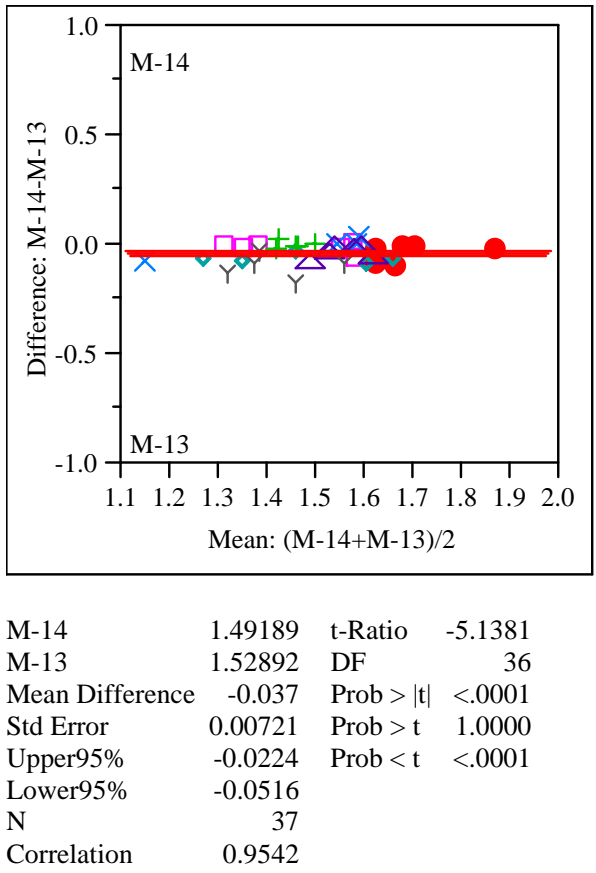


Exhibit A3. Initial Comparisons by SME Batch among M-13, M-14, and Prototypic Measurements for Each Element by Type of Sample after Screening

\section{Difference: Screened Prototypic-M-13}

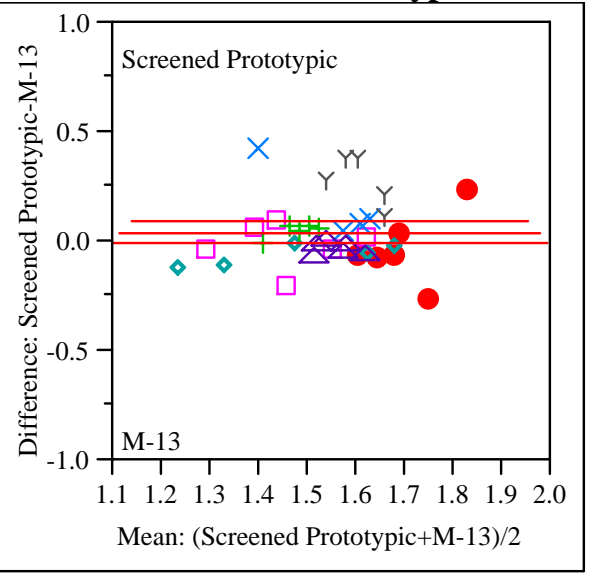

Screened Prototypic 1.56811 t-Ratio 1.583652

M-13 1.52892 DF 36

Mean Difference $\quad 0.03919$ Prob $>|t| \quad 0.1220$

Std Error $\quad 0.02475$ Prob $>\mathrm{t} \quad 0.0610$

Upper95\% $\quad 0.08938$ Prob $<\mathrm{t} \quad 0.9390$

Lower95\%

$\mathrm{N}$

Correlation

$-0.011$

0.46826

\section{Difference: Screened Prototypic-M-14}

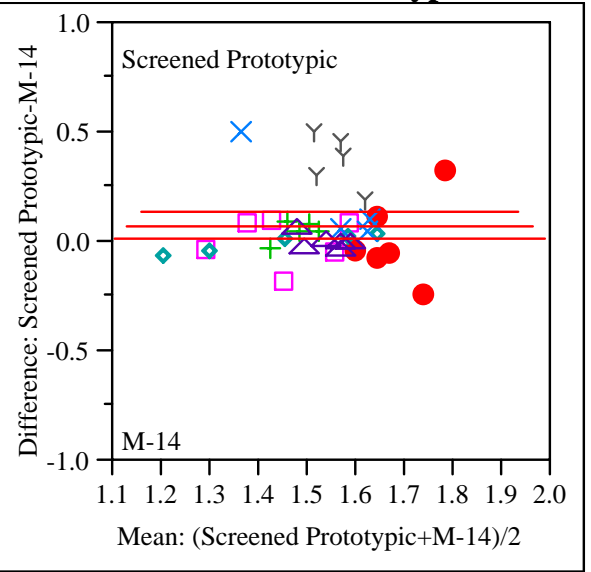

Screened Prototypic 1.56811 t-Ratio 2.663012

M-14 1.49189 DF 36

Mean Difference $\quad 0.07622$ Prob $>|\mathrm{t}| \quad 0.0115$

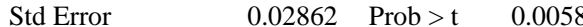

Upper95\% $\quad 0.13426 \quad$ Prob $<\mathrm{t} \quad 0.9942$

Lower95\% $\quad 0.01817$

$\mathrm{N}$

Correlation
Type/ Analyte/UoM=SME/Na/wt \%

Matched Pairs

Difference: M-14-M-13

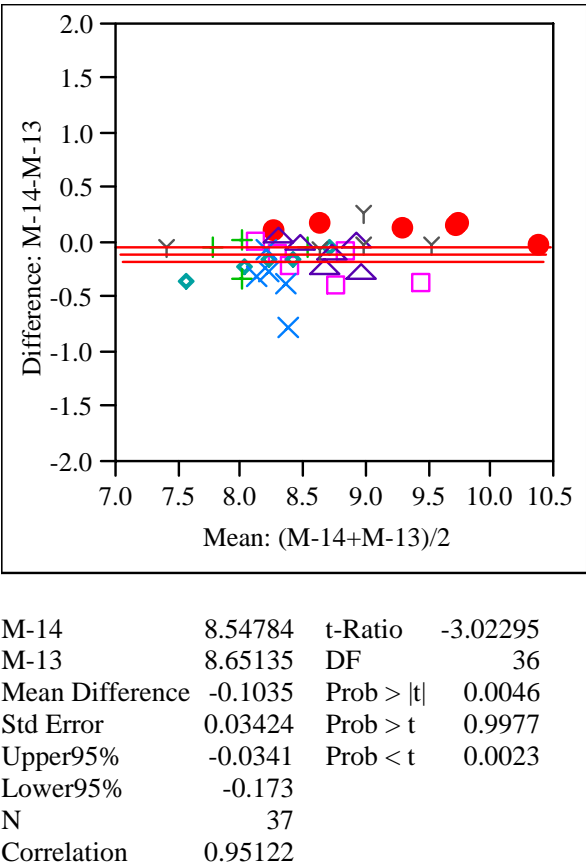

Difference: Screened Prototypic-M-13

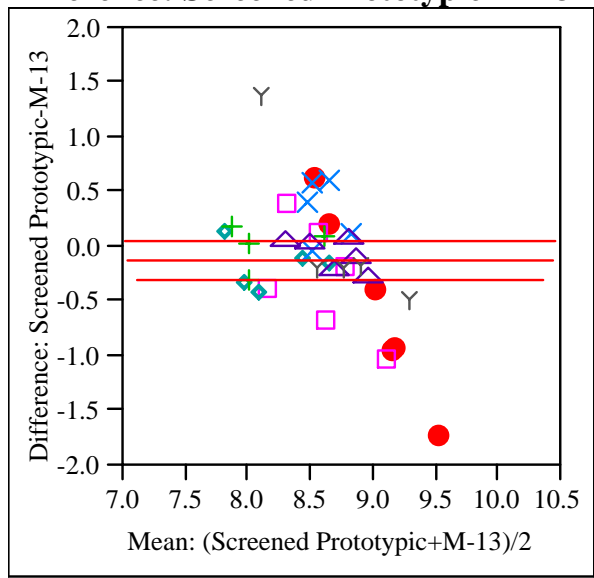

$\begin{array}{lrlr}\text { Screened Prototypic } & 8.53784 & \text { t-Ratio } & -1.2854 \\ \text { M-13 } & 8.65135 & \text { DF } & 36 \\ \text { Mean Difference } & -0.1135 & \text { Prob > t } \mid & 0.2069 \\ \text { Std Error } & 0.08831 & \text { Prob }>\text { t } & 0.8966 \\ \text { Upper95\% } & 0.06559 & \text { Prob < t } & 0.1034 \\ \text { Lower95\% } & -0.2926 & & \\ \text { N } & 37 & & \\ \text { Correlation } & 0.46972 & & \end{array}$


Exhibit A3. Initial Comparisons by SME Batch among M-13, M-14, and Prototypic Measurements for Each Element by Type of Sample after Screening

\section{Difference: Screened Prototypic-M-14}

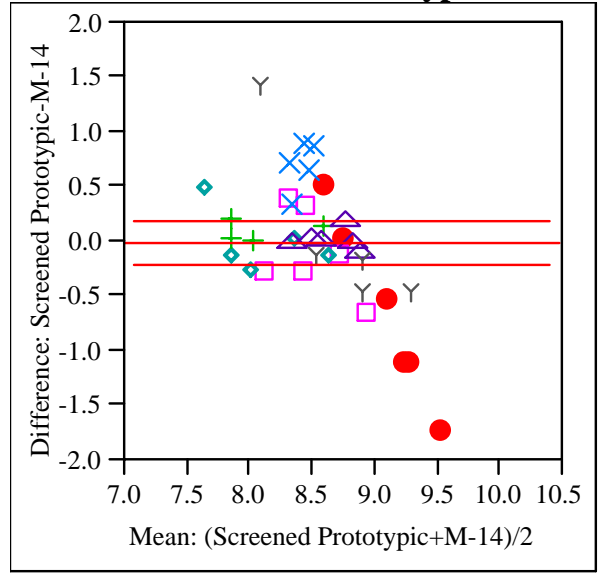

Screened Prototypic 8.53784 t-Ratio $\quad-0.104$

M-14

Mean Difference

Std Error

Upper95\%

Lower95\%

$\mathrm{N}$

Correlation

8.54784 DF

-0.01 Prob $>|\mathrm{t}| \quad 0.9177$

0.09616 Prob $>$ t 0.5411

0.18502 Prob $<\mathrm{t} \quad 0.4589$

$-0.205$

0.48363

Type/ Analyte/UoM=SME/Ni/wt \%

Matched Pairs

Difference: M-14-M-13

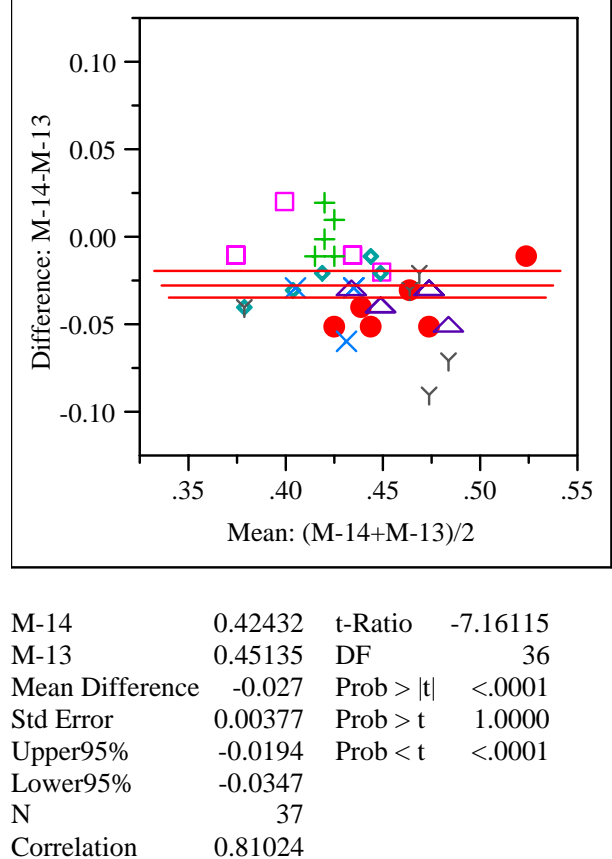

Correlation $\quad 0.81024$
Difference: Screened Prototypic-M-13

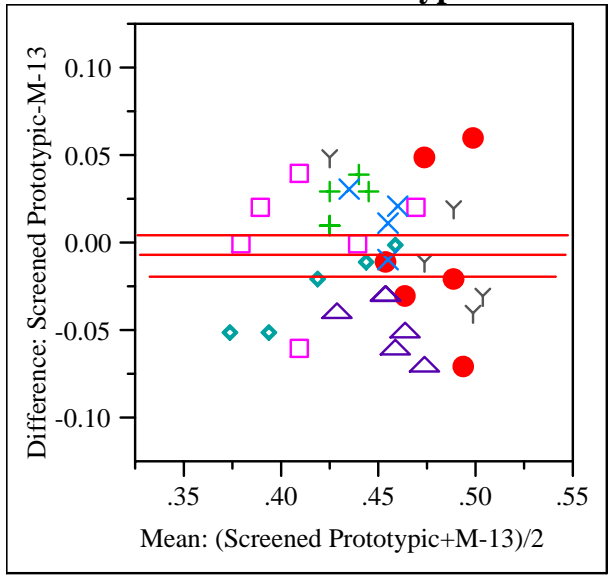

$\begin{array}{lrlr}\text { Screened Prototypic } & 0.44459 & \text { t-Ratio } & -1.13493 \\ \text { M-13 } & 0.45135 & \text { DF } & 36 \\ \text { Mean Difference } & -0.0068 & \text { Prob }>|t| & 0.2639 \\ \text { Std Error } & 0.00595 & \text { Prob }>\text { t } & 0.8680 \\ \text { Upper95\% } & 0.00532 & \text { Prob }<\text { t } & 0.1320 \\ \text { Lower95\% } & -0.0188 & & \\ \text { N } & 37 & & \\ \text { Correlation } & 0.55252 & & \end{array}$

Difference: Screened Prototypic-M-14

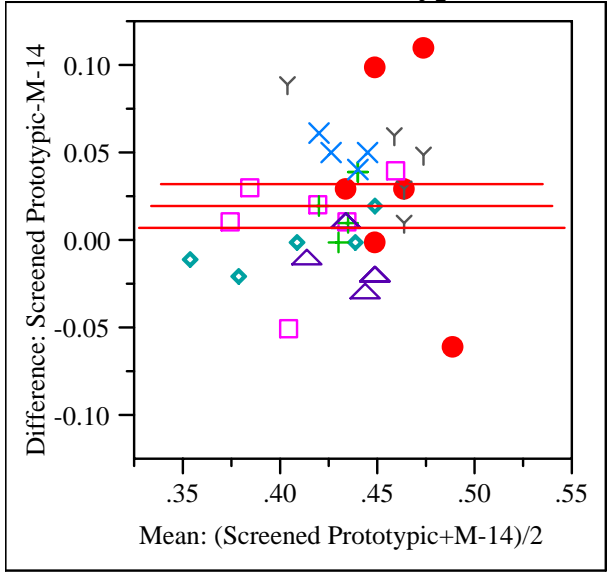

Screened Prototypic 0.44459 t-Ratio 3.311869

M-14

0.42432

0.02027

0.00612

0.03268

0.00786

Upper95\%

Lower95\%

$\mathrm{N}$

Correlation
DF 36

Prob $>|t| \quad 0.0021$

Prob $>t \quad 0.0011$

Prob $<\mathrm{t} \quad 0.9989$ 
Exhibit A3. Initial Comparisons by SME Batch among M-13, M-14, and Prototypic Measurements for Each Element by Type of Sample after Screening

Type/ Analyte/UoM=SME/Si/wt \% Matched Pairs

Difference: M-14-M-13

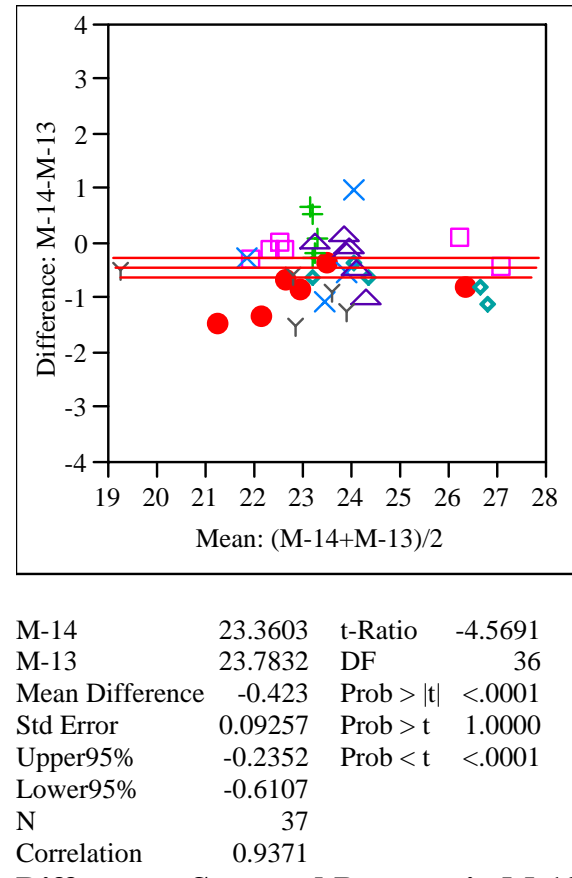

Difference: Screened Prototypic-M-13

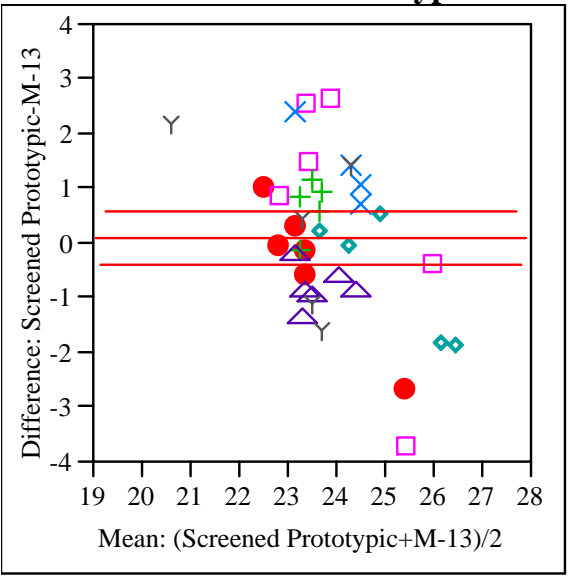

Screened Prototypic 23.8995 t-Ratio 0.494498

$\begin{array}{llll}\text { M-13 } 23.7832 & \text { DF } & 36\end{array}$

Mean Difference 0.11622 Prob $>|t| \quad 0.6240$

$\begin{array}{llll}\text { Std Error } & 0.23502 & \text { Prob }>t & 0.3120\end{array}$

Upper95\% $\quad 0.59286$ Prob $<\mathrm{t} \quad 0.6880$

Lower95\% $\quad-0.3604$

$\mathrm{N}$

Correlation

0.45891
Difference: Screened Prototypic-M-14

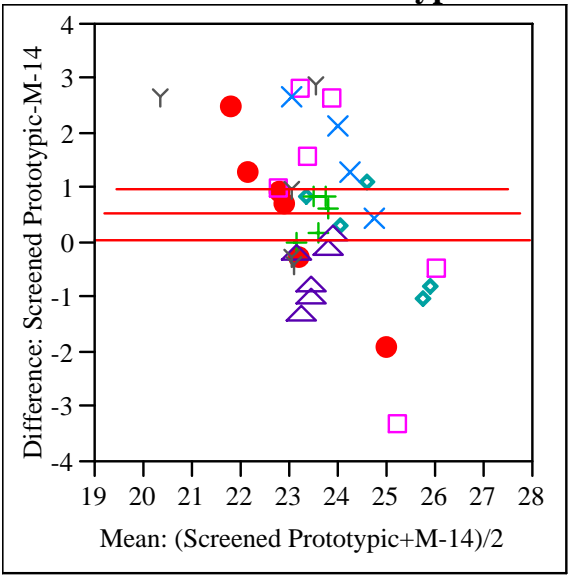

$\begin{array}{lrlr}\text { Screened Prototypic } & 23.8995 & \text { t-Ratio } & 2.336089 \\ \text { M-14 } & 23.3603 & \text { DF } & 36 \\ \text { Mean Difference } & 0.53919 & \text { Prob }>|t| & 0.0252 \\ \text { Std Error } & 0.23081 & \text { Prob }>\text { t } & 0.0126 \\ \text { Upper95\% } & 1.00729 & \text { Prob }<\mathrm{t} & 0.9874 \\ \text { Lower95\% } & 0.07109 & & \\ \text { N } & 37 & & \\ \text { Correlation } & 0.47716 & & \end{array}$

Type/ Analyte/UoM=SME/Ti/wt \%

Matched Pairs

Difference: M-14-M-13

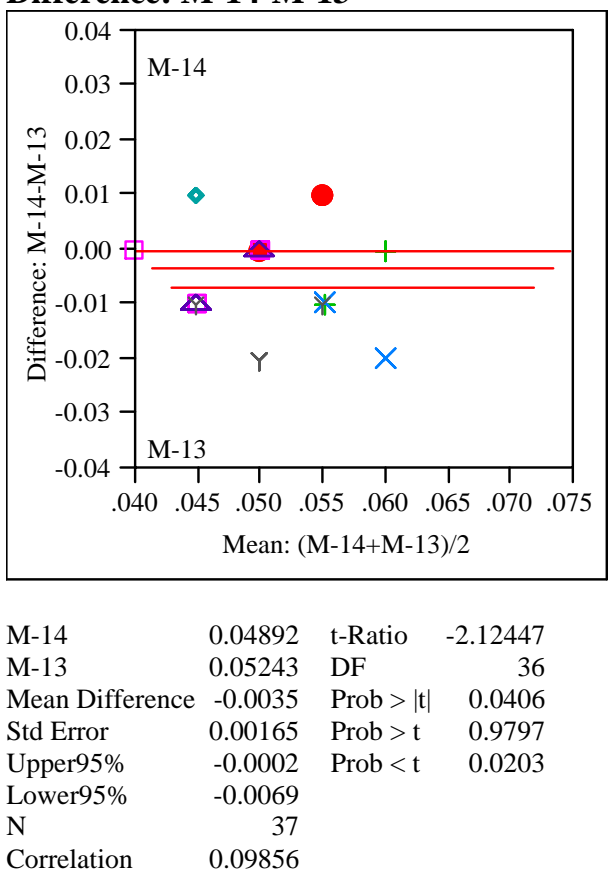


Exhibit A3. Initial Comparisons by SME Batch among M-13, M-14, and Prototypic Measurements for Each Element by Type of Sample after Screening

\section{Difference: Screened Prototypic-M-13}

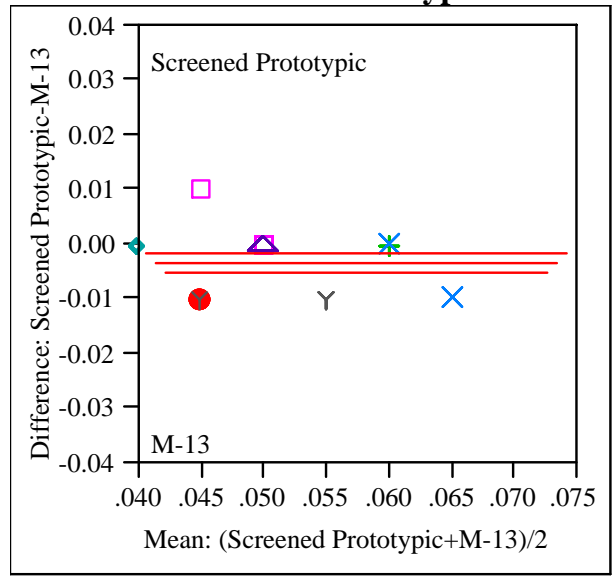

Screened Prototypic 0.04919 t-Ratio $\quad-3.72303$

M-13 0.05243 DF 36

Mean Difference $\quad-0.0032$ Prob $>|t| \quad 0.0007$

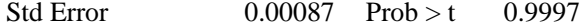

Upper95\% $\quad-0.0015$ Prob $<\mathrm{t} \quad 0.0003$

Lower95\%

$\mathrm{N}$

Correlation

$-0.005$

0.76885

\section{Difference: Screened Prototypic-M-14}

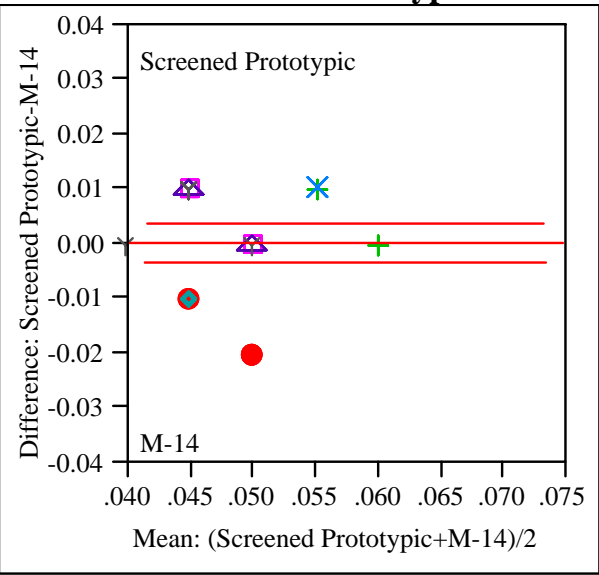

Screened Prototypic 0.04919 t-Ratio 0.158004

M-14

Mean Difference

Std Error

Upper95\%

Lower95\%

$\mathrm{N}$

Correlation
0.04892 DF 36

0.00027 Prob $>|\mathrm{t}| \quad 0.8753$

$0.00171 \quad$ Prob $>$ t $\quad 0.4377$

0.00374 Prob $<\mathrm{t} \quad 0.5623$

$-0.0032$

37

$-0.017$
Type/ Analyte/UoM=SME/U/wt \%

Matched Pairs

Difference: M-14-M-13

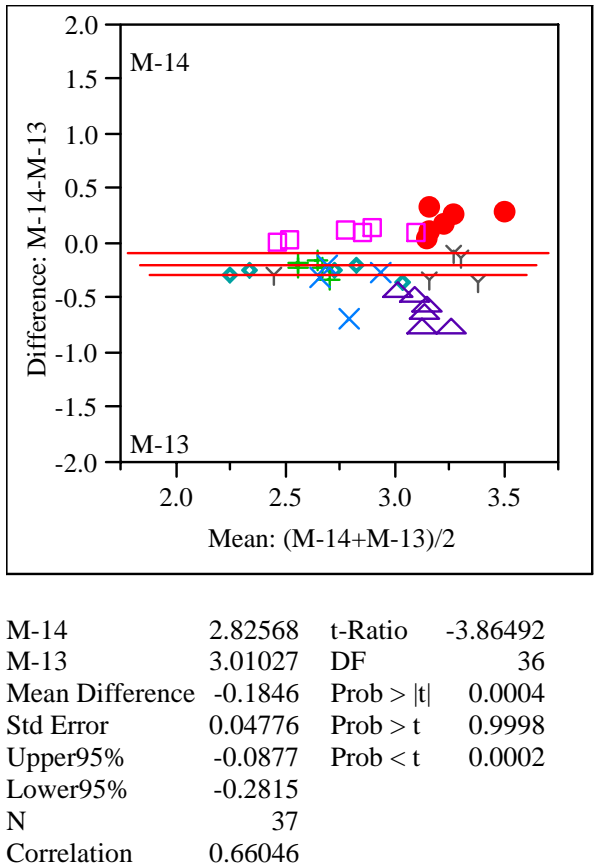

Difference: Screened Prototypic-M-13

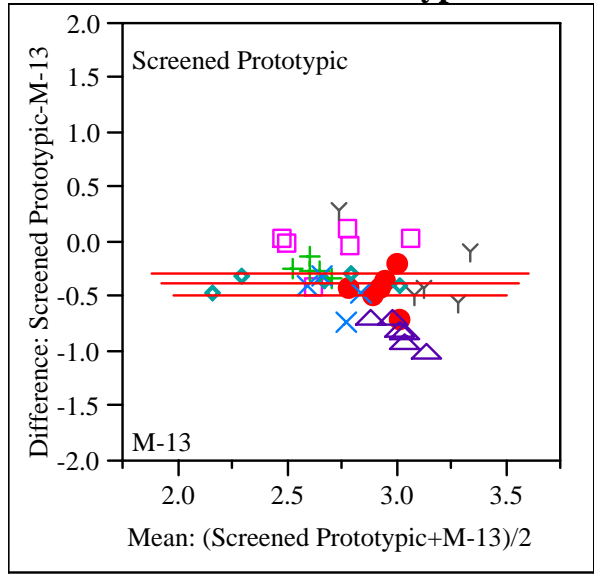

$\begin{array}{lrlr}\text { Screened Prototypic } & 2.63486 & \text { t-Ratio } & -7.70947 \\ \text { M-13 } & 3.01027 & \text { DF } & 36 \\ \text { Mean Difference } & -0.3754 & \text { Prob }>|t| & <.0001 \\ \text { Std Error } & 0.04869 & \text { Prob }>\text { t } & 1.0000 \\ \text { Upper95\% } & -0.2766 & \text { Prob }<\text { t } & <.0001 \\ \text { Lower95\% } & -0.4742 & & \\ \text { N } & 37 & & \\ \text { Correlation } & 0.53863 & & \end{array}$ 
Exhibit A3. Initial Comparisons by SME Batch among M-13, M-14, and Prototypic Measurements for Each Element by Type of Sample after Screening

\section{Difference: Screened Prototypic-M-14}

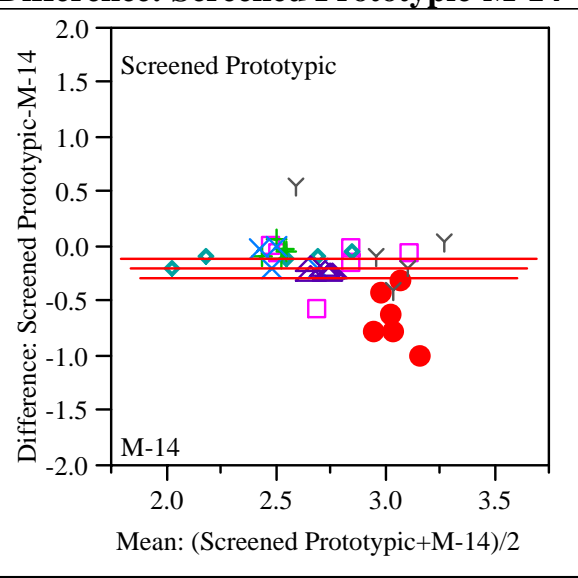

Screened Prototypic 2.63486 t-Ratio $\quad-4.22214$

M-14 2.82568 DF 36

Mean Difference $\quad-0.1908$ Prob $>|t| \quad 0.0002$

Std Error $\quad 0.04519 \quad$ Prob $>$ t 0.9999

Upper95\% $\quad-0.0992$ Prob $<\mathrm{t} \quad<.0001$

Lower95\% $\quad-0.2825$

$\mathrm{N}$

Correlation

0.65249

\section{Type/ Analyte/UoM=SME/Zr/wt \%}

Matched Pairs

Difference: M-14-M-13

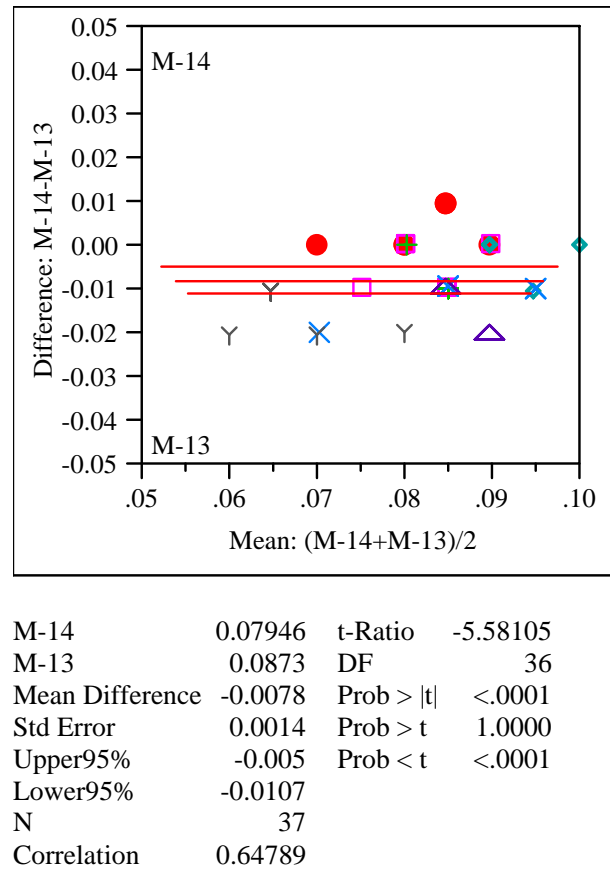

Correlation $\quad 0.64789$

\section{Difference: Screened Prototypic-M-13}

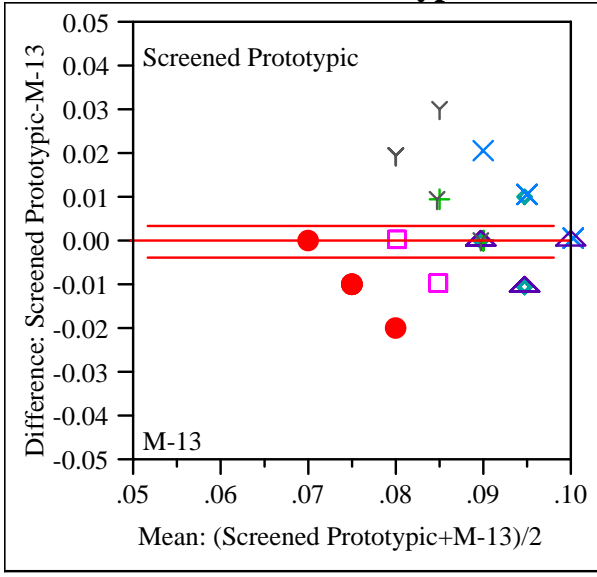

$\begin{array}{lrlr}\text { Screened Prototypic } & 0.0873 & \text { t-Ratio } & 0 \\ \text { M-13 } & 0.0873 & \text { DF } & 36 \\ \text { Mean Difference } & 0 & \text { Prob }>|t| & 1.0000 \\ \text { Std Error } & 0.00178 & \text { Prob }>\text { t } & 0.5000 \\ \text { Upper95\% } & 0.0036 & \text { Prob }<\text { t } & 0.5000 \\ \text { Lower95\% } & -0.0036 & & \\ \text { N } & 37 & & \\ \text { Correlation } & 0.36999 & & \end{array}$

\section{Difference: Screened Prototypic-M-14}

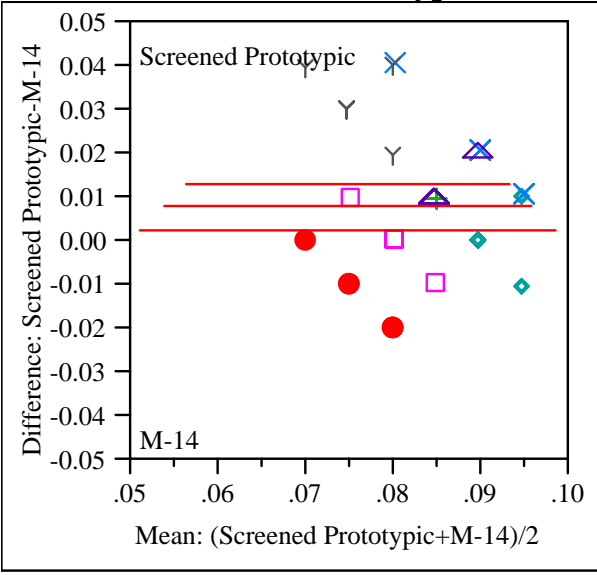

Screened Prototypic 0.0873 t-Ratio 3.044677

M-14

Mean Difference $\quad 0.00784 \quad$ Prob $>|t| \quad 0.0043$

Std Error

$0.00257 \quad$ Prob $>t \quad 0.0022$

Upper95\%

$0.01306 \quad$ Prob $<\mathrm{t} \quad 0.9978$

Lower95\%

0.00262

$\mathrm{N}$

Correlation

0.144 
Distribution:

C.J. Bannochie, 773-42A

M.J. Barnes, SRNL

N.E. Bibler, SRNL

D.R. Best, 786-1A

D.B. Burns, 786-5A

T.B. Calloway, 999-W

L.M. Chandler, SRNL

D.R. Click, SRNL

C.J. Coleman, SRNL

A.J. Cross, 704-71S

D.A. Crowley, SRNL

B.H. Culbertson, 704-27S

B.A. Davis, 704-27S

R.E. Edwards, SRNL

T.B. Edwards, 773-42A

M.T. Feller, 704-28S

T.L. Fellinger, 704-27S
S.P. Harris, 773-42A

C.C. Herman, 773-42A

C.M. Jantzen, SRNL

R.N. Mahannah, 704-28S

J.E. Marra, SRNL

W.L. Melton III, 704-28S

M. S. Miller, 704-S

J.E. Occhipinti, 704-S

P.M. Patel, 704-27S

F.M. Pennebaker, SRNL

D.K. Peeler, 999-W

J.W. Ray, 704-S

M.E. Smith, 773-42A

M.E. Stone, 999-W

R.C. Tuckfield, 773-42A

J.P. Vaughan, 773-41A

S.W. Wilkerson, 704-S 